\author{
University of Szeged \\ Faculty of Pharmacy \\ Department of Pharmaceutical Technology \\ Head: Prof. Dr. Piroska Szabó-Révész
}

Ph.D. Thesis

\title{
PREPARATION AND INVESTIGATION OF POLYMETHACRYLATE-BASED MATRIX SYSTEMS
}

by

Anita Korbely

Pharmacist

Supervisor:

Prof. Dr. Klára Pintye-Hódi

Szeged

2013 


\section{PUBLICATIONS RELATED TO THE THESIS}

I J. Bajdik, A. Korbely, K. Pintye-Hódi:

Formulation of intelligent tablets with an antacid effect

Pharmaceutical Development and Technology, 14(5), 471-475, $2009 \quad$ IF:0.895

II J. Bajdik, A. Korbely, K. Pintye-Hódi:

Evaluation of phenomena occurring during the preparation of matrix granules by the hot melt technique

Journal of Thermal Analysis and Calorimetry, 104, 241-247, 2011

IF 1.604

III A. Korbely, A. Kelemen, P. Kása Jr., K. Pintye-Hódi:

Effects of processing on the release profiles of matrix systems containing 5aminosalicylic acid

AAPS PharmSciTech, 13(4), 1341-1347, 2012

IF:1.432

\section{PRESENTATIONS RELATED TO THE THESIS}

I A. Korbely: Formulation and investigation of matrix tablets with an antacid effect Conference of Student Research Program (TDK), Szeged, Hungary, 2008

II J. Bajdik, A. Korbely, K. Pintye-Hódi: Formulation of matrix tablets with an antacid effect

$6^{\text {th }}$ World Meeting on Pharmaceutics, Biopharmaceutics and Pharmaceutical Technology, Barcelona, Spain, 2008

III A. Korbely: Preparation of antacid tablets by compression of granules Conference of Student Research Program (TDK), Szeged, Hungary, 2009 
IV A. Korbely: Preparation and investigation of intelligent matrix tablets with an antacid effect

Hungarian Science Festival, Szeged, Hungary, 2009

V A. Korbely, J. Bajdik, K. Pintye-Hódi: Formulation of intelligent tablets with an antacid effect

$14^{\text {th }}$ National Pharmaceutical Congress (CPhH), Budapest, Hungary, 2009

VI A. Korbely, K. Pintye-Hódi: Role of the surface free energy in the preparation of granules and in the selection of a suitable device

$8^{\text {th }}$ Central European Symposium on Pharmaceutical Technology, Graz, Austria, 2010

VII A. Korbely, K. Pintye-Hódi: Influence of matrix forming polymers on the properties of granules with mesalazine

$16^{\text {th }}$ National Pharmaceutical Technology Conference and $8^{\text {th }}$ „Medicine on the turn of the millennium” Postgraduate Conference, Siófok, Hungary, 2010

VIII A. Korbely, É. Bölcskei, K. Pintye-Hódi: Preparation of matrix systems with timecontrolled release

Oral Controlled Release Dosage Forms with Eudragit ${ }^{\circledR}$ (Workshop), Budapest, Hungary, 2011

IX A. Korbely: Preparation of matrix systems for colonic drug delivery $10^{\text {th }}$ “Ottó Clauder” Memorial Competition, Budapest, Hungary, 2011 


\section{CONTENT}

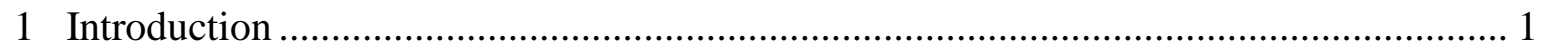

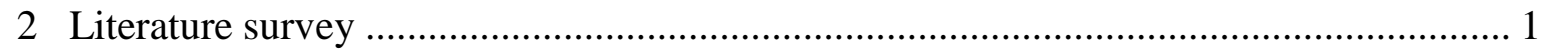

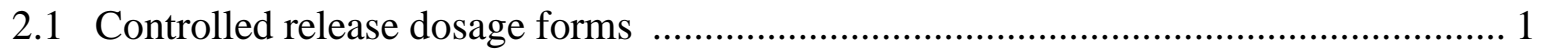

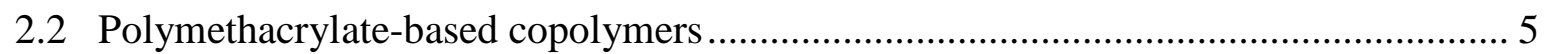

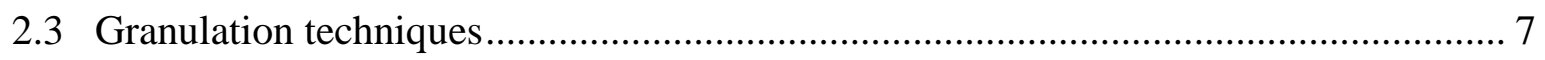

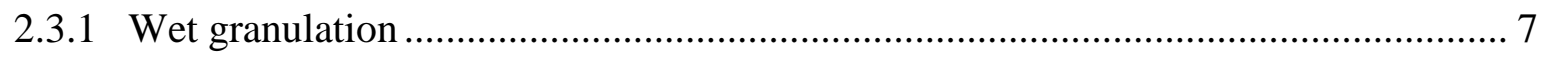

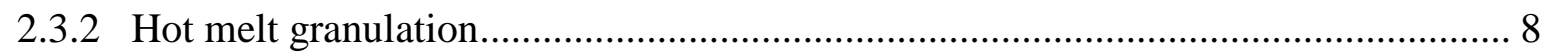

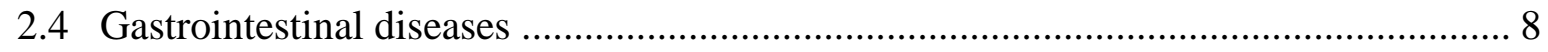

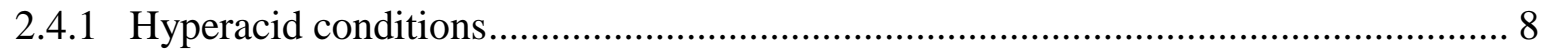

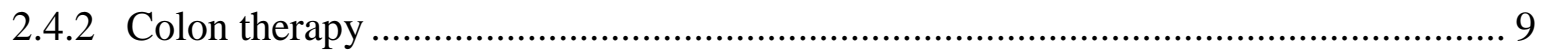

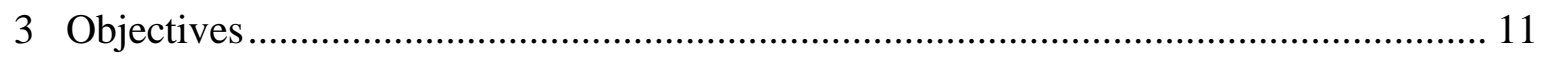

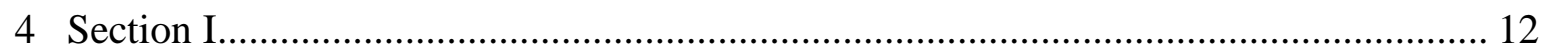

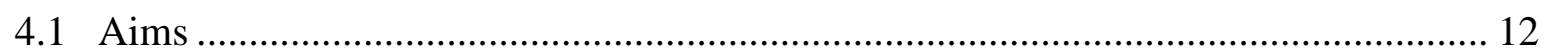

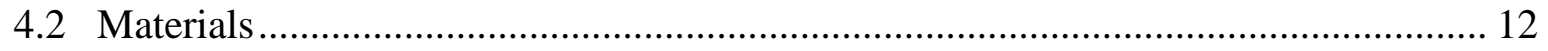

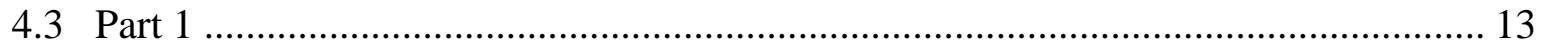

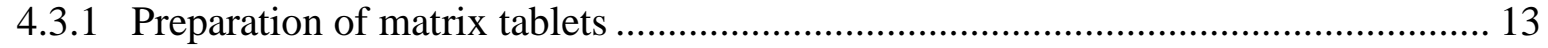

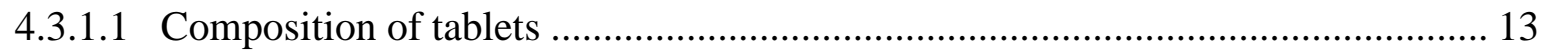

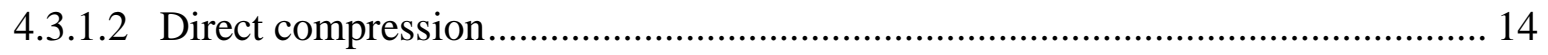

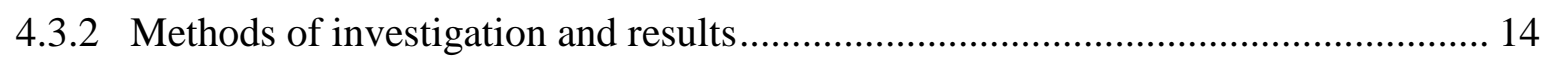

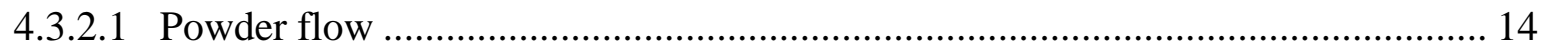

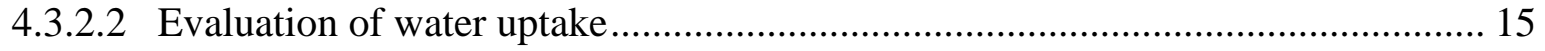

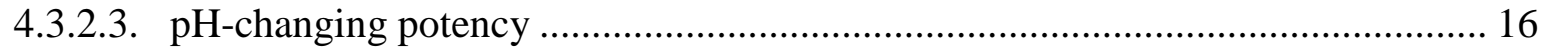

4.3.2.4 Geometry and mechanical properties of matrix tablets..................................... 17

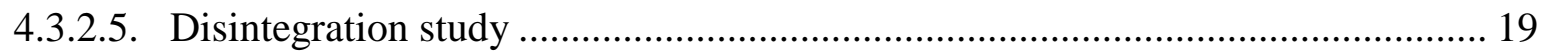

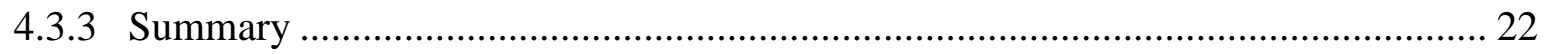

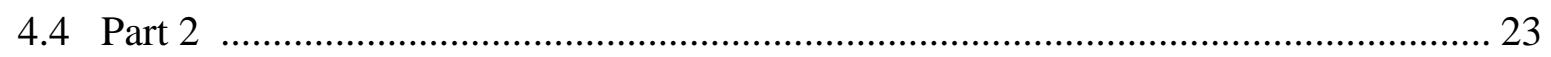

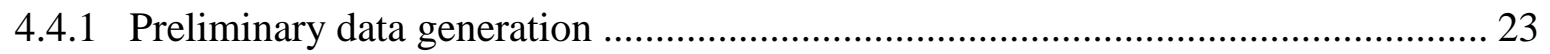

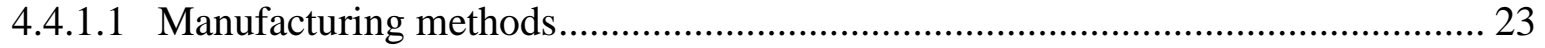

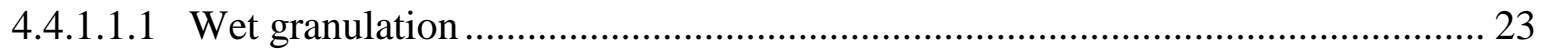

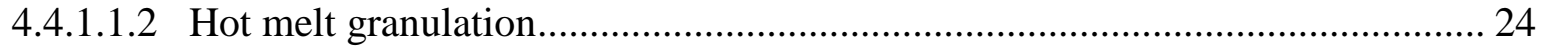

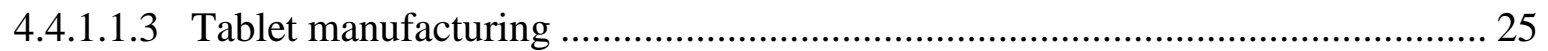

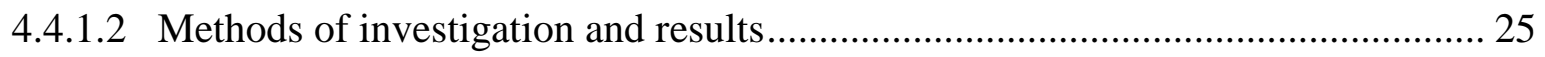




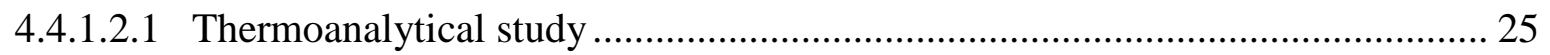

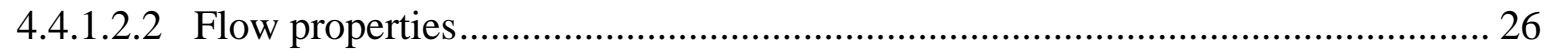

4.4.1.2.3 Evaluation of water uptake and particle size analysis ...................................... 27

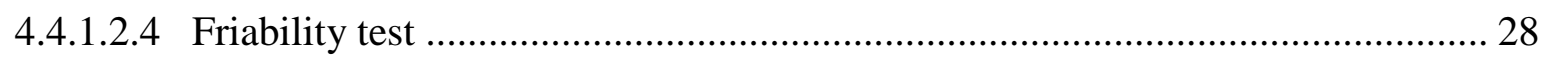

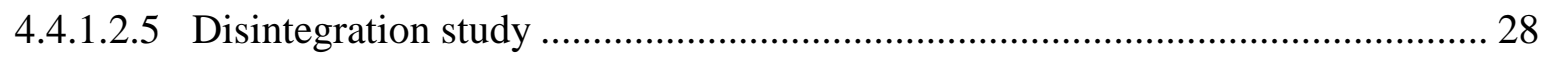

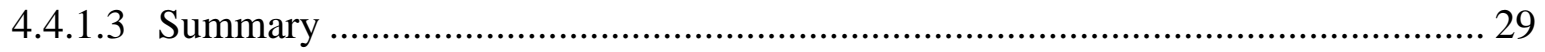

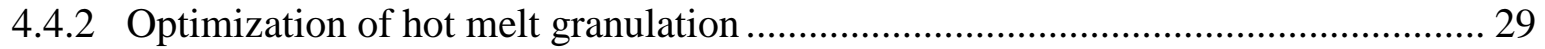

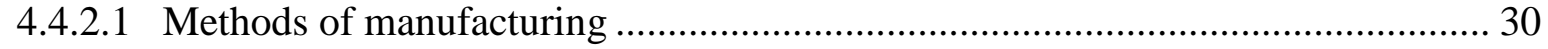

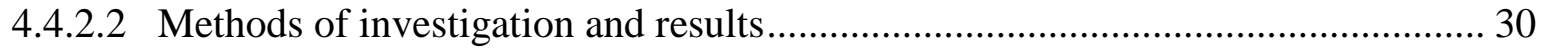

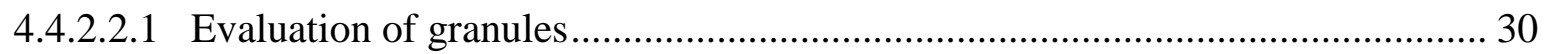

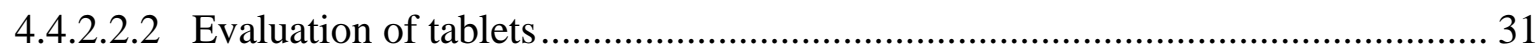

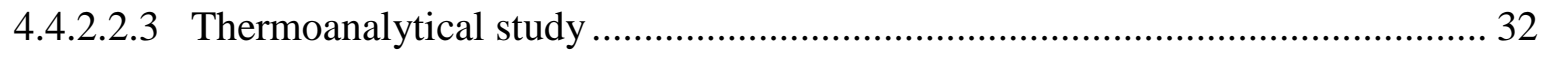

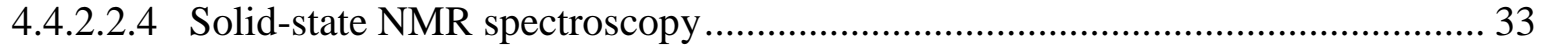

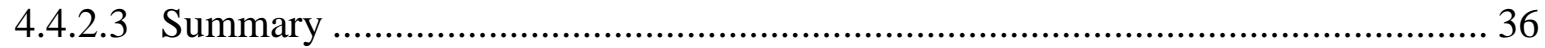

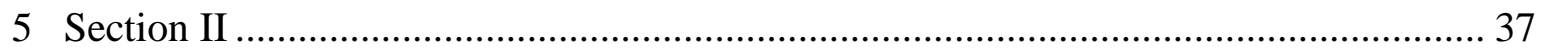

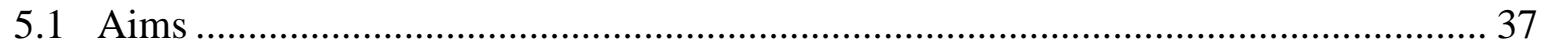

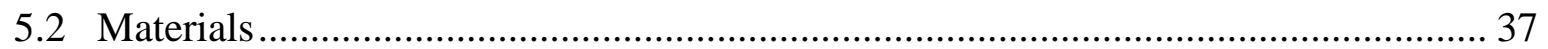

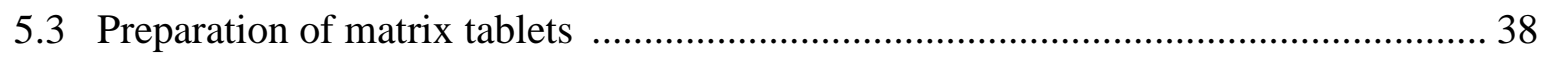

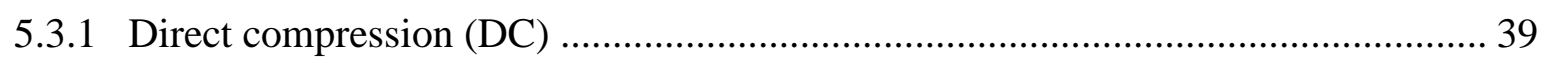

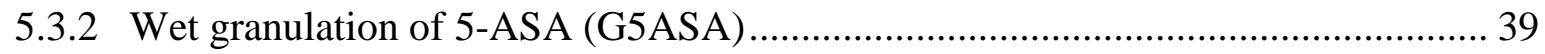

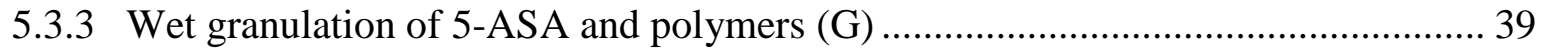

5.3.4 Wet granulation of 5-ASA with polymer dispersions (GD ) ................................. 40

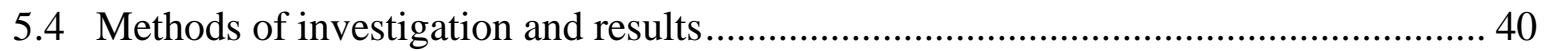

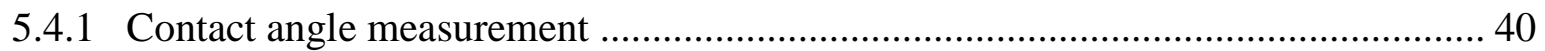

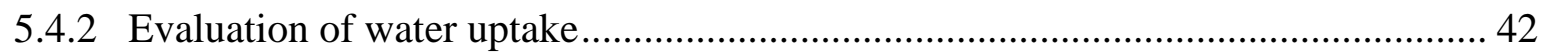

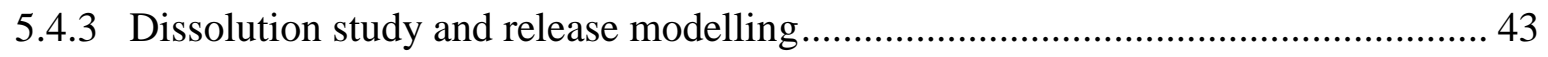

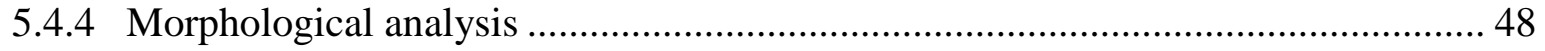

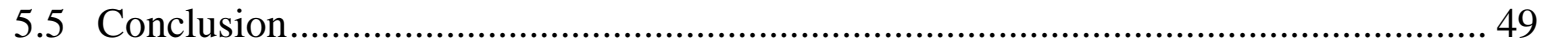

6 Final conclusions, novelty, practical usefulness …................................................... 51

References

Acknowledgements

Appendix 


\section{INTRODUCTION}

The development of novel drug delivery systems is one of the major focuses of formulation scientists since these systems offer several benefits compared to the conventional dosage forms. The time and site-dependent release provides a more targeted, patient and disease-centric therapeutic approach. On the other hand, it makes the researchers and formulators face a challenging situation. Nowadays the trends show that the pharmaceutical industry orients the development into the direction of individual drugs. The "one-size-fits-all" approach of ordinary drug therapy seems to decline as newer and newer chemical and biological entities reach the market. This provides several significant benefits that are capable to overwhelm the individual physiological and pathophysiological differences between patients. However, there is still a need for production of medicines that are available for a larger population, relatively cost-effective, and simultaneously meet the requirements of safety and efficacy. Controlled release is one of the most important innovative areas in pharmaceutics. These delivery systems are frequently applied for the incorporation of commercialised drugs. This strategy can extend the lifespan of patented drugs as part of the life cycle management [1,2], thus preserving the market shares from generic drug makers. Nevertheless, these novel drug delivery systems contribute to an improved patient compliance and to the reduction of material costs.

\section{LITERATURE SURVEY}

\subsection{Controlled release dosage forms}

Solid oral formulations are the most common and most preferred dosage forms due to greater convenience in administration and ease of manufacturing, transport, and storage [3]. The aim of the controlled release (CR) oral formulations is the delivery of the active pharmaceutical ingredient (API) from the formulation to the site of action (local effect) or to the site of absorption (systemic effect). Controlled release formulations allow to decrease the dosing frequency [4,5], therefore, improve the patient compliance [5,6], and ensure better pharmacokinetic profile [7]. The API liberates from the delivery system in a pre-designed fashion, thus maintains a constant plasma level and improves the therapeutic efficacy. A successful therapy requires the elimination of those periods when plasma concentration falls 
below the therapeutic value. This fact is especially important in the treatment of chronic diseases, where the symptoms may occur during night or early morning. These events could not be managed by conventional formulations; nonetheless, a delayed or extended release preparation can uninterruptedly ensure the adequate plasma level. Additionally, these novel formulations contribute to the comprehensive improvement of quality of life, better control of symptoms, and reduction of medical costs [8].

Controlled release is used as an umbrella term that involves a range of delivery systems with different release profiles:

- delayed release

- sustained release

- extended release

- prolonged release

The current oral controlled delivery systems are classified as diffusion-controlled, solvent activated, or chemically controlled systems [9].

The controlled release formulations basically release the API according to three major mechanisms: diffusion, degradation, and swelling followed by diffusion. The control of release rate can be established in time-controlled [10] and stimuli-induced [11] manner. Oral modified release dosage forms can also be differentiated according to being monolithic (tablet, capsule) or multiparticulate systems (pellets or beads that are further processed into tablets or capsules).

CR formulations ensure time and/or space controlled release through the application of special excipients, modification of drug substance or using carrier molecules. One of the most widespread techniques is the use of polymers that can be considerably diverse according to their origin, application, and release kinetics. Significant advantages of the controlled release formulations are that they do not require special and expensive equipment or new methodologies in the production. For instance, conventional tablet pressing or wet granulation can be applied to manufacture extended release tablets. The beneficial properties of the products are granted by the polymer or by the polymer and drug interaction [12].

In general, two major types of CR formulations are distinguished: reservoir and matrix systems [13]. 
Reservoir systems are composed of a core that contains the active ingredient and this core is coated with a high molecular weight polymer film layer. While entering a biological environment, the polymer layer either dissolves ( $\mathrm{pH}$-dependent or $\mathrm{pH}$-independent dissolution) or becomes permeable due to formation of pores and the drug liberates in a diffusion controlled manner [14]. Soluble excipients are frequently applied in the permeable coatings that are responsible for the pore formation; therefore, the drug release is driven by diffusion. The amount and size of the pores can be regulated by the proportion of pore forming excipients.

Reservoir diffusion controlled systems are fabricated by coating (e.g. with water insoluble polymer) of beads, pellets, tablets or capsules [15] and by microencapsulation [16]. The thickness of coating and the nature of polymer layer determine the permeability of the membrane. The drug release from reservoir type systems is explained by the Fick's Law $[17,18]$.

Matrix systems are prepared by homogeneous mixing of API and matrix forming polymer. Plastics (polymethacrylates, polyethylene), hydrophilic (methylcellulose, hypromellose), and lipophilic (carnauba wax, glyceryl tristearate) materials are commonly used for matrix preparation [19]. The monolithic systems are divided into two major groups according to the properties of the applied polymer:

1. Hydrophilic matrices

a) $\mathrm{pH}$-dependent soluble, swellable, hydrophilic matrices

b) Stimuli-responsive, soluble, hydrophilic matrices

2. Water-insoluble matrices

a) Inert matrices

b) Lipophilic matrices

Several macromolecules are available to form $\mathrm{pH}$-independent soluble hydrophilic matrix system, e.g. starch, carboxymethyl starch, cellulose ethers, alginates, galactomannan or polyvinyl alcohol. These polymers ensure appropriate disintegration, provided they are applied in small quantities, whilst elevation of their ratio leads to the development of a gelling matrix. Hydrophilic matrix tablets swell or form a gel in the presence of water or gastrointestinal fluids. The incorporated drug dissolves via diffusion. Entrance of water into the tablet is the rate limiting step; however, the rate of dissolution depends on the 
concentration of the hydrocolloid. Due to the hydration of the matrix, the tablet disintegrates, albeit the skeleton of the tablet can remain intact through passage of the gastrointestinal tract. Initially the dissolution rate is more rapid (release of loading dose), but the developing gel layer elongates the time of diffusion and allows the liberation of the maintenance dose. Meanwhile, the surface of the inner core decreases. Matrix systems can be manufactured by direct compression and wet granulation. Subdivision of this kind of tablet should be avoided since splitting increases the surface of the tablet that can be in contact with the gastrointestinal fluids; therefore, the rate of dissolution accelerates. Further extension in the release rate can be achieved by coating of tablets.

Erosion controlled drug delivery systems are also called stimuli-induced systems where an external stimulus, e.g. $\mathrm{pH}$, temperature, enzymes or osmotic pressure may trigger the material loss of the delivery system [20]. Depending on the mechanism of erosion [21], surface [22] or bulk [23] erosion may occur. If the dosage form enters an environment with $\mathrm{pH}$ that is not favourable for the dissolution, the drug release will not occur; however, diffusion controlled release should also be considered. Polymers that are commonly used in pH-sensitive polymer coating can be applied to form matrix systems, e.g. acrylates (methacrylic acid copolymers [24]) and cellulose esters (cellulose acetate phthalate).

Diffusion controlled matrix systems are composed of insoluble non-swellable hydrophobic or swellable hydrophilic polymers, the API is homogenously dispersed in the matrix structure. Swellable matrix systems can efficaciously sustain the release rate of highly water soluble drugs [25]. Wet granulation can be employed to prepare matrices in which the API and plastic materials or their organic solutions are kneaded together and the produced granules are suitable for tablet compression. The main driving force of dissolution is diffusion. The process of diffusion comprises two steps: first the gastric or intestinal fluid penetrates into the matrix through a semipermeable membrane and dissolves the entrapped API. The diffusion of the dissolved drug occurs down a concentration gradient. The matrix systems have the benefit over the reservoir type systems that the risk of dose dumping is eliminated that may take place during reservoir membrane rupture [26]; nevertheless, zero order kinetics cannot be achieved by matrix formulation but reservoir systems [27].

Preparation of lipophilic matrices may occur by direct compression or melt granulation. The API is embedded into a hydrophobic matrix with low melting point materials (e.g. 
triglycerides). The matrix system commonly remains intact after the depletion of the API. The release rate is controlled by diffusion but erosion may also occur [28,29].

Hybrid systems [30] combine the robustness of matrix systems with the constant release kinetics of reservoir systems. The drug is entrapped in a release controlled matrix that is coated with a polymer layer. Their benefits are versatility, cost-effectiveness, and simple manufacturing that can be accomplished by conventional pharmaceutical processes and equipment. High molecular weight compounds can also be incorporated.

A further, advanced representative of the modified release delivery systems is the multilayered tablet [13], such as, Geomatrix system [31] that is a hydrophilic matrix system coated with an impermeable layer that reduces the release rate from the matrix core.

\subsection{Polymethacrylate-based copolymers}

Polymethacrylate type polymers are composed of acrylic or methacrylic acids or their esters. The development of biocompatible polymethacrylate polymers has been started in the early 1950s by Röhm and Hass. Since that time a wide portfolio of synthetic polymers has been available for the pharmaceutical and food industry; these polymers are commonly known as Eudragit ${ }^{\circledR}$ polymers, majority of them have been introduced into USP/NF and Ph. Eur. Polymethacrylate copolymers offer several solutions from taste masking [32] to time and pH-controlled colon delivery [33]. Their characteristics are determined by the different functional groups and the proportion of acid, alkaline, and neutral groups [5]. These polymers are good starting point of the pharmaceutical research since they can be combined with each other [34] and with other excipients; however, it is well known that certain APIs, e.g. ibuprofen and metoprolol tartrate have a plasticizing effect on polymethacrylates with low permeability (Eudragit ${ }^{\circledR}$ RS), therefore these drugs modify the release profile $[35,36]$.

Polymers developed by Röhm and Haas were initially used for coating of tablets and capsules that were, therefore, resistant to gastric acid and dissolved only in an alkaline environment. Consequently, these polymers are still applied for film coating; however, they have been suggested applying in sustained release matrix formulations [37,38]. Adjusting to the various applications, Eudragit ${ }^{\circledR}$ polymers are available in different physical forms like dry powder, aqueous dispersion, and organic solution. The Eudragit ${ }^{\circledR}$ product portfolio comprises polymers for sustained release (time-controlled release with $\mathrm{pH}$-independent swelling 
polymers), protective, and enteric formulations ( $\mathrm{pH}$-dependent delivery for colon targeting) [39].
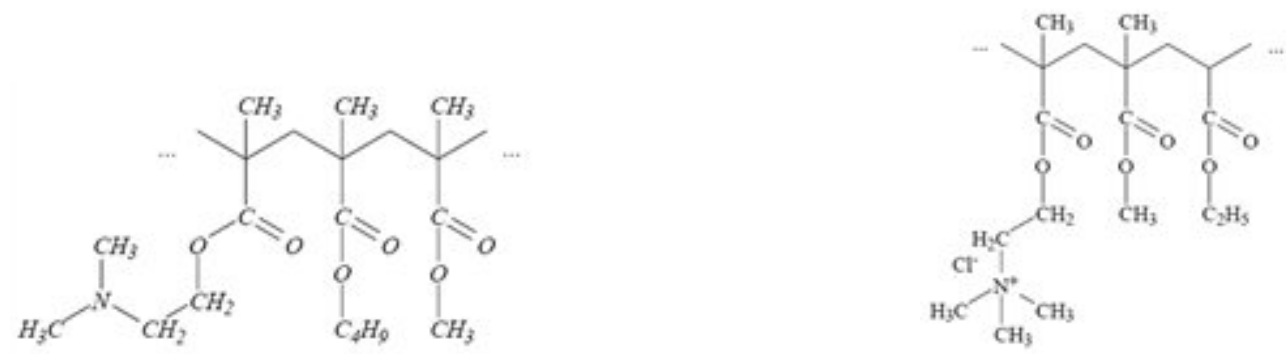

Fig. 1 Chemical structure of Eudragit ${ }^{\circledR}$ E (left) and Eudragit ${ }^{\circledR}$ RS and RL (right)

The present thesis investigated the Eudragit ${ }^{\circledR}$ E PO, Eudragit ${ }^{\circledR}$ RS, and RL. Eudragit ${ }^{\circledR}$ E PO cationic copolymer commonly used as protective coating and film coating to achieve taste masking [40,41]. Eudragit ${ }^{\circledR}$ RS and RL are water-insoluble swelling polymers [42], they have low and high permeability, respectively, that makes them suitable for time-controlled formulations and their combination allows tailor-made drug release [43]. They are frequently used in combination with $\mathrm{pH}$-dependent polymers to attain colon-specific delivery. EUDRACOL $^{\mathrm{TM}}$ [44] delivery system provides multi-unit technology for colon delivery. EUDRACOL $^{\mathrm{TM}}$ formulation is composed of a nonpareil seed coated with the layer of the active substance. The API layer is coated with an inner (Eudragit ${ }^{\circledR}$ RS and RL, timecontrolled release) and an outer (Eudragit ${ }^{\circledR}$ FS 30D, pH-dependent delivery) polymer film. The mechanism of dissolution from polymethacrylate-based systems is complex; usually it takes place according to the following principles:

- diffusion

- erosion

- $\quad$ ion exchange

- osmosis

Eudragit ${ }^{\circledR} \mathrm{RL}$ and RS provide diffusion controlled drug release where the release rate can be modified with the different ratios of the polymers and the method of processing. Processing of Eudragit ${ }^{\circledR}$ RS PO and RL PO by melting solvent-method revealed that the release rate decreases from solid dispersions compared to the physical mixtures [45]. 


\subsection{Granulation techniques}

Granulation is a size enlargement process that decreases the specific surface area, thus it reduces the adhesion between the powder particles. Its development was strongly facilitated by the advance in tablet press. Granulation is employed in order to achieve homogeneous distribution of drug particles in a blend, better flowability, and consequently improved compression characteristics [46]. This approach can be used in the manufacturing of conventional and modified release dosage forms [47]. The granulation techniques are usually classified according to wet and dry granulation [48,49], albeit it has to be emphasized that the hot melt granulation and extrusion are techniques that have already gained considerable interest. The most commonly used equipment is low and high-shear granulators (batch granulation); furthermore, spray dryers, extruders, fluid bed granulators, and roller compactors are also applied in continuous granulation [50].

The purpose of granulation can be [51]:

- $\quad$ production of final dosage form

- preparation of intermediates prior to tablet compression

The present study employed the method of granulation to obtain intermediates with improved flow for tablet press.

\subsubsection{Wet granulation}

Wet granulation is the most commonly used granulation method prior to tablet compression since any drug load can be processed properly by wet granulation. The first step of the procedure is the dry blending of powders that is followed by the wet massing. For this purpose, organic solvents, water or binder solutions can be applied. Finally the granules are dried until they reach the required moisture content. Three principal mechanisms control the granule properties: wetting and nucleation, consolidation and growth, and attrition and breakage [52].

Additional excipients can be integrated into the granules, e.g. binders, diluents, disintegrants, stabilizing agents, and pigments. Traditionally high-shear mixer and fluid bed granulator are applied to perform wet granulation. Their main differences are the mechanism of granule growth and the applied solid agitation technique [53]. High-shear wet granulation 
offers several advantages: shorter process time, more dense and less friable granules, and less granulation liquid consumption compared to fluid bed or low shear granulators [50].

\subsubsection{Hot melt granulation}

The hot melt granulation technique does not require either solvent; therefore, it is environmentally friendly, or water that eliminates the drying step of the product. It is a less time-consuming process due to the decreased number of intermediate steps; moreover, it is continuous and efficient. The prepared granules are uniform particles with good mechanical strength and stability against moisture. The restrictions of hot melt method are that heatsensitive materials cannot be processed; it requires high energy input and addition of melting binders. Hydrophilic (poloxamer 188 [54]), polyethylene glycols [55-57]) and hydrophobic (carnauba wax, glycerol behenate, glyceryl monostearate [5]) melting binders can be used during manufacturing. This method is applicable in the pharmaceutical industry if the goal is taste masking, modification of the release profile [55] or achievement of a better bioavailability and improved dissolution rate.

The melt extrusion represents a more advanced technique that is used for the preparation of solid dispersions, reservoir and matrix type controlled release systems [58].

\subsection{Gastrointestinal diseases}

\subsubsection{Hyperacid conditions}

The hydrochloric acid is secreted by the parietal cells of the stomach and its presence is essential for the absorption of iron, calcium, and vitamin $\mathbf{B}_{12}$. Furthermore, it prevents the colonization of the ingested bacteria [59]. Gastric acid ensures the adequate $\mathrm{pH}$ for pepsin activity that is responsible for the cleavage of proteins. Nevertheless, overproduction of gastric acid may result in the shift of balance from protective to aggressive factors; therefore, it can lead to the development of an ulcer. In pathological circumstances, the increased acid secretion causes disruption of oesophageal, ventricular, and duodenal mucosa.

Another pathological factor, the Helicobacter pylori infection may also lead to acute and chronic gastritis [60]. The Gram negative bacteria colonize the stomach and neutralize the hydrochloric acid through production of urease enzyme [61], albeit hypo and hyperchlorhydria can occur, as well [62]. 
The duodenal ulcer is characteristic of the constantly high level of gastric acid; therefore, the therapy should consist of antacid medication. Contrary to the duodenal ulcer, only the postprandial acid secretion is affected in peptic ulcer while the basal level is normal or decreased.

Following long-term administration of non-steroid anti-inflammatory drugs, the mucosal barrier may damage due to the inhibition of cyclooxygenase enzyme. This inhibition decreases the level of protective prostaglandin [63,64].

$\mathrm{H}_{2}$-receptor blockers (famotidine, cimetidine) and proton pump inhibitors (omeprazole, lansoprazole) are commonly used in diseases with acid hypersecretion to suppress the production of gastric acid. In severe cases, antibiotics and bismuth salts are also involved into the therapy in order to eradicate Helicobacter pylori.

Antacid preparations are used as adjuvants in the treatment of peptic diseases or for the alleviation of mild complaints since they are available as over-the-counter drugs. Antacids are inorganic bases that chemically bound the hydrochloric acid resulting in immediate relief of the symptoms. Combination of antacids are recommended to eliminate the side effects since the magnesium derivatives may result in diarrhoea, the aluminium compounds may cause constipation [65]. Administration of these compounds is limited due to the interaction with tetracyclines and inhibition of absorption of iron, phosphates, and antifungal drugs [66,67]. Furthermore, frequent prescription of the above-mentioned drugs may result in noncompliance $[65,67,68]$.

\subsubsection{Colon therapy}

Initially, colon drug delivery aimed at the treatment of inflammatory bowel diseases (IBD). Later on, colon cancer and systemic diseases (asthma, angina, rheumatoid arthritis) were treated with drugs delivered via the large intestine. Moreover, vaccines are potential candidates for colon drug delivery due to the fact that the colon is rich in lymphoid tissue.

Targeting of the colon can be managed by both oral and rectal administration; however, patients show more adherence to the oral route [69]. Nevertheless, the delivery of APIs to the colon needs to meet several criteria: the system should survive the acidic environment of the stomach and release the incorporated drug substance only in the site of action or absorption. 
Additionally, a time and/or pH-dependent, prolonged or extended release pattern can be required.

The inflammatory bowel diseases involve Crohn's disease and ulcerative colitis. Both diseases have unclear etiology, nonetheless, a positive family history indicates the greatest risk. They differ from each other in the extent of the inflammation: while colitis ulcerosa is localized to the colon and affects only the mucous layer of the intestinal lumen, Crohn's diseases is a transmural inflammatory disease that may affect the entire alimentary canal [70]. The therapy is restricted to symptomatic treatment.<smiles>Nc1ccc(O)c(C(=O)O)c1</smiles>

Fig. 2 Chemical structure of 5-aminosalicylic acid

The medication depends on the severity of the disease. In mild-to-moderate phase salicylates, e.g. sulfasalazin or its active moiety, 5-aminosalicylic acid (5-ASA) are recommended [71]. The 5-ASA itself, if orally administered, can not reach the colon since it will absorb in the upper jejunum; therefore, controlled release dosage forms are required. Moreover, the usual dosage of 5-ASA is high (400-1500 mg/day) that should be given once a day since according to the evidences of clinical studies, once daily administered 5-ASA proved therapeutically superior compared to b.i.d. dosing regimen [72].

The primary colon delivery covered the use of prodrugs: sulphasalazine itself represents a prodrug that is composed of 5-ASA (active moiety) and a carrier molecule. The linking azobond is cleaved by the bacteria of the colon. Nowadays, time and $\mathrm{pH}$-controlled delivery systems and their combinations are applied.

The commercial formulations are mainly based on $\mathrm{pH}$-dependent release that is achieved by coating of tablets, capsules, and microgranules. A novel technique is the multi matrix (MMX) formulation that was patented by Cosmo Pharmaceuticals in 1999. This multi matrix system is based on a lipophilic and hydrophilic polymer matrix and a $\mathrm{pH}$-dependent coating. MMX formulation contains 5-ASA that has been proved to be efficient and well-tolerated [73]. 


\section{OBJECTIVES}

Polymethacrylate-based polymers are frequently used excipients in pharmaceutical formulations. A wide range of polymers are available for tailor-made controlled release formulations. The present work focused on the preparation and investigation of solid matrix systems that contained polymers ensuring $\mathrm{pH}$ or time-dependent drug release.

In the first section, a gastric soluble cationic methacrylate copolymer was studied that was applied in an antacid formulation with pH-dependent drug release. In this case not only the optimization of the tablet composition but also the optimization of the processability was investigated. Therefore, the work was divided into two parts. In the first part the tablet composition was optimized through investigation of several tablet compositions. The composition that provided $\mathrm{pH}$-dependent disintegration and appropriate tablet characteristics was selected for further processing. Since the powder blends prepared in the first step exhibited poor flow properties, wet and hot melt granulation were employed to improve flow in the second part.

The second section describes the dissolution kinetics of an anti-inflammatory API from a $\mathrm{pH}$-independent modified release system. Matrix systems were manufactured with different pharmaceutical processes and it was investigated how the method of production influences the dissolution properties. Mathematical modelling of the dissolution kinetics was also assessed. 


\section{SECTION I}

\subsection{Aims}

A pH-dependent matrix system was developed via a range of experiments. In the first step the optimization of composition was performed: Five different compositions of tablets were prepared by direct compression and followed by the characterization of tablets including disintegration study. The composition that was found eligible for further development was selected. This blend was later on used to prepare granules and; therefore, improve the flow properties of the product that is a critical point during tableting.

\subsection{Materials}

Aluminium hydroxide and magnesium trisilicate were used as active pharmaceutical ingredients. The matrix was formed with Eudragit ${ }^{\circledR}$ E PO, sodium bicarbonate was utilized as a disintegrant that also has an antacid effect. Polyethylene glycol 2000 was used as polymeric binder during hot melt granulation.

Aluminium hydroxide (AH) (Ph. Eur.) is a white amorphous powder that reacts with gastric acid and the formed gel coats the mucosal layer of the stomach. Since it has an astringent effect, it commonly causes constipation. Aluminium hydroxide does not absorb from the gastrointestinal tract, albeit it bounds phosphate that may lead to osteomalatia [66]. It has the potential to change the $\mathrm{pH}$ in the stomach and it has an impact on the absorption of other drugs due to its complex forming ability. In order to eliminate the risk of interactions, a 2-3 hr delay is recommended before the administration of other drugs [65].

Magnesium trisilicate (MT) (Ph. Eur.) is an inorganic compound with an antacid effect that is used for dyspepsia, cardialgia, and gastroesophageal reflux disease. It is rarely used in monotherapy, it is usually combined with other antacid drugs like aluminium hydroxide or sodium bicarbonate. Preferably, magnesium trisilicate is combined with aluminium hydroxide due to the compensation of side effects. However; magnesium salts act more rapidly than aluminium salts [65].

Sodium bicarbonate (SB) (Ph. Eur.) was used as a disintegrant that facilitates the disintegration of the tablet. Sodium bicarbonate reacts with gastric acid while carbon dioxide develops that contributes to the disintegration of the tablet [74]. Due to the antacid effect of 
sodium bicarbonate, it can also be considered as an API in the present formulation. However, the side effects and rebound hyperacidity effect resulted in the less frequent use of this compound as an active ingredient.

Eudragit $^{\circledR}$ E PO (EE) (Evonik Rhöm GmbH, Darmstadt, Germany) is a cationic copolymer based on dimethylaminoethyl methacrylate, butyl methacrylate, and methyl methacrylate. Its average molecular weight is about 150’000, it is a white, micronized powder. It is soluble in gastric fluid up to $\mathrm{pH} 5$, thus programmed drug release can be ensured. It is frequently used as a coating agent due to its film forming capability and as a binder in tablets prepared by direct compression in $10 \%$ to $50 \%$ concentration $[75,76]$.

Polyethylene glycol (PEG) 2000. Polyethylene glycols or macrogola have the general chemical formula of $\mathrm{HOCH}_{2}\left(\mathrm{CH}_{2} \mathrm{OCH}_{2}\right)_{\mathrm{n}} \mathrm{CH}_{2} \mathrm{OH}$ where „n” represents the number of oxyethylene groups. In the case of PEG 2000 n=40-50, PEG 2000 is a water soluble polymer with an average molecular weight of $1800-2200$. Due to its low melting point $\left(45-50^{\circ} \mathrm{C}\right)$, it can be used as binder during melt granulation [77].

\subsection{Part 1}

\subsubsection{Preparation of matrix tablets}

\subsubsection{Composition of tablets}

The experiments were performed with seven different compositions that always comprised a constant ratio of APIs while the ratio of excipients altered; the decreasing amount of polymer was accompanied by the weight increase of disintegrant (Table 1).

Table 1 Composition of tablets

\begin{tabular}{|cccccc|}
\hline Sample & AH (mg) & MT (mg) & SB (mg) & EE (mg) & Total (mg) \\
\hline S0 & 210 & 210 & - & - & $\mathbf{4 2 0}$ \\
\hline S1 & 135 & 135 & - & 150 & $\mathbf{4 2 0}$ \\
\hline S2 & 135 & 135 & 25 & 125 & $\mathbf{4 2 0}$ \\
\hline S3 & 135 & 135 & 37.5 & 112.5 & $\mathbf{4 2 0}$ \\
\hline S4 & 135 & 135 & 50 & 100 & $\mathbf{4 2 0}$ \\
\hline S5 & 135 & 135 & 75 & 75 & $\mathbf{4 2 0}$ \\
\hline S6 & 135 & 135 & 100 & 50 & $\mathbf{4 2 0}$ \\
\hline
\end{tabular}




\subsubsection{Direct compression}

The tablet compositions mentioned in Table 1 were blended in a rotating shaker mixer (Turbula, Willy A. Bachofen AG Maschinenfabrik, Basel, Switzerland). The mixing step was performed for $10 \mathrm{~min}$ at $50 \mathrm{rpm}$. The matrix tablets were produced with the Korsch EK0 instrumented eccentric tablet machine (Emil Korsch Maschinenfabrik, Berlin, Germany). The round, convex-faced tablets were $13 \mathrm{~mm}$ in diameter and $420 \pm 5 \mathrm{mg}$ in weight. Three different compression forces were applied as following: $5 \pm 2 \mathrm{kN}, 15 \pm 2 \mathrm{kN}$, and $25 \pm 2 \mathrm{kN}$.

\subsubsection{Methods of investigation and results}

\subsubsection{Powder flow}

Investigation of powder flow belongs to the basic preformulation study during powder handling. The evaluation of powder characteristics prior to tableting has a specific importance since it provides deeper insight into powder behaviour during compression. Provided that a powder or mixture has poor flow properties that can lead to fluctuations in the tablet weight and, thus, it can jeopardize the content uniformity.

Assessment of powder flow properties covered the measurement of angle of repose, flow time, and determination of bulk and tapped density.

The Powder Testing System PTG-1 (Pharma Test Apparatebau GmbH, Hainburg, Germany) was applied to test the flow properties of powders before tableting. This equipment is viable to determine the flow time, weight, and angle of repose. $100 \mathrm{~mL}$ sample of powder was filled into a teflon funnel with an orifice of $10 \mathrm{~mm}$ in diameter. $25 \mathrm{rpm}$ stirring was required due to the poor flow properties of the tested materials. Three parallel measurements were performed.

Compression properties of powders also have a critical role during tablet preparation. Measurement of bulk and tapped density allows the calculation of Carr's index [78] that indicates the compressibility of a powder:

$$
\begin{gathered}
\text { Carr's index }=\frac{\rho_{\infty}-\rho_{0}}{\rho_{\infty}} \times 100 \quad \text { (Eq. 1) } \\
\rho_{\infty} \text { : tapped density, } \rho_{0} \text { : bulk density }
\end{gathered}
$$


This characteristic measure is related to the particle size, flow rate, and cohesiveness of powder materials. The smaller value of Carr`s index indicates better flow [79].

The tapping of the tested powders was performed by means of a volumeter (STAV 2003 Stampfvolumeter, Engelsmann A.G., Ludwigshafen, Germany). Samples of powder blends were filled into a glass cylinder and accurately weighed. In the next step, the filled powder was tapped until its volume became constant. Three parallel measurements were performed. The bulk and tapped density was calculated from the measured data (volume and weight).

Independently of the composition, the manufactured powder blends exhibited poor flow properties (Table 2) that was supported by the necessity of stirring during the test.

Table 2 Flow properties and tapped density

\begin{tabular}{|c|c|c|c|c|}
\hline Sample & $\begin{array}{c}\text { Flow time } \\
\text { (s) }\end{array}$ & $\begin{array}{l}\text { Loose density } \\
\qquad\left(\mathrm{g} / \mathrm{cm}^{3}\right)\end{array}$ & $\begin{array}{l}\text { Tapped density } \\
\qquad\left(\mathrm{g} / \mathrm{cm}^{3}\right)\end{array}$ & $\begin{array}{c}\text { Carr's index } \\
(\%)\end{array}$ \\
\hline So & $74.9 \pm 11.9$ & $0.325 \pm 0.005$ & $0.414 \pm 0.006$ & $21.60 \pm 1.39$ \\
\hline S1 & $165.1 \pm 16.6$ & $0.277 \pm 0.009$ & $0.409 \pm 0.001$ & $32.27 \pm 2.01$ \\
\hline S2 & $162.9 \pm 17.0$ & $0.290 \pm 0.013$ & $0.426 \pm 0.003$ & $31.91 \pm 2.86$ \\
\hline S3 & $157.2 \pm 10.2$ & $0.303 \pm 0.004$ & $0.442 \pm 0.003$ & $31.47 \pm 0.92$ \\
\hline S4 & $157.8 \pm 8.9$ & $0.313 \pm 0.005$ & $0.450 \pm 0.003$ & $30.40 \pm 0.80$ \\
\hline S5 & $148.1 \pm 14.7$ & $0.328 \pm 0.012$ & $0.468 \pm 0.004$ & $29.87 \pm 2.44$ \\
\hline S6 & $121.3 \pm 13.0$ & $0.350 \pm 0.012$ & $0.490 \pm 0.002$ & $28.53 \pm 2.44$ \\
\hline
\end{tabular}

\subsubsection{Evaluation of water uptake}

The water uptake kinetics may influence the application of pharmaceutical formulations and further processing. Therefore, both baseline materials and powder blends were tested for wettability. The study was performed using an Enslin apparatus that provides a simple method to evaluate the water uptake. The apparatus consists of a glass filter and a pipette with an accuracy of $0.01 \mathrm{~mL}$. The test material should be weighed with analytical accuracy before the test and the volume of water taken up by the test material should be recorded as a function of time. The Enslin number expresses the volume of water absorbed by $1.0 \mathrm{~g}$ of the test material. Five parallel measurements were performed.

Out of the tested materials, aluminium hydroxide had the highest water sorption capacity due to being a gel forming agent. Partially this characteristic is utilized during the 
pharmaceutical application. The wettability of the matrix forming polymer is negligible, sodium bicarbonate proved low water sorption, as well (Table 3).

Table 3 Wetting properties of baseline materials

\begin{tabular}{|c|c|}
\hline Compound & Enslin number $(\mathbf{m L} / \mathbf{g})$ \\
\hline Aluminium hydroxide & $4.73 \pm 0.16$ \\
\hline Magnesium trisilicate & $0.99 \pm 0.04$ \\
\hline Eudragit $^{\circledR}$ E PO & $0.03 \pm 0.01$ \\
\hline Sodium bicarbonate & $0.38 \pm 0.02$ \\
\hline
\end{tabular}

The S0 powder mixture without any excipient absorbed the most amount of water, while an increasing proportion of matrix former in the blend resulted in lower water absorption that is in good agreement with the properties of the applied polymer. Eudragit ${ }^{\circledR}$ E PO is poorly soluble in water and, thus, it can be difficult to moisten with water. The wettability improved whilst the amount of matrix forming polymer decreased or the ratio of sodium bicarbonate increased that had a better wetting property compared to the matrix former (Table 4).

Table 4 Wetting properties of powder blends

\begin{tabular}{|cc|}
\hline Sample & Enslin number $(\mathrm{mL} / \mathbf{g})$ \\
\hline S0 & $2.31 \pm 0.10$ \\
\hline S1 & $0.25 \pm 0.04$ \\
\hline S2 & $0.37 \pm 0.05$ \\
\hline S3 & $0.38 \pm 0.04$ \\
\hline S4 & $0.41 \pm 0.04$ \\
S5 & $0.56 \pm 0.06$ \\
\hline S6 & $0.65 \pm 0.09$ \\
\hline
\end{tabular}

\subsubsection{3. pH-changing potency}

Considering the efficacy of the preparation, it is useful to study the ability how the powder mixtures can influence the $\mathrm{pH}$ of different solutions. The produced blends were subjected to test for $\mathrm{pH}$-changing potency. $420 \mathrm{mg}$ of powder mixture (corresponding to one tablet) was placed into a glass beaker containing $100 \mathrm{~mL}$ test liquid with the following $\mathrm{pH}$ : 
$1.2 \pm 0.1 ; 2.0 \pm 0.1 ; 2.5 \pm 0.1$; and $3.0 \pm 0.1$. The $\mathrm{pH}$ was adjusted with hydrochloric acid $(\mathrm{pH}=1.2)$, and phosphate buffer according to Ph. Eur. [80]. After $20 \mathrm{~min}$ of constant stirring, the change in $\mathrm{pH}$ was checked by means of $\mathrm{pH}$ meter (WinLab $\mathrm{pH}-$ Meter, WindausLabortechnik GmbH \& Co. KG, Clausthal-Zellerfeld, Germany). Three parallel measurements were performed.

The powder blends due to their antacid effect caused applicable change in the $\mathrm{pH}$. The change was slightly higher for the blends that contained higher amounts of sodium bicarbonate (S3, S4, S5). The pH-changing tendency of mixtures was observed especially in solutions with higher $\mathrm{pH}$ (Table 5).

Table $5 \mathrm{pH}$ of different test liquids after mixing with powder mixtures

\begin{tabular}{|ccccc|}
\hline Sample & $\begin{array}{c}\text { Test liquid } \\
\text { with pH 1.2 }\end{array}$ & $\begin{array}{c}\text { Test liquid } \\
\text { with pH 2.0 }\end{array}$ & $\begin{array}{c}\text { Test liquid } \\
\text { with pH 2.5 }\end{array}$ & $\begin{array}{c}\text { Test liquid } \\
\text { with pH } 3.0\end{array}$ \\
\hline S0 & $1.54 \pm 0.03$ & $2.37 \pm 0.02$ & $5.87 \pm 0.08$ & $6.16 \pm 0.05$ \\
\hline S1 & $1.52 \pm 0.02$ & $2.15 \pm 0.02$ & $5.66 \pm 0.12$ & $5.70 \pm 0.03$ \\
\hline S2 & $1.45 \pm 0.02$ & $2.27 \pm 0.03$ & $5.94 \pm 0.03$ & $6.17 \pm 0.07$ \\
\hline S3 & $1.47 \pm 0.01$ & $2.30 \pm 0.01$ & $5.99 \pm 0.15$ & $6.30 \pm 0.04$ \\
\hline S4 & $1.46 \pm 0.02$ & $2.31 \pm 0.01$ & $6.23 \pm 0.06$ & $6.33 \pm 0.04$ \\
\hline S5 & $1.51 \pm 0.02$ & $2.32 \pm 0.01$ & $6.24 \pm 0.05$ & $6.48 \pm 0.02$ \\
\hline S6 & $1.51 \pm 0.02$ & $2.36 \pm 0.03$ & $6.34 \pm 0.06$ & $6.59 \pm 0.05$ \\
\hline
\end{tabular}

\subsubsection{Geometry and mechanical properties of matrix tablets}

Following direct compression, the geometry of tablets including thickness and diameter was determined. The test was performed by means of the Mitutoyo screw micrometer (Mitutoyo Co., Kawasaki, Japan) with an accuracy of $0.001 \mathrm{~mm} .10$ tablets were randomly selected for the measurement.

Applying higher compression force or increasing the amount of sodium bicarbonate, the thickness of tablets decreased (Table 6). The latter phenomena can be partially explained by the increased loose density. 
Table 6 Thickness of tablets $(\mathrm{mm})$

\begin{tabular}{|c|c|c|c|}
\hline Sample & $\begin{array}{c}5 \mathrm{kN} \\
(\mathrm{n}=10)\end{array}$ & $\begin{array}{l}15 \mathrm{kN} \\
(\mathrm{n}=10)\end{array}$ & $\begin{array}{l}25 \mathrm{kN} \\
(\mathrm{n}=10)\end{array}$ \\
\hline So & & Capping & \\
\hline S1 & $3.812 \pm 0.037$ & $3.440 \pm 0.038$ & $3.335 \pm 0.028$ \\
\hline S2 & $3.764 \pm 0.016$ & $3.446 \pm 0.028$ & $3.080 \pm 0.027$ \\
\hline S3 & $3.532 \pm 0.020$ & $3.335 \pm 0.021$ & $2.918 \pm 0.032$ \\
\hline S4 & $3.565 \pm 0.021$ & $3.361 \pm 0.017$ & $2.960 \pm 0.025$ \\
\hline S5 & $3.451 \pm 0.029$ & $3.252 \pm 0.008$ & $2.881 \pm 0.024$ \\
\hline S6 & & Capping & \\
\hline
\end{tabular}

S0 and S6 compositions represented the extremities: S0 corresponded to the mixture of the APIs without any binder; S6 contained the polymer in the lowest concentration that was not sufficient to compensate the elastic behaviour of sodium bicarbonate. Therefore, these formulations were not feasible to press into tablets due to capping (Fig. 3). Materials having plastic behaviour [81] undergo permanent deformation during tableting and they are able to maintain the formed shape after stress while elastic relaxation is negligible. Capping occurs if elastic behaviour of the compressed materials is more dominant and they recover after ejection [82]. In these cases, application of excipients with plastic features can improve the compressibility.

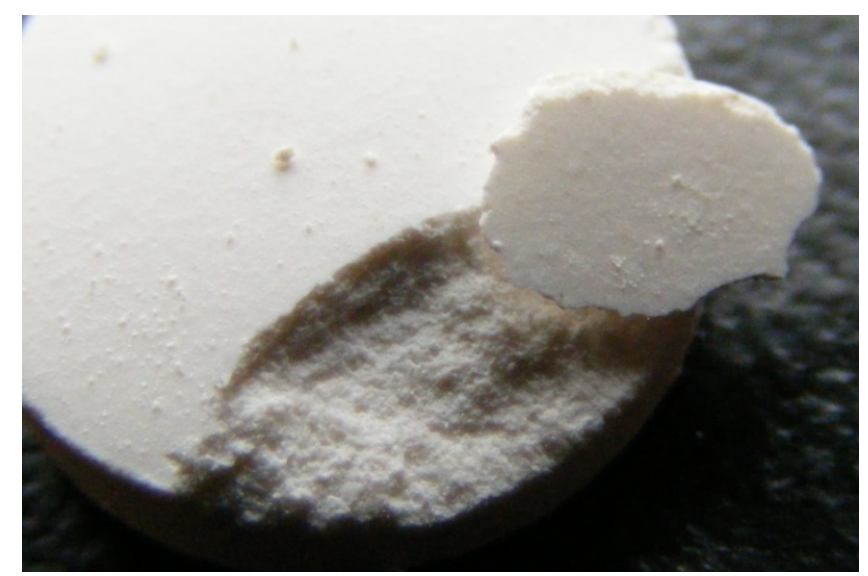

Fig. 3 Tablet capping (SO) 
Pharmaceutical tablets require adequate mechanical strength to withstand erosion and fracture during manufacturing and handling. This property can be quantified by hardness and friability. Hardness test was performed by Heberlein apparatus (Flisa, Le Locle, Switzerland). 20 tablets were investigated and they proved to have large mechanical strength.

The Erweka friability tester (Erweka GmbH, Heusenstamm, Germany) was employed to determine the friability of matrix tablets. 20 tablets were used during testing that was performed according to Ph. Eur. "Friability of uncoated tablets" [80].

Higher sodium bicarbonate content increased the friability of the tablets. Using higher compression force, friability lessened independently of composition. Friability values remained below 1\% (threshold value for acceptance in Ph. Eur.) in each case, thus all the tablet formulations passed the test (Table 7).

Table 7 Friability (\%)

\begin{tabular}{|cccc|}
\hline Sample & $\mathbf{5 ~ k N}$ & $\mathbf{1 5} \mathbf{k N}$ & $\mathbf{2 5} \mathbf{~ k N}$ \\
\hline S1 & 0.032 & 0.002 & 0.024 \\
\hline S2 & 0.132 & 0.024 & 0.009 \\
\hline S3 & 0.204 & 0.147 & 0.107 \\
\hline S4 & 0.293 & 0.205 & 0.128 \\
\hline S5 & 0.336 & 0.235 & 0.093 \\
\hline
\end{tabular}

\subsubsection{Disintegration study}

Disintegration study was carried out to determine the disintegration time of tablets in four test liquids with different $\mathrm{pH}: 1.2 ; 2.0 ; 2.5 ; 3.0$. The study was performed in the Erweka ZT 71 (Erweka GmbH, Heusenstamm) disintegration apparatus described in Ph. Eur "Disintegration of uncoated tablets" [80]. The test solutions were adjusted with phosphate buffers according to the Ph. Eur. Since the applied APIs changed the $\mathrm{pH}$ of the disintegration test liquid, the medium was replaced every 20 min to ensure the constant $\mathrm{pH}$. Six tablets were tested from each tablet compositions.

Higher compression force applied during tableting can slightly increase the disintegration time in medium $\mathrm{pH} 1.2$ (Table 8). This tendency seemed not to prevail if the tablet did not 
contain disintegrant. S5 tablets exhibited the shortest disintegration time at $5 \mathrm{kN}$ that may be explained by the weakest mechanical strength and the highest water uptake capacity.

Table 8 Disintegration time in $\min (\mathrm{pH}=1.2)$

\begin{tabular}{|cccc|}
\hline Sample & $\mathbf{5} \mathbf{k N}$ & $\mathbf{1 5} \mathbf{~ k N}$ & $\mathbf{2 5} \mathbf{~ k N}$ \\
\hline S1 & $11.01 \pm 1.30$ & $11.63 \pm 2.15$ & $11.51 \pm 1.32$ \\
\hline S2 & $12.89 \pm 0.92$ & $13.56 \pm 1.27$ & $14.43 \pm 1.67$ \\
\hline S3 & $11.34 \pm 1.02$ & $12.66 \pm 0.78$ & $16.15 \pm 2.57$ \\
\hline S4 & $12.22 \pm 1.06$ & $12.56 \pm 0.66$ & $16.95 \pm 2.09$ \\
\hline S5 & $9.87 \pm 0.38$ & $11.22 \pm 1.25$ & $16.97 \pm 1.82$ \\
\hline
\end{tabular}

In medium $\mathrm{pH}$ 2.0, a similar tendency was observed than in medium $\mathrm{pH} 1.2$, nevertheless, the disintegration time was more independent of the applied compression force or composition (Table 9). Increasing the amount of the disintegrant, contrary to expectations, the tablet disintegration decelerated. S5 did not follow this tendency due to its high Enslin number, i.e. having the highest water uptake.

Table 9 Disintegration time in $\min (p H=2.0)$

\begin{tabular}{|cccc|}
\hline Sample & $\mathbf{5} \mathbf{k N}$ & $\mathbf{1 5} \mathbf{~ k N}$ & $\mathbf{2 5} \mathbf{~ k N}$ \\
\hline S1 & $13.08 \pm 1.46$ & $13.91 \pm 1.04$ & $14.50 \pm 0.88$ \\
\hline S2 & $14.63 \pm 1.36$ & $14.80 \pm 1.41$ & $16.03 \pm 2.48$ \\
\hline S3 & $14.34 \pm 1.17$ & $15.68 \pm 0.77$ & $16.08 \pm 1.90$ \\
\hline S4 & $16.75 \pm 1.25$ & $16.88 \pm 1.76$ & $16.88 \pm 2.41$ \\
\hline S5 & $15.64 \pm 1.01$ & $16.35 \pm 0.92$ & $16.81 \pm 2.44$ \\
\hline
\end{tabular}

Performing the study in disintegration media $\mathrm{pH} 2.5$ (Table 10), disintegration times extended. The time increased as soon as higher compression forces or increasing amount of sodium bicarbonate were applied. S5 proved contrary tendency at this $\mathrm{pH}$, as well: disintegration time was shorter than expected. 
Table 10 Disintegration time in $\min (\mathrm{pH}=2.5)$

\begin{tabular}{|cccc|}
\hline Sample & $\mathbf{5 ~ k N}$ & $\mathbf{1 5} \mathbf{~ k N}$ & $\mathbf{2 5} \mathbf{~ k N}$ \\
\hline S1 & $66.40 \pm 6.53$ & $65.20 \pm 11.28$ & $71.43 \pm 9.06$ \\
\hline S2 & $103.19 \pm 4.26$ & $114.86 \pm 8.24$ & $113.50 \pm 8.25$ \\
\hline S3 & $104.16 \pm 4.95$ & $121.57 \pm 3.35$ & $127.10 \pm 14.51$ \\
\hline S4 & $115.92 \pm 7.17$ & $145.52 \pm 8.64$ & $148.46 \pm 10.69$ \\
\hline S5 & $89.92 \pm 5.29$ & $128.05 \pm 5.12$ & $164.51 \pm 17.82$ \\
\hline
\end{tabular}

The disintegration behaviour of the tablets was similar in $\mathrm{pH} 3$ to $\mathrm{pH}$ 2.5; however, further increase of disintegration time was observed (Table 11). The only exception was the S5 tablet compressed at the lowest force.

Table 11 Disintegration time in $\min (\mathrm{pH}=3.0)$

\begin{tabular}{|cccc|}
\hline Sample & $\mathbf{5} \mathbf{~ k N}$ & $\mathbf{1 5} \mathbf{~ k N}$ & $\mathbf{2 5} \mathbf{~ k N}$ \\
\hline S1 & $110.70 \pm 5.14$ & $112.27 \pm 13.68$ & $127.31 \pm 7.27$ \\
\hline S2 & $127.73 \pm 12.27$ & $143.93 \pm 17.39$ & $165.41 \pm 18.86$ \\
\hline S3 & $147.15 \pm 10.91$ & $160.49 \pm 13.05$ & $165.41 \pm 15.87$ \\
\hline S4 & $184.36 \pm 8.59$ & $183.43 \pm 4.51$ & $188.56 \pm 16.78$ \\
\hline S5 & $151.82 \pm 6.46$ & $218.65 \pm 10.37$ & $242.41 \pm 22.78$ \\
\hline
\end{tabular}

Considering the results of disintegration study, the S5 tablets manufactured at the lowest compression force $(5 \mathrm{kN})$ proved different disintegration properties, deviating from the observed tendency at each $\mathrm{pH}$. This phenomenon was further investigated. An independent study was performed to reveal the background of the observations. S4 and S5 tablets (compressed at $5 \mathrm{kN}$ force) were placed into disintegration medium $\mathrm{pH} 3.0$ and the tablets were weighed after 20 min testing. Different erosion occurred on the surface of S4 and S5 tablets: S5 tablets proved to have a more uneven surface (Fig. 4). Possibly the higher friability and better wettability of these tablets also contributed to significant surface erosion. 
Furthermore, the ratio of the matrix forming polymer was not sufficient to ensure adequate binding forces in the tablets.

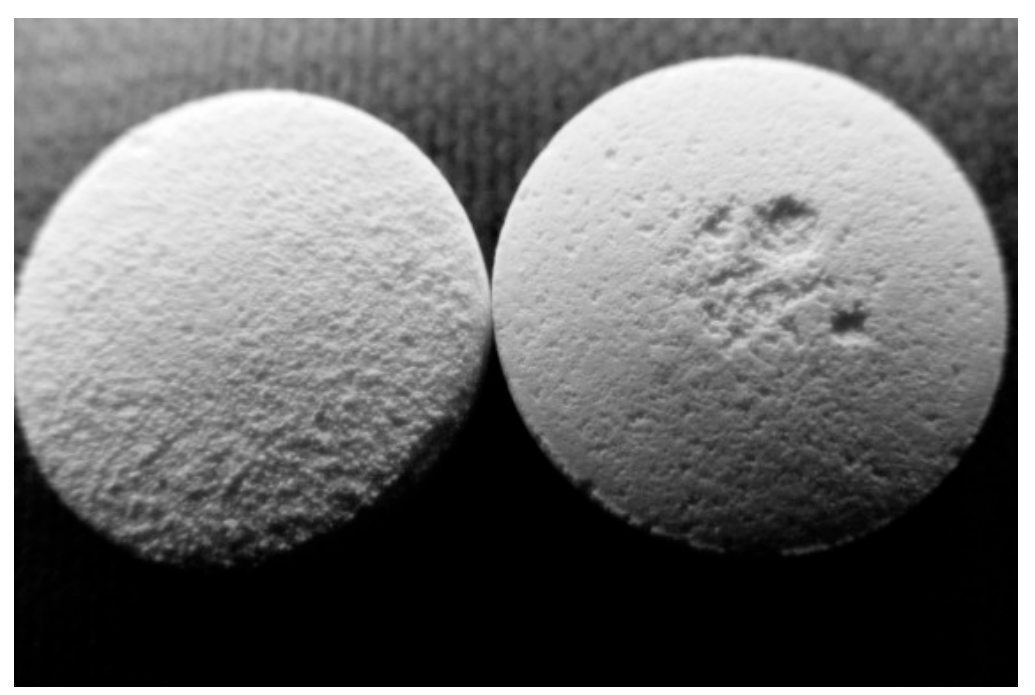

Fig. 4 Surface of S4 (left) and S5 tablets (right) after 20 min disintegration at pH 3.0

The expected disintegration time was calculated from the eroded matrix weight in $20 \mathrm{~min}$. Resuming the disintegration test, the S4 and S5 tablets required by $26 \%$ and $20 \%$, respectively, longer time to disintegrate completely (Table 12). Supposing, the APIs developed a thin alkaline fluid layer around the tablet cores that restricted the further erosion of the matrix.

Table 12 Predicted and real disintegration times of S4 and S5

\begin{tabular}{|ccc|}
\hline S4 & & S5 \\
\hline $13.68 \pm 0.82 \%$ & Percentage of eroded tablet mass in 20 min & $15.69 \pm 0.42 \%$ \\
\hline 146 min & Predicted disintegration time & $127 \mathrm{~min}$ \\
\hline $184 \mathrm{~min}$ & Real disintegration time & $152 \mathrm{~min}$ \\
\hline
\end{tabular}

\subsubsection{Summary}

Application of Eudragit ${ }^{\circledR}$ E PO pH-dependent matrix former ensured suitable disintegration of antacid tablets in solutions with different $\mathrm{pH}$. Above $\mathrm{pH} 2$, the liberation of the APIs markedly decreased. At $\mathrm{pH}$ 3.0, the disintegration time elongated to a significant extent that ensures that the antacid tablet does not release further API which is unnecessary at this $\mathrm{pH}$. 


\subsection{Part 2}

In the previous part of the work, S4 composition (Table 13) exhibited appropriate properties regarding drug release. However, the powder blend was not suitable for direct compression due to poor flow properties. Consequently, size-enlargement process was applied to improve compaction characteristics and simultaneously maintain the $\mathrm{pH}$-dependent disintegration profile of the tablets. Wet granulation and hot melt granulation were investigated. Primarily additional excipients were not used; the purpose of the experiments was to study the general effects of granulation on product features.

Table 13 Composition of powder blends used for granulation

\begin{tabular}{|cc|}
\hline Compound & Amount per tablet \\
\hline Aluminium hydroxide & $135 \mathrm{mg}$ \\
\hline Magnesium trisilicate & $135 \mathrm{mg}$ \\
\hline Sodium bicarbonate & $50 \mathrm{mg}$ \\
\hline Eudragit $^{\circledR}$ E PO & $100 \mathrm{mg}$ \\
\hline
\end{tabular}

\subsubsection{Preliminary data generation}

Prior to optimization of the process of granulation, preliminary data were collected about the effect of different granulation techniques on the powder flow, wetting characteristics, and disintegration of matrix tablets. The composition detailed in Table 13 was subjected to wet and hot melt granulation.

\subsubsection{Manufacturing methods}

\subsection{Wet granulation}

The most common granulation technique is the wet granulation due to its simplicity and relative cost-effectiveness. Development of agglomerates may occur with solvent that partially dissolves the components and solid bridges form following solvent evaporation or binders as special excipients can be added to the powder mixture in the agglomeration phase of granulation and the binder keeps together the agglomerated particles. In the present study ethanol and purified water were applied as solvents to manufacture granules by wet granulation. The matrix forming polymer (Eudragit ${ }^{\circledR} \mathrm{E}$ PO) dissolves in ethanol but it is practically insoluble in water. The process of granulation was carried out in a high-shear 
mixer (Pro-C-epT 4M8, Pro-C-epT nv, Zelzate, Belgium) and the torque of impeller was employed to determine the endpoint [83,84]. 15\% impeller torque was selected as the endpoint based on preliminary studies. During formation of granules, $55 \mathrm{~mL}$ of ethanol and as a consequence of poor wetting of the polymer with water - double amount, $110 \mathrm{~mL}$ of purified water was required to obtain the final wet mass. Important to note that wet granulation with water required special attention during the determination of the endpoint since over-kneading of the wet mass could easily happen.

Blending of the powders was performed in a rotating shaker mixer (Turbula, Willy A. Bachofen AG Maschinenfabrik, Basel, Switzerland) for $10 \mathrm{~min}$ at $50 \mathrm{rpm}$. The homogeneous mixture was transferred into the vessel of the high-shear mixer that operated with the following settings:

speed of impeller $.1000 \mathrm{rpm}$

speed of chopper $.4000 \mathrm{rpm}$

dosing speed of liquid. $.5 \mathrm{~mL} / \mathrm{min}$

The manufactured granules were dried on trays at ambient conditions for $24 \mathrm{hr}$.

\subsection{Hot melt granulation}

The hot melt granulation is an alternative granulation technique that requires a molten binder that forms bridges between particles after solidification [50]. The same blend composition was submitted for hot melt granulation as it was described in Table 13 and the preparation of powder mixture was performed according to the method detailed in 4.4.1.1.1.

Granules were prepared in a laboratory scale high-shear mixer (Pro-C-epT 4M8, Pro-CepT nv, Zelzate, Belgium) equipped with jacketed vessel that allows hot water to be circulated around the mixing vessel. The jacket temperature was raised up to $70^{\circ} \mathrm{C}$ that was above the glass transition temperature of Eudragit ${ }^{\circledR} \mathrm{E}$ PO $\left(\sim 48^{\circ} \mathrm{C}\right.$ [85]). A thermostat (Julabo F12, Julabo Labortechnik GmbH, Seelbach) was applied to maintain a permanent temperature. A pre-warming phase was applied to attain the equilibrium temperature of the powder. This was $5-7^{\circ} \mathrm{C}$ lower than the set value. The operational parameters were as follows:

speed of impeller. $.1000 \mathrm{rpm}$

speed of chopper. $4000 \mathrm{rpm}$

process time at the equilibrium temperature $.10 \min$ 


\subsection{Tablet manufacturing}

The matrix tablets were produced with the Korsch EK0 instrumented eccentric tablet machine (Emil Korsch Maschinenfabrik, Berlin, Germany) at $15 \pm 2 \mathrm{kN}$ compression force. The round, convex-faced tablets were $13 \mathrm{~mm}$ in diameter and $420 \pm 5 \mathrm{mg}$ in weight. The tablets did not contain any further excipients like glidant or lubricant.

\subsubsection{Methods of investigation and results}

\subsection{Thermoanalytical study}

Heat-sensitive materials represent the group that is unsuitable to be processed by hot melt granulation as it was indicated among the limitations. Albeit the applied APIs and matrix forming polymer are thermally stable, sodium bicarbonate may undergo thermal decomposition. The temperature of chemical decomposition was reported $\sim 90^{\circ} \mathrm{C}$ by literature [74], and the applied temperature during granulation was kept well below this temperature $\left(70^{\circ} \mathrm{C}\right)$. Notwithstanding, thermal analysis of sodium bicarbonate was performed to exclude the possibility of thermal decomposition.

Differential Scanning Calorimetry (DSC) is one of the most commonly used thermoanalytical methods. This method provides quantitative and qualitative information about physical and chemical reactions through determination of the absorbed or emitted heat generated in endothermic or exothermic processes. DSC studies are commonly used to determine the melting point, glass transition temperature, and to assess stability and phase transition studies.

The Mettler-Toledo DSC 821e (Mettler-Toledo GmbH, Basel, Switzerland) instrument was employed to detect thermal changes. The measurement was carried out with a dynamic method; using a heating rate of $10^{\circ} \mathrm{C} / \mathrm{min}$. Sodium bicarbonate was tested in the temperature interval of $0-200^{\circ} \mathrm{C}$. Argon was used as a purge gas. $10 \mathrm{mg}$ of samples was added to the aluminium pans $(40 \mu \mathrm{L})$. The curves were evaluated with STAR $^{\mathrm{e}}$ software.

According to the results, sodium bicarbonate developed the first peak indicating thermal degradation at $\sim 90^{\circ} \mathrm{C}$. At the temperature of the granulation process $\left(\sim 70^{\circ} \mathrm{C}\right)$ thermal phenomenon was not observed (Fig. 5). 


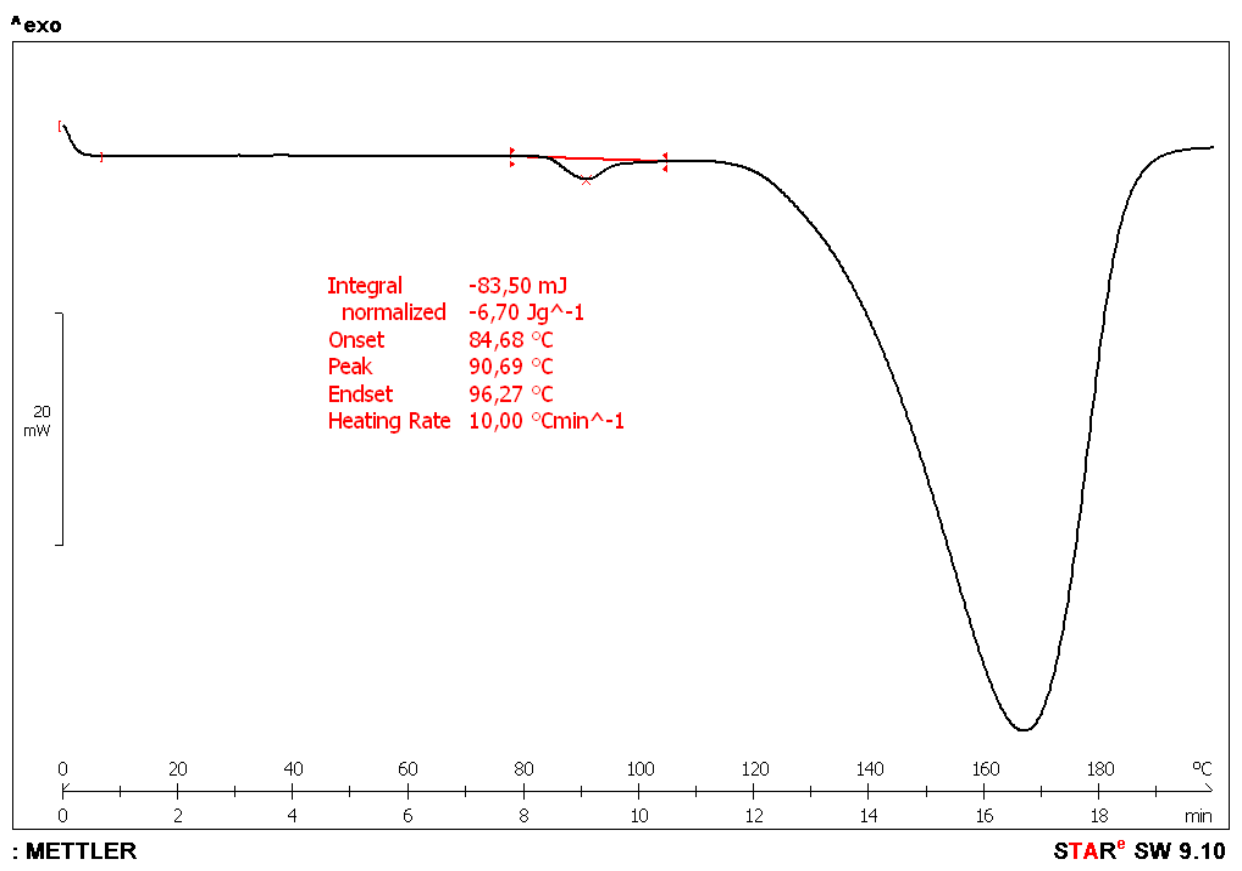

Fig. 5 DSC curve of sodium bicarbonate

\subsection{Flow properties}

The granules produced by wet granulation had remarkably good flow properties independently of the applied solvent, i.e. significant improvement has been achieved with wet granulation compared to the properties of the baseline blend. The most meaningful alteration occurred in the flow time of $100 \mathrm{~mL}$ powder: whilst the original powder mixture required $157 \mathrm{~s}$ with stirring to flow through the test funnel, the granules exhibited free-flowing characteristics. The improved flowability was also confirmed by the Carr`s index that diminished by $50 \%$ compared to the value measured on baseline powder blend. Albeit the improvement in Carr`s index was remarkable, it could not be considered as significant achievement regarding processability (Table 14). 
Table 14 Flow properties of powder blend and granules

\begin{tabular}{|c|ccc|}
\hline Method of processing & $\begin{array}{c}\text { Flow time } \\
\mathbf{( s )}\end{array}$ & $\begin{array}{c}\text { Loose density } \\
\left(\mathbf{g} / \mathbf{c m}^{\mathbf{3}}\right)\end{array}$ & $\begin{array}{c}\text { Carr`s index } \\
\mathbf{( \% )}\end{array}$ \\
\hline Direct compression & $\begin{array}{c}157.8 \pm 8.9 \\
(25 \mathrm{rpm})^{*}\end{array}$ & $0.313 \pm 0.005$ & $30.4 \pm 0.8$ \\
\hline Wet granulation with water & $6.3 \pm 0.1$ & $0.413 \pm 0.006$ & $15.64 \pm 0.44$ \\
\hline Wet granulation with ethanol & $7.3 \pm 0.1$ & $0.567 \pm 0.010$ & $14.10 \pm 0.44$ \\
\hline Hot melt granulation & $153.6 \pm 15.4$ & $0.387 \pm 0.007$ & $26.4 \pm 0.8$ \\
\hline
\end{tabular}

*Speed of stirring required during flow test

\subsection{Evaluation of water uptake and particle size analysis}

Water uptake study was performed according to the method described in 4.3.2.2.

Determination of particle size distribution was performed with Retsch vibratory sieve (Retsch GmbH, Haan, Germany) using the following mesh sizes: 1000, 900, 800, 700, 600, $500,400,300,200$, and $100 \mu \mathrm{m}$. To determine the certain size fractions, $100 \mathrm{~g}$ of granules was used. The D50 value of average particle size was determined by EasySieve software (Retsch GmbH, Haan, Germany).

Wet granulation with ethanol provided the largest particle size of granules. The wetting properties of the granulated products also changed; each processing method markedly increased the water uptake (Table 15).

Table 15 Wettability and mean particle size of granules and baseline blend

\begin{tabular}{|ccc|}
\hline Processing method & $\begin{array}{c}\text { Enslin number } \\
(\mathbf{m L} / \mathbf{g})\end{array}$ & $\begin{array}{c}\text { D50 } \\
(\mathbf{m m})\end{array}$ \\
\hline Direct compression & $0.41 \pm 0.04$ & $\mathrm{n} / \mathrm{a}$ \\
\hline Wet granulation with water & $1.69 \pm 0.02$ & 0.184 \\
\hline Wet granulation with ethanol & $1.21 \pm 0.02$ & 0.261 \\
\hline Hot melt granulation & $1.62 \pm 0.05$ & 0.154 \\
\hline
\end{tabular}




\subsection{Friability test}

Friability of tablets manufactured from granules deteriorated compared to the directly compressed tablets (Table 16). The most pronounced alteration was observed in samples prepared by hot melt granulation. These tablets proved to have higher friability value than the acceptance limit of Ph. Eur. (1\%).

Table 16 Friability of tablets prepared by direct compression and compression of granules

\begin{tabular}{|cc|}
\hline Processing method & Friability (\%) \\
\hline Direct compression & 0.21 \\
\hline Wet granulation with water & 0.26 \\
\hline Wet granulation with ethanol & 0.40 \\
\hline Hot melt granulation & 2.55 \\
\hline
\end{tabular}

\subsection{Disintegration study}

Besides the improvement of compressibility, the major aim of the processing was to maintain the $\mathrm{pH}$-dependent disintegration of the compressed tablets that was described in details in Part 1. Thus the disintegration of the tablets compressed from granules was studied according to the method specified in 4.3.2.5.

Performing the study in four test liquids with different $\mathrm{pH}$, the tablets compressed from wet granulated samples disintegrated in 1 to $4 \mathrm{~min}$ and the disintegration time did not correlate with the $\mathrm{pH}$ (Table 17). The tablets showed fast disintegration, and the granules did not retain the $\mathrm{pH}$-dependent API release. These observations are in good agreement with wettability and friability that also revealed the decreasing ability of matrix former to control the drug release from wet granulated samples. Contrarily hot melt granulated samples exhibited appropriate disintegration times: the disintegration times extended alongside increasing $\mathrm{pH}$. 
Table 17 Disintegration time at different $\mathrm{pH}$

\begin{tabular}{|ccccc|}
\hline Processing method & $\begin{array}{c}\mathbf{p H = 1 . 2} \\
\mathbf{( m i n )}\end{array}$ & $\begin{array}{c}\mathbf{p H = 2 . 0} \\
\mathbf{( m i n )}\end{array}$ & $\begin{array}{c}\mathbf{p H = 2 . 5} \\
\mathbf{( m i n )}\end{array}$ & $\begin{array}{c}\mathbf{p H = 3 . 0} \\
(\mathbf{m i n})\end{array}$ \\
\hline Direct compression & $12.56 \pm 0.66$ & $16.88 \pm 1.76$ & $145.52 \pm 8.64$ & $183.43 \pm 4.51$ \\
\hline Wet granulation with water & $1.70 \pm 0.05$ & $2.13 \pm 0.17$ & $1.99 \pm 0.43$ & $1.43 \pm 0.42$ \\
\hline Wet granulation with ethanol & $3.61 \pm 0.24$ & $1.55 \pm 0.10$ & $1.37 \pm 0.07$ & $1.12 \pm 0.05$ \\
\hline Hot melt granulation & $7.48 \pm 0.58$ & $9.84 \pm 0.82$ & $27.83 \pm 6.75$ & $38.87 \pm 4.58$ \\
\hline
\end{tabular}

\subsubsection{Summary}

Wet granulation technique was a suitable method to improve the flow properties of the blend, although this procedure caused unfavourable change in the disintegration profile of the matrix tablets, consequently the pH-dependent API release ceased. Well-defined, individual particles developed during granulation that lost the ability to form a cohesive matrix system. Hot melt granulation did not improve the processability considerably, albeit the matrix tablets composed of hot melt granules partially preserved the $\mathrm{pH}$-dependent disintegration profile. Based on the findings of preliminary processing, the hot melt granulation was selected for further investigation.

\subsubsection{Optimization of hot melt granulation}

Optimization of preparation of hot melt granules was initiated in order to customize the pH-dependent disintegration of matrix tablets and to achieve good flow of intermediate granules. Blend composition listed in Table 13 was supplemented by a melting excipient. For this purpose, polyethylene glycol (molecular weight: 2000; PEG 2000) was selected that is a hydrophilic polymer acting as a binder. Polyethylene glycols have several applications and they represent a wide excipient family. The decision was made on usage of PEG 2000 since this type of PEGs has a melting point $\left(49-52^{\circ} \mathrm{C}\right)$ close to the glass transition temperature of Eudragit $^{\circledR}$ E PO. The two polymers were applied in different ratios (Table 18). 
Table 18 Composition of hot melt samples (quantities are given per tablet)

\begin{tabular}{|c|c|c|c|c|c|c|}
\hline & Hot0 & Hot1 & Hot2 & Hot3 & Hot4 & Hot5 \\
\hline $\mathrm{AH}$ & $135 \mathrm{mg}$ & $135 \mathrm{mg}$ & $135 \mathrm{mg}$ & $135 \mathrm{mg}$ & $135 \mathrm{mg}$ & $135 \mathrm{mg}$ \\
\hline MT & 135 mg & $135 \mathrm{mg}$ & $135 \mathrm{mg}$ & $135 \mathrm{mg}$ & $135 \mathrm{mg}$ & $135 \mathrm{mg}$ \\
\hline SB & $50 \mathrm{mg}$ & $50 \mathrm{mg}$ & $50 \mathrm{mg}$ & $50 \mathrm{mg}$ & $50 \mathrm{mg}$ & $50 \mathrm{mg}$ \\
\hline $\mathrm{EE}$ & 100 mg & $100 \mathrm{mg}$ & $100 \mathrm{mg}$ & $100 \mathrm{mg}$ & $100 \mathrm{mg}$ & - \\
\hline $\begin{array}{l}\text { PEG } \\
2000\end{array}$ & - & - & $50 \mathrm{mg}$ & $100 \mathrm{mg}$ & $150 \mathrm{mg}$ & $100 \mathrm{mg}$ \\
\hline Total & $420 \mathrm{mg}$ & $420 \mathrm{mg}$ & $470 \mathrm{mg}$ & $520 \mathrm{mg}$ & $570 \mathrm{mg}$ & $420 \mathrm{mg}$ \\
\hline Remark & $\begin{array}{c}\text { Powder } \\
\text { mixture for } \\
\text { direct } \\
\text { compression }\end{array}$ & \multicolumn{5}{|c|}{ Hot melt granules } \\
\hline
\end{tabular}

\subsubsection{Methods of manufacturing}

The powder blends were prepared using the ratios reported in Table 18 in a rotating shaker mixer and the granulation process was carried out in laboratory scale high-shear mixer equipped with jacketed vessel. The manufactured granules were used for tablet compression. For more details on manufacturing methodology please refer to 4.4.1.1.2 and 4.4.1.1.3.

\subsubsection{Methods of investigation and results}

\subsection{Evaluation of granules}

Increasing the amount of PEG 2000 contributed to the development of improved characteristics: samples Hot3 and Hot4 exhibited good flow properties; no stirring was required during testing (Table 19). The above-mentioned samples were composed of larger and denser particles, thus Carr`s index indicated an excellent flow. Heating of the blend without PEG 2000 (Hot1) did not lead to relevant alteration in flowability and compressibility, however the water uptake significantly $(\mathrm{p}<0.05)$ increased. Properties of polymers prevailed in the granules, consequently the water uptake decreased. Evaluation of Hot5 sample (absence of matrix former) revealed deterioration in each examined parameter. 
Hot1 and Hot5 compositions were considered as extremities due to the lack of one out of two polymers. The examined features were expected to fall into a range determined by the two extremities. Contrary to expectations, the measured values were divergent, occasionally more favourable.

Table 19 Key features of hot melt granules

\begin{tabular}{|c|c|c|c|c|c|}
\hline Sample & $\begin{array}{c}\text { Flow time } \\
\text { (s) }\end{array}$ & $\begin{array}{c}\text { Bulk density } \\
\qquad\left(\mathrm{g} / \mathrm{cm}^{3}\right)\end{array}$ & $\begin{array}{c}\text { Carr`s } \\
\text { index } \\
(\%)\end{array}$ & $\begin{array}{c}\text { Enslin } \\
\text { number } \\
\text { (mL/g) }\end{array}$ & $\begin{array}{r}\text { D50 } \\
(\mathrm{mm})\end{array}$ \\
\hline Hot0 & $\begin{array}{l}157.8 \pm 8.9 \\
(25 \mathrm{rpm})^{*}\end{array}$ & $0.313 \pm 0.005$ & $30.4 \pm 0.8$ & $0.41 \pm 0.04$ & $\mathrm{n} / \mathrm{a}$ \\
\hline Hot1 & $\begin{array}{c}153.6 \pm 15.4 \\
(25 \mathrm{rpm})^{*}\end{array}$ & $0.387 \pm 0.007$ & $26.4 \pm 0.8$ & $1.62 \pm 0.05$ & 0.154 \\
\hline Hot2 & $\begin{array}{c}80.3 \pm 6.4 \\
(25 \mathrm{rpm})^{*}\end{array}$ & $0.448 \pm 0.008$ & $26.7 \pm 1.7$ & $1.19 \pm 0.03$ & 0.215 \\
\hline Hot3 & $\begin{array}{l}8.5 \pm 2.3 \\
(0 \mathrm{rpm})^{*}\end{array}$ & $0.742 \pm 0.001$ & $9.3 \pm 0.6$ & $0.74 \pm 0.02$ & 0.242 \\
\hline Hot4 & $\begin{array}{c}4.1 \pm 0.2 \\
(0 \text { rpm)* }\end{array}$ & $0.719 \pm 0.001$ & $3.5 \pm 0.3$ & $0.66 \pm 0.03$ & 0.376 \\
\hline Hot5 & $\begin{array}{c}60.4 \pm 3.6 \\
(25 \text { rpm)* }\end{array}$ & $0.537 \pm 0.007$ & $19.2 \pm 0.8$ & $1.03 \pm 0.02$ & 0.169 \\
\hline
\end{tabular}

*speed of stirring during flow test

\subsection{Evaluation of tablets}

Tablets were compressed using the above-described granules at $15 \pm 2 \mathrm{kN}$ compression force. PEG 2000 increased the mechanical strength of the tablets provided Eudragit ${ }^{\circledR}$ E PO was also present. Tablets prepared in the absence of matrix former (Hot5) displayed poor mechanical strength and the samples broke apart during the friability test (Table 20).

Disintegration of tablets prepared from hot melt granules verified a $\mathrm{pH}$-dependent disintegration (Table 20). Application of PEG 2000 extended the disintegration time, however this tendency failed to prevail in sample Hot5. Hot2 formulation disintegrated the most rapidly where the $\mathrm{pH}$-sensitive effect was negligible. The most pronounced delay in 
disintegration time was assessed in Hot4 tablets that might be considered as a biopharmaceutically remarkable alteration between the different $\mathrm{pH}$ conditions. The compressibility of Hot4 granules was also the most appropriate. It can be concluded that there was no unambiguous correlation between the water uptake and disintegration time. The heatinduced interaction between the polymers resulted in severe alterations in the inner structure of the granules, therefore the prediction of their behaviour became impossible solely from the baseline materials.

Table 20 Friability and disintegration time (in min) of tablets prepared using hot melt granules

\begin{tabular}{|cccccc|}
\hline Sample & $\begin{array}{c}\text { Friabilty } \\
(\mathbf{\%})\end{array}$ & $\begin{array}{c}\mathbf{p H = 1 . 2} \\
\mathbf{( m i n )}\end{array}$ & $\begin{array}{c}\mathbf{p H}=\mathbf{2 . 0} \\
\mathbf{( m i n})\end{array}$ & $\begin{array}{c}\mathbf{p H}=\mathbf{2 . 5} \\
\mathbf{( m i n})\end{array}$ & $\begin{array}{c}\mathbf{p H}=\mathbf{3 . 0} \\
(\mathbf{m i n})\end{array}$ \\
\hline Hot0 & 0.21 & $12.56 \pm 0.66$ & $16.88 \pm 1.76$ & $145.52 \pm 8.64$ & $183.43 \pm 4.51$ \\
\hline Hot1 & 2.55 & $7.48 \pm 0.58$ & $9.84 \pm 0.82$ & $27.83 \pm 6.75$ & $38.87 \pm 4.58$ \\
\hline Hot2 & 1.81 & $4.82 \pm 0.55$ & $4.56 \pm 0.47$ & $6.37 \pm 1.83$ & $10.89 \pm 2.18$ \\
\hline Hot3 & 0.29 & $13.74 \pm 0.62$ & $15.00 \pm 0.34$ & $50.58 \pm 4.51$ & $80.82 \pm 7.96$ \\
\hline Hot4 & $\mathbf{0 . 2 1}$ & $\mathbf{1 6 . 9 6} \pm \mathbf{0 . 6 7}$ & $\mathbf{1 7 . 4 0} \pm \mathbf{0 . 9 6}$ & $\mathbf{6 4 . 1 4} \pm 3.59$ & $\mathbf{1 0 7 . 4 2} \pm \mathbf{6 . 5 8}$ \\
\hline Hot5 & broken & $4.18 \pm 0.28$ & $4.81 \pm 0.17$ & $11.86 \pm 3.15$ & $37.38 \pm 1.34$ \\
\hline
\end{tabular}

\subsection{Thermoanalytical study}

The polymers reacted which led to beneficial properties since those formulations indicated appropriate features which contained both polymers. Differential Scanning Calorimetry (Mettler-Toledo DSC 821e, Mettler-Toledo GmbH, Basel, Switzerland) was performed to investigate the possible physico-chemical interaction between the polymers. Specimens were Eudragit ${ }^{\circledR}$ E PO and PEG 2000, separately; in addition, the mixtures of the polymers in the following ratios: 2:1, 2:2, and 2:3, Eudragit ${ }^{\circledR}$ E PO and PEG 2000, respectively. The tested ratios corresponded to the polymer ratios applied in hot melt 
granules. The temperature interval was $25-200^{\circ} \mathrm{C}$, the other parameters were used as discussed in 4.4.1.2.1.

During the investigation of mixtures, the peaks of DSC curves shifted to higher temperature, moreover, double peaks emerged (Fig. 6). These findings pointed to the fact that chemical interaction occurred between the matrix former and hydrophilic binder. The interaction induced process seemed not to be completed at the temperature of granulation. The completion of the phenomenon could occur above $80^{\circ} \mathrm{C}$; nonetheless, the risk of decomposition of sodium bicarbonate would significantly increase at this temperature. The polymer ratio of sample Hot4 exhibited a uniform peak on the DSC curve at the temperature of the granulation. In this case, the favourable effect of the binder and the synergistic effect of the rate-limiting polymer were detected, as well.

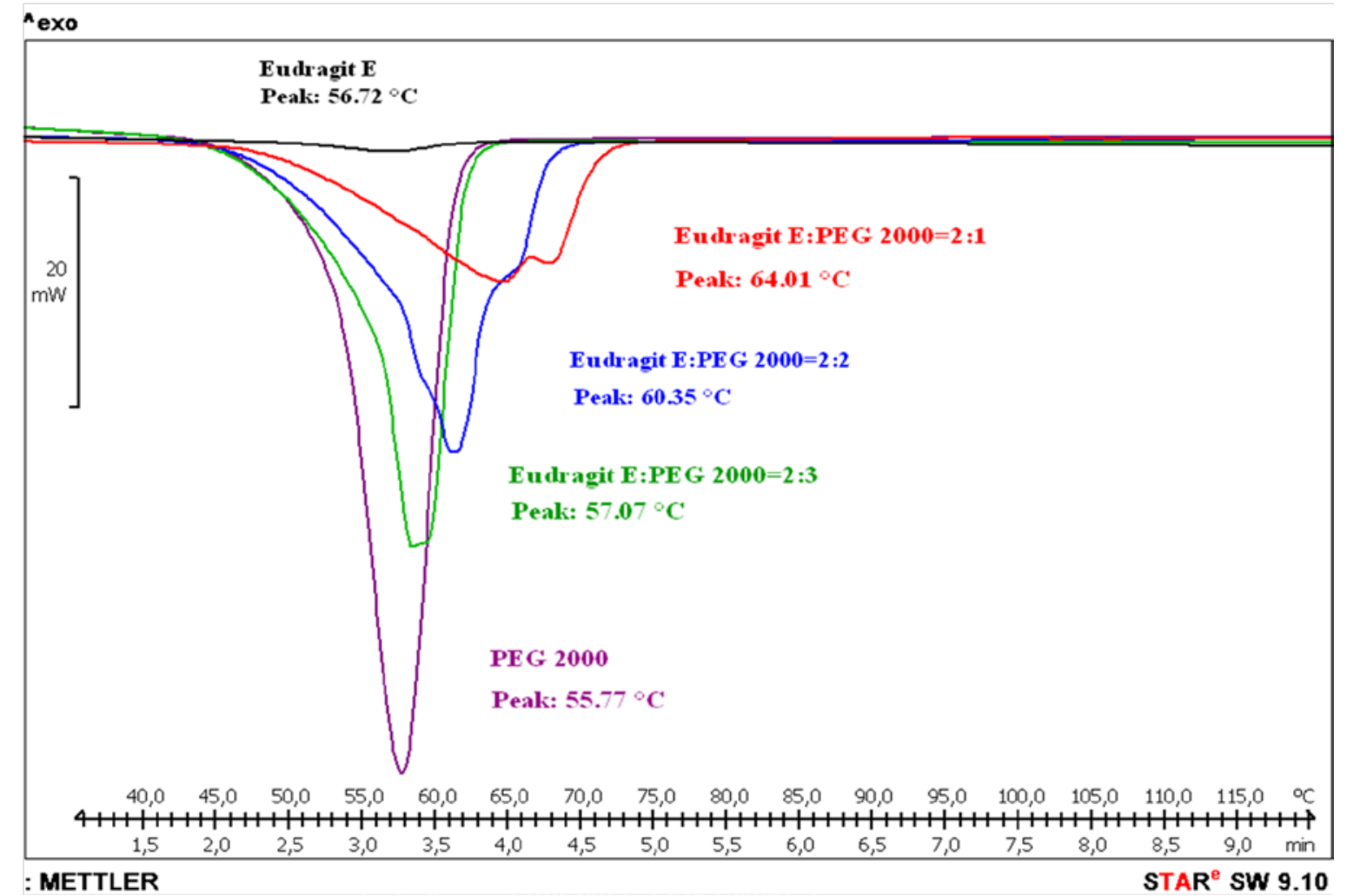

Fig. 6 DSC curves of polymers and polymer mixtures

\subsection{Solid-state NMR spectroscopy}

Solid-state NMR (Nuclear Magnetic Resonance) spectroscopy was carried out in order to reveal the structural changes of polymers following melt granulation. Mono-component and complex macromolecular systems can be investigated by the solid-state NMR technique 
$[86,87]$. The selection of an adequate technique results in additional information about the conformation of polymer chains, mobility of the side and main chains, and molecular motion.

During the investigation, $2 \mathrm{D}{ }^{1} \mathrm{H}-{ }^{1} \mathrm{H}$ and ${ }^{1} \mathrm{H}-{ }^{13} \mathrm{C}$ correlation measurements were performed that did not reveal considerable mixing of PEG 2000 and Eudragit ${ }^{\circledR}$ E PO. However, the 1D ${ }^{13} \mathrm{C}$ MAS (magic angle spinning) measurements proved that the granulation process slightly altered the structure of PEG 2000 and Eudragit ${ }^{\circledR}$ E PO compared to the pure baseline materials. The measurements were performed by direct excitation (DE) and cross polarization (CP).

The spectrum of PEG 2000 split into three signals (Fig. 7). Signal I referred to the crystalline PEG 2000 while the signal II and III indicated more mobile phases. Signal I was not detected in the granules denoting that PEG 2000 did not appear in a crystalline form in the granules.

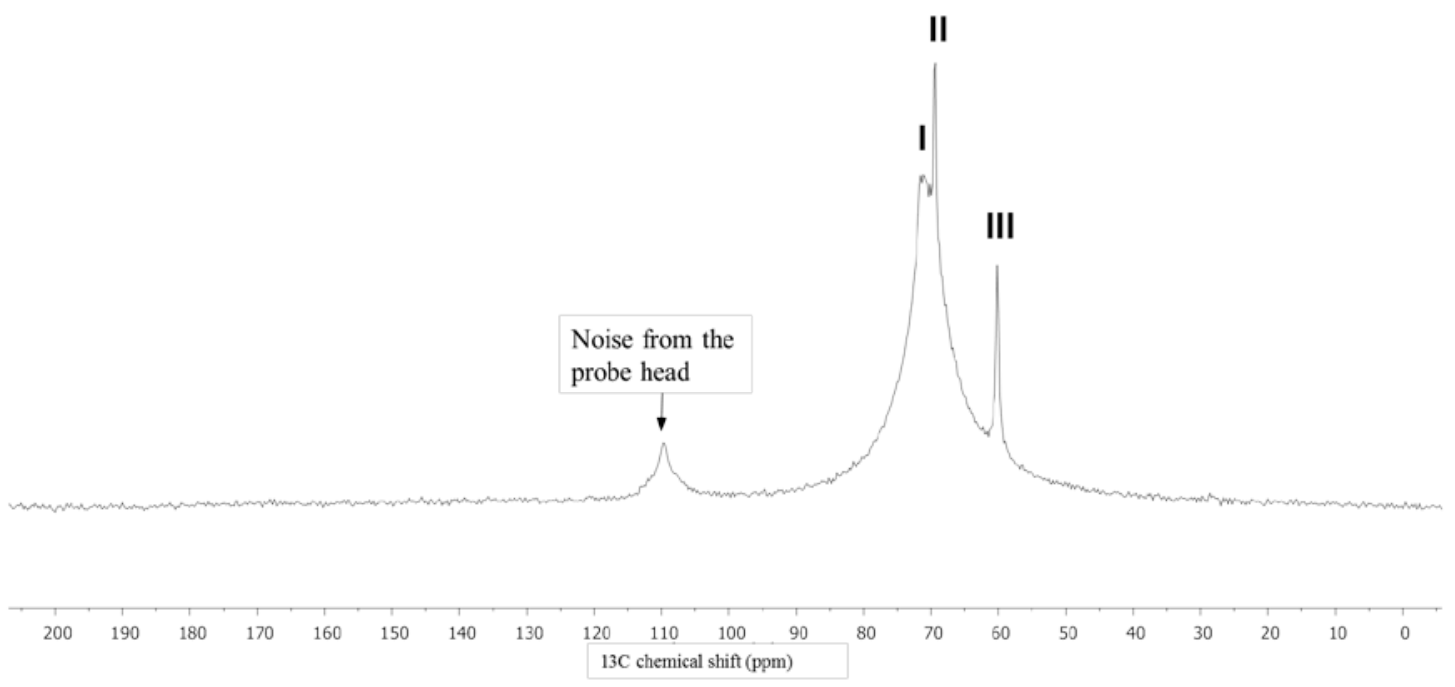

Fig. $7{ }^{13}$ C DE MAS solid-state spectrum of PEG 2000 (The signal at 110 ppm derives from the components of plastic (teflon) probe head.)

The phase signals of Eudragit ${ }^{\circledR}$ E PO were identical in the granules. Nevertheless, the signal II and III of PEG 2000 could not be identified in the granules (Fig. 8). Consequently, the structure of PEG 2000 altered in the pharmaceutical intermediates compared to the pure PEG 2000. 


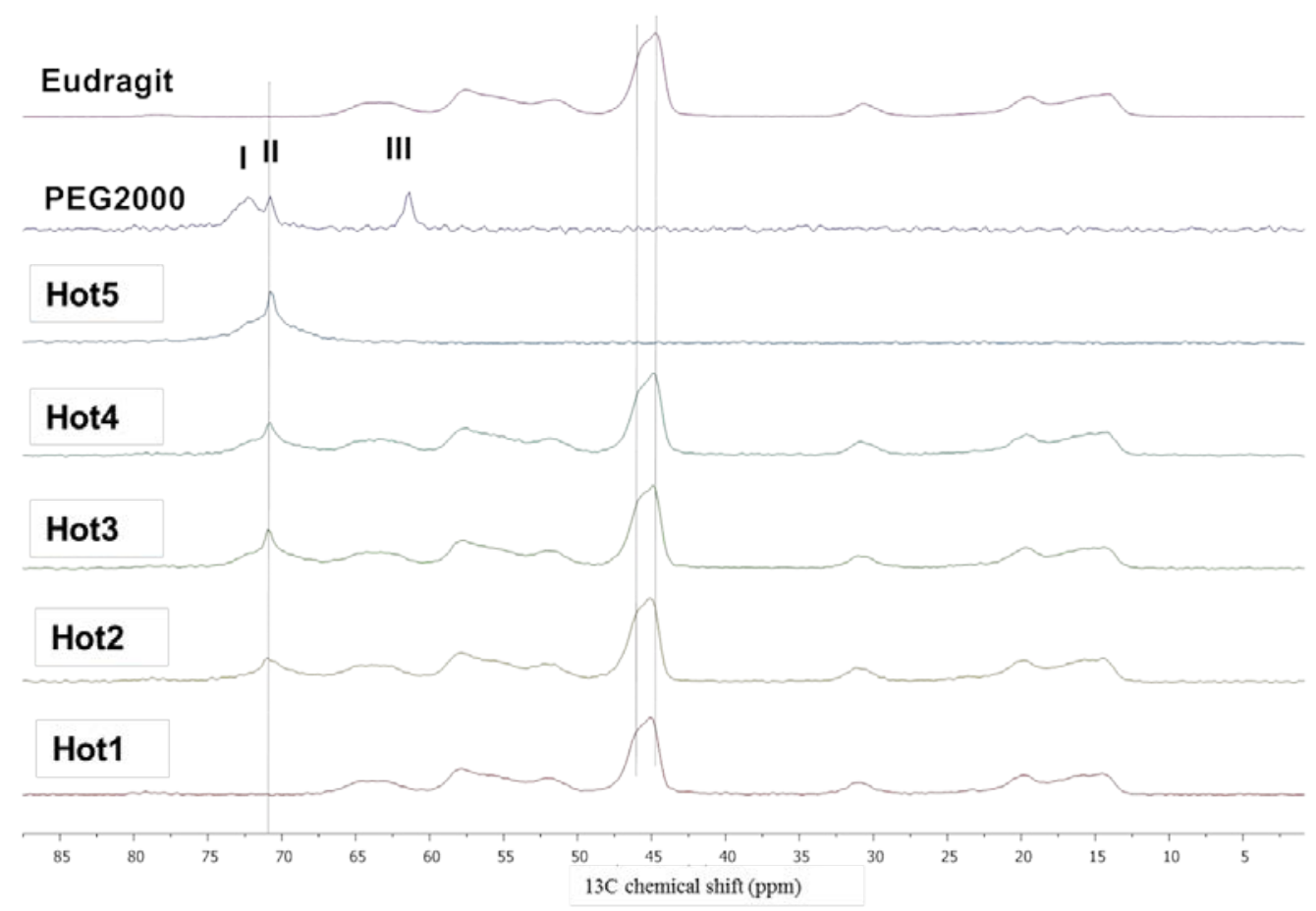

Fig. $8{ }^{13}$ C CP MAS solid-state NMR spectra. Parameters of measurement: cross polarization time: $2 \mathrm{~ms}$, spin: $10 \mathrm{kHz}$, temperature: $25^{\circ} \mathrm{C}$, relaxation delay: $5 \mathrm{~s}$

The spectra obtained from direct excitation (Fig. 9) depicted that the signals of Eudragit ${ }^{\circledR}$ E PO were slightly but obviously different. Eudragit ${ }^{\circledR}$ E PO exhibited different signals in Hot2 compared to Hot3 and Hot4. This difference could also be observed in the spectra of PEG 2000. Signal III of PEG 2000 seemed to appear in Hot4. The missing signal I indicated the absence of crystalline PEG 2000 in the granules, however, it can be assumed that the resolution of signal II to a broader and a narrower signal may have occurred due to the formation of microcrystals. In addition, the ratio of narrower and broader signals is different in Hot2 compared to Hot3 and Hot4. 


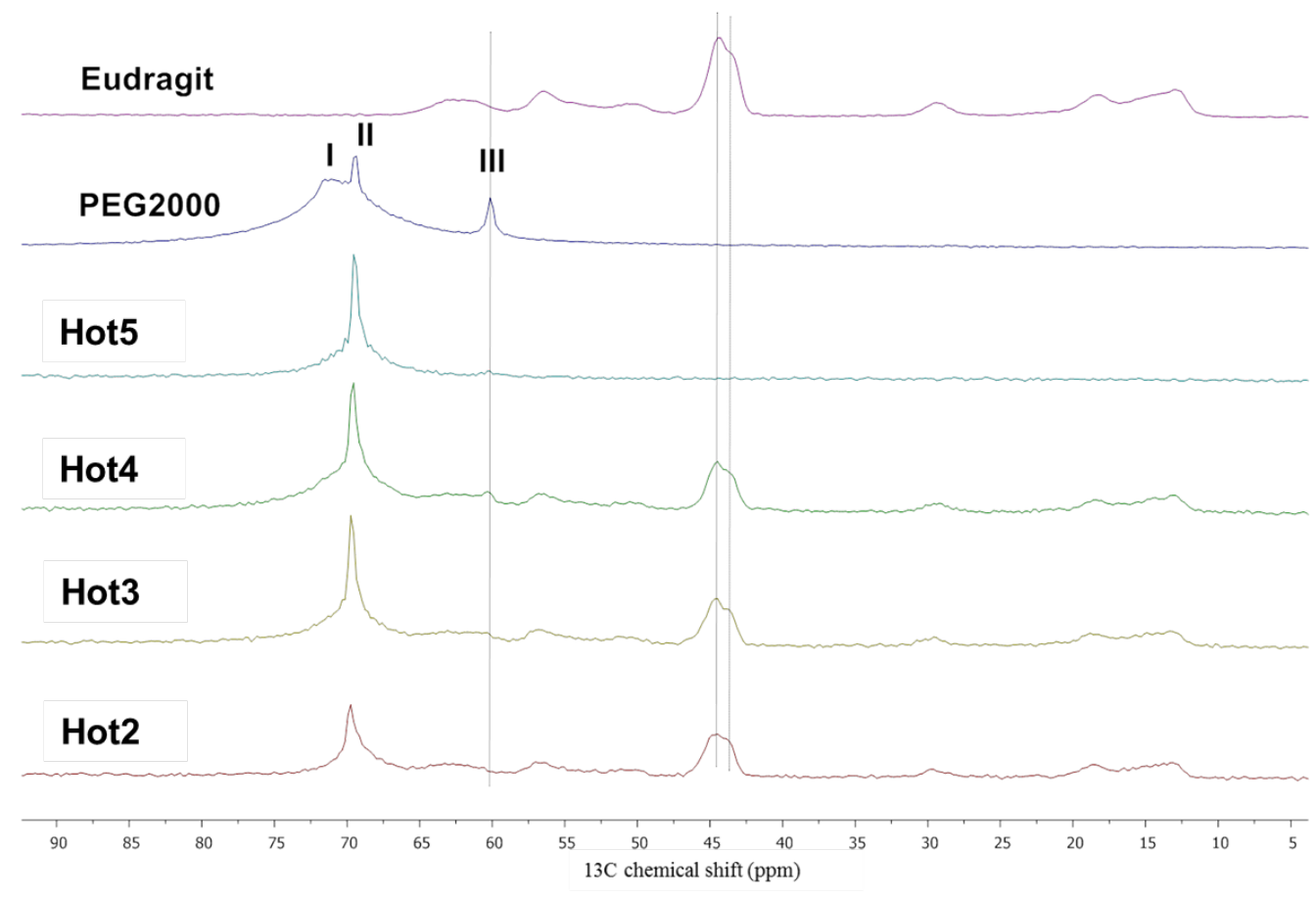

Fig. $9{ }^{13}$ C DE MAS solid-state NMR spectra. Parameters of measurement: cross polarization time: $2 \mathrm{~ms}$, spin: $10 \mathrm{kHz}$, temperature: $25^{\circ} \mathrm{C}$, relaxation delay: $5 \mathrm{~s}$

The results of the solid-state NMR study reflected that the mixing of polymers occurred on the surface. The differences of the spectra of granules and pure polymers may explain the beneficial mechanical and disintegration properties of tablets prepared from hot melt granules.

\subsubsection{Summary}

Utilization of PEG 2000 enabled the formulation of suitable pharmaceutical intermediates by hot melt granulation. Nevertheless, the tablets made of hot melt granules retained the ability of the $\mathrm{pH}$ dependent disintegration. In so far the disintegration time at $\mathrm{pH} 3$ exceeded the time that is necessary for the emptying of the stomach. 


\section{SECTION II}

\subsection{Aims}

Controlled release formulations are highly preferred to conventional tablets in the treatment of bowel diseases. Several studies made evidence that the administration of 5aminosalicylic acid is recommended once daily rather than b.i.d. Therefore, incorporation of high drug load is required into a dosage unit. Nevertheless, the high drug load can have a significant impact on the powder blend considering the poor flow properties of the API, and thus, it may influence the compressibility. Consequently, pharmaceutical processing, e.g. granulation is required due to the unfavourable flow properties.

In this section the study of matrix systems containing 5-aminosalicylic acid is described. The formulations contained time-dependent polymethacrylate polymers as matrix formers which were applied themselves and in combination. Other excipients were omitted to gain a clear picture about the effect of different pharmaceutical processing methods on drug release. The effect of processing is not negligible considering the findings of the previous section where the granulation methods induced significant alterations in tablet properties compared to direct compression, moreover made the product unsuitable for the intended purpose.

\subsection{Materials}

5-aminosalicylic acid (5-ASA) (Alfa Aesar) was selected as a model drug that is a locally acting anti-inflammatory agent and it is commonly used in the first-line treatment of mild-to-moderate ulcerative colitis due to its relatively safety profile. The API is slightly soluble in water but soluble in hydrochloric acid. Orally administered 5-ASA absorbs rapidly and almost completely from the small intestine [88,89]. Since the absorption inclines to the development of side-effects, colon delivery is recommended where the 5-ASA acts locally and the probability of systemic events decreases.

Eudragit $^{\circledR}$ RS and Eudragit ${ }^{\circledR}$ RL (Evonik Rhöm GmbH, Darmstadt, Germany) polymethacrylate copolymers were applied as matrix forming polymers that embedded the API. Chemically, Eudragit ${ }^{\circledR}$ RS and Eudragit ${ }^{\circledR}$ RL are copolymers of ethyl acrylate, methyl methacrylate, and a low content of methacrylic acid ester with quaternary ammonium groups. The salts of the ammonium groups make the polymers permeable. These polymers are water 
insoluble; nevertheless, a pH-independent swelling of the matrices may occur. The drug liberation is governed by the permeability of the polymers: Eudragit ${ }^{\circledR}$ RL aids a higher drug release rate compared to Eudtragit ${ }^{\circledR}$ RS since Eudragit ${ }^{\circledR}$ RL has higher permeability than Eudragit $^{\circledR}$ RS. The methacrylate copolymers were used in forms of dry powder and aqueous dispersion.

\subsection{Preparation of matrix tablets}

Matrix tablets were prepared with four different processing methods: direct compression (DC), compression of the wet granulated API with polymer(s) in the external phase (G5ASA), compression of the wet granulated API and polymers in the internal phase (G), and wet granulation of the API with aqueous dispersion(s) of the polymer(s) (GD). Each processing method included five different tablet formulations differing from each other in their permeability (Table 21).

Table 21 Composition of tablets

\begin{tabular}{|ccccc|}
\hline Tablet code & 5ASA (mg) & E RS (mg) & E RL (mg) & Total (mg) \\
\hline DC1 & 200 & 200 & 0 & 400 \\
\hline DC2 & 200 & 180 & 20 & 400 \\
\hline DC3 & 200 & 100 & 100 & 400 \\
\hline DC4 & 200 & 20 & 180 & 400 \\
\hline DC5 & 200 & 0 & 200 & 400 \\
\hline G5ASA1 & 200 & 200 & 0 & 400 \\
\hline G5ASA2 & 200 & 180 & 20 & 400 \\
\hline G5ASA3 & 200 & 100 & 100 & 400 \\
\hline G5ASA4 & 200 & 20 & 180 & 400 \\
\hline G5ASA5 & 200 & 0 & 200 & 400 \\
\hline G1 & 200 & 200 & 0 & 400 \\
\hline G2 & 200 & 180 & 20 & 400 \\
\hline G3 & 200 & 100 & 100 & 400 \\
\hline G4 & 200 & 20 & 180 & 400 \\
\hline G5 & 200 & 0 & 200 & 400 \\
\hline GD1 & 350 & 50 & 0 & 400 \\
\hline GD2 & 350 & 45 & 5 & 400 \\
\hline GD3 & 350 & 25 & 25 & 400 \\
\hline GD4 & 350 & 5 & 45 & 400 \\
\hline GD5 & 350 & 0 & 50 & 400 \\
\hline
\end{tabular}




\subsubsection{Direct compression (DC)}

The blend of API and polymers were prepared in a rotating shaker mixer (Turbula, Willy A. Bachofen AG Maschinenfabrik, Basel, Switzerland) at $50 \mathrm{rpm}$ for $10 \mathrm{~min}$ prior to compression. The tablets were compressed with a hydraulic press (Specac Inc., Graseby, England); samples were pressurized at $10 \mathrm{kN}$ with a dwell time of $10 \mathrm{~s}$, the punch was $13 \mathrm{~mm}$ in diameter and the tablets were flat-shaped. The tablets were $400 \mathrm{mg}$ in weight and contained $200 \mathrm{mg}$ API. In the present study, direct compression intended to serve the basis of comparison for other processing techniques.

\subsubsection{Wet granulation of 5-ASA (G5ASA)}

5-ASA was granulated with purified water in a laboratory scale high-shear mixer (ProCepT nv, Zelzate, Belgium), the process was performed in a stainless steel vessel: preliminary results showed that the work of adhesion was less in a steel vessel than in a glass one. The kneading parameters were as follows:

speed of impeller $.1000 \mathrm{rpm}$

speed of chopper $3000 \mathrm{rpm}$

dosing speed of purified water. $.5 \mathrm{~mL} / \mathrm{min}$

The wet mass was forced through a $1.2 \mathrm{~mm}$ mesh sieve to achieve a homogeneous particle size distribution. Drying was carried out under ambient conditions $\left(25^{\circ} \mathrm{C}, 60 \%\right.$ relative humidity) for $24 \mathrm{hr}$. The polymer(s) was (were) added to the external phase prior to compression and mixed in a rotating shaker mixer as described in 5.3.1.

\subsubsection{Wet granulation of 5-ASA and polymers (G)}

After blending of API and polymers in a rotating shaker mixer (see 5.3.1), the mixture was granulated with purified water in a high-shear mixer using the same settings reported in 5.3.2. The agglomerates were dispersed by means of a $1.2 \mathrm{~mm}$ mesh sieve. Drying was carried out under ambient conditions $\left(25^{\circ} \mathrm{C}, 60 \%\right.$ relative humidity) for $24 \mathrm{hr}$. 


\subsubsection{Wet granulation of 5-ASA with polymer dispersions (GD)}

5-ASA was granulated with the aqueous dispersion(s) of polymer(s) in a high-shear mixer until an appropriate wet mass was achieved. The process parameters were as follows:

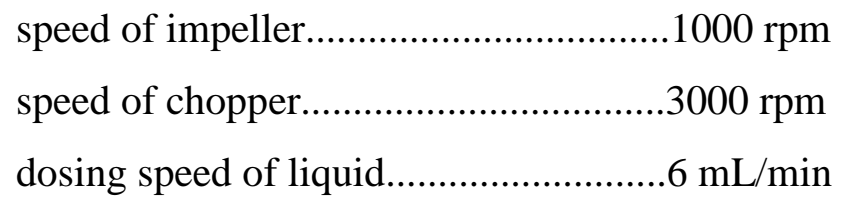

The wet mass was forced through a $1.2 \mathrm{~mm}$ mesh sieve to achieve a definite particle size and drying was performed as above-mentioned.

Following granulation and drying, the intermediates were compressed into tablets by the compression method detailed in 5.3.1. It has to be highlighted that the weight of tablets was constant, therefore the tablet formulations containing aqueous polymer dispersions incorporated higher portion of API compared to the tablets comprising solid polymers.

\subsection{Methods of investigation and results}

\subsubsection{Contact angle measurement}

The determination of contact angles and indirectly of surface free energy permits a deeper insight into how the materials behave during wetting. Evaluation of this property is crucial considering the fact that the extent of wetting of a solid surface influences the dissolution wetting of the system is a prerequisite for dissolution [90].

The wetting properties of the baseline materials and their mixtures were determined by an Optical Contact Angle Measuring System (OCA 20, Dataphysics Instruments GmbH, Filderstadt, Germany). Flat comprimates with smooth surface were prepared by a hydraulic press equipped with a highly polished stainless steel punch and die (Specac Inc., Graseby, England) at a force of $50 \mathrm{kN}$. Contact angles were measured using polar and apolar test liquids, purified water and diiodomethane (Sigma-Aldrich, Steinheim, Germany), respectively. The liquids were dispensed by means of an automatic syringe. Ten parallel measurements were made.

Contact angles of probe liquids were used to assess the polar and disperse components of the surface energy. The $\mathrm{Wu}$ equation [91] was applied to calculate the surface free energy. The spreading coefficient $\left(\mathrm{S}_{12}\right)$ was determined according to the following equation [92]: 


$$
S_{12}=4\left[\frac{\gamma_{1}^{d} \gamma_{2}^{d}}{\gamma_{1}^{d}+\gamma_{2}^{d}}+\frac{\gamma_{1}^{p} \gamma_{2}^{p}}{\gamma_{1}^{p}+\gamma_{2}^{p}}-\frac{\gamma_{1}}{2}\right]
$$

where $\gamma^{d}$ refers to the disperse component of surface free energy and $\gamma^{p}$ to the polar component.

The determination of contact angles revealed that 5-ASA had a polar characteristic, and the presence of highly water-insoluble polymers in the same proportion did not decrease the polarity significantly (Table 22) - as it could be estimated from the equal ratio of API and excipients.

Table 22: Contact angles and surface free energies of raw materials and their mixtures

\begin{tabular}{|c|c|c|c|c|c|c|}
\hline Composition & $\begin{array}{c}\text { Contact } \\
\text { angle } \\
\text { water } \\
\Theta_{\mathrm{w}} \\
\left(^{\circ} \pm \text { S.D. }\right.\end{array}$ & $\begin{array}{c}\text { Contact } \\
\text { angle } \\
\text { diiodo- } \\
\text { methane } \\
\Theta_{\mathrm{d}}\left({ }^{\circ}\right) \pm S . D .\end{array}$ & $\begin{array}{c}\text { Suface } \\
\text { free } \\
\text { energy } \\
\gamma_{s}(\mathbf{m N} / \mathbf{m})\end{array}$ & $\begin{array}{c}\text { Disperse } \\
\text { component } \\
\gamma_{\mathrm{s}}^{\mathrm{d}}(\mathrm{mN} / \mathrm{m})\end{array}$ & $\begin{array}{c}\text { Polar } \\
\text { component } \\
\gamma_{\mathrm{s}}^{\mathrm{p}}(\mathrm{mN} / \mathrm{m})\end{array}$ & $\begin{array}{c}\text { Polarity } \\
\text { P (\%) }\end{array}$ \\
\hline 5-ASA & $32.5 \pm 1.86$ & $20.2 \pm 1.10$ & 73.0 & 43.1 & 29.9 & 41.0 \\
\hline E RL PO & $71.0 \pm 1.37$ & $19.9 \pm 1.40$ & 55.0 & 43.7 & 11.3 & 20.6 \\
\hline E RS PO & $70.2 \pm 1.29$ & $22.8 \pm 0.82$ & 54.6 & 42.8 & 11.8 & 21.6 \\
\hline DC1 & $38.1 \pm 3.68$ & $16.4 \pm 2.74$ & 71.1 & 44.1 & 27.1 & 33.8 \\
\hline DC2 & $39.7 \pm 2.36$ & $14.4 \pm 2.72$ & 70.7 & 44.5 & 26.2 & 37.1 \\
\hline DC3 & $39.9 \pm 3.76$ & $16.7 \pm 2.15$ & 70.3 & 44.0 & 26.3 & 37.4 \\
\hline DC4 & $40.4 \pm 3.79$ & $15.1 \pm 1.68$ & 70.3 & 44.3 & 25.9 & 36.9 \\
\hline DC5 & $41.2 \pm 3.25$ & $14.2 \pm 2.30$ & 70.0 & 44.5 & 25.5 & 36.4 \\
\hline
\end{tabular}

The calculated spreading coefficient indicated that the polymers spread on the surface of 5-ASA (Table 23); nonetheless, the fine polymer particles did not evenly cover the API crystals which exhibited large surface area. Therefore, the fine polymer particles could not significantly reduce the polarity of the API. 
Table 23 Spreading coefficient

\begin{tabular}{|cc|}
\hline Composition & Spreading coefficient $\left(\mathbf{S}_{\mathbf{1 , 2}}\right)$ \\
\hline 5-ASA(1)+E RS PO(2) & -26.25 \\
\hline 5-ASA(1)+E RL PO(2) & -26.40 \\
\hline
\end{tabular}

\subsubsection{Evaluation of water uptake}

The water uptake of matrix tablets was carried out by means of an Enslin apparatus, consisting of a glass filter and a pipette with an accuracy of $0.01 \mathrm{~mL}$. The tablets were measured with analytical accuracy prior to being placed onto the filter. The water uptake was recorded in $\mathrm{mL}$ at pre-defined time points. Three parallel measurements were performed.

The water was absorbed by the wet granulated samples (wet granulation with water) more rapidly than by the samples prepared with aqueous polymer dispersions. The curves of water uptake showed that the wetting rate was steadier in the case of the wet granulated samples (Fig. 10), while the more compact structure of the granules produced with the aqueous dispersions allowed a slower and staggered water uptake due to the prevailing hydrophobic features (Fig. 11). In the case of wet granulated samples that were prepared with aqueous polymer dispersions, the water uptake capacity correlated with the dissolution rate.

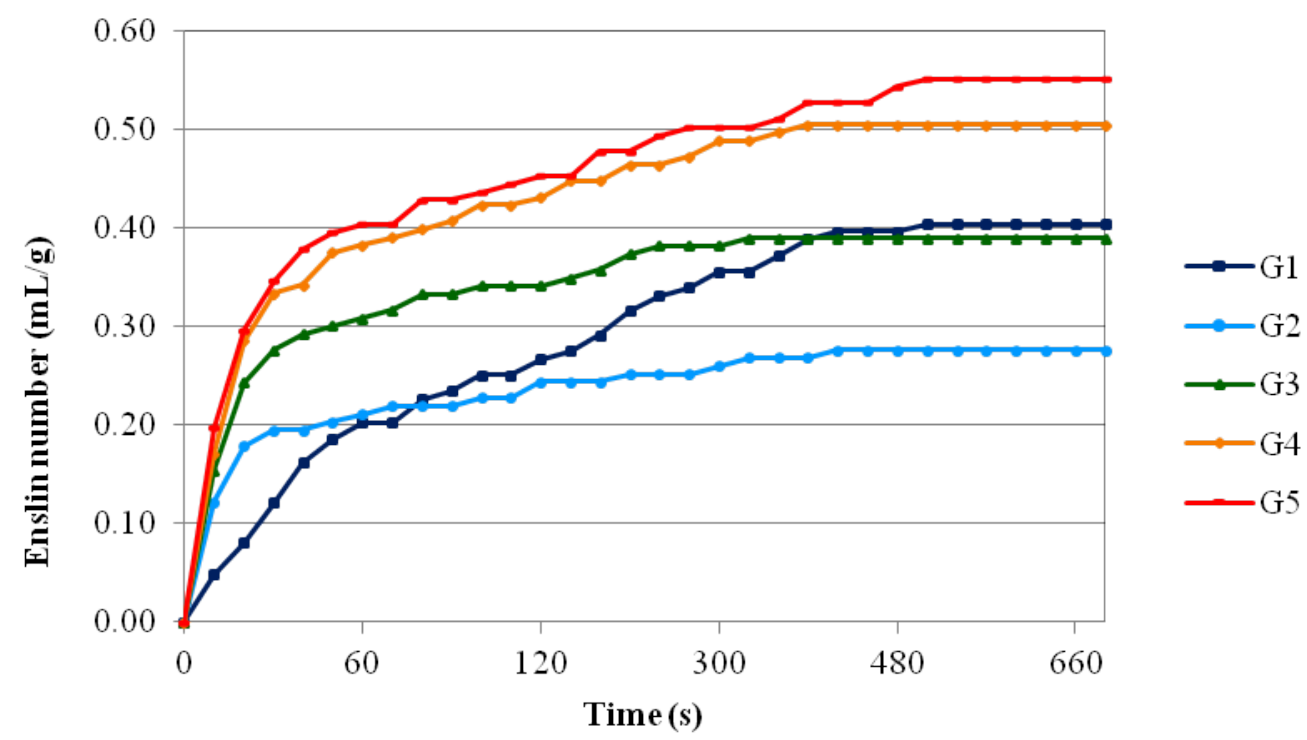

Fig. 10 Water uptake of wet granulated samples prepared with water 


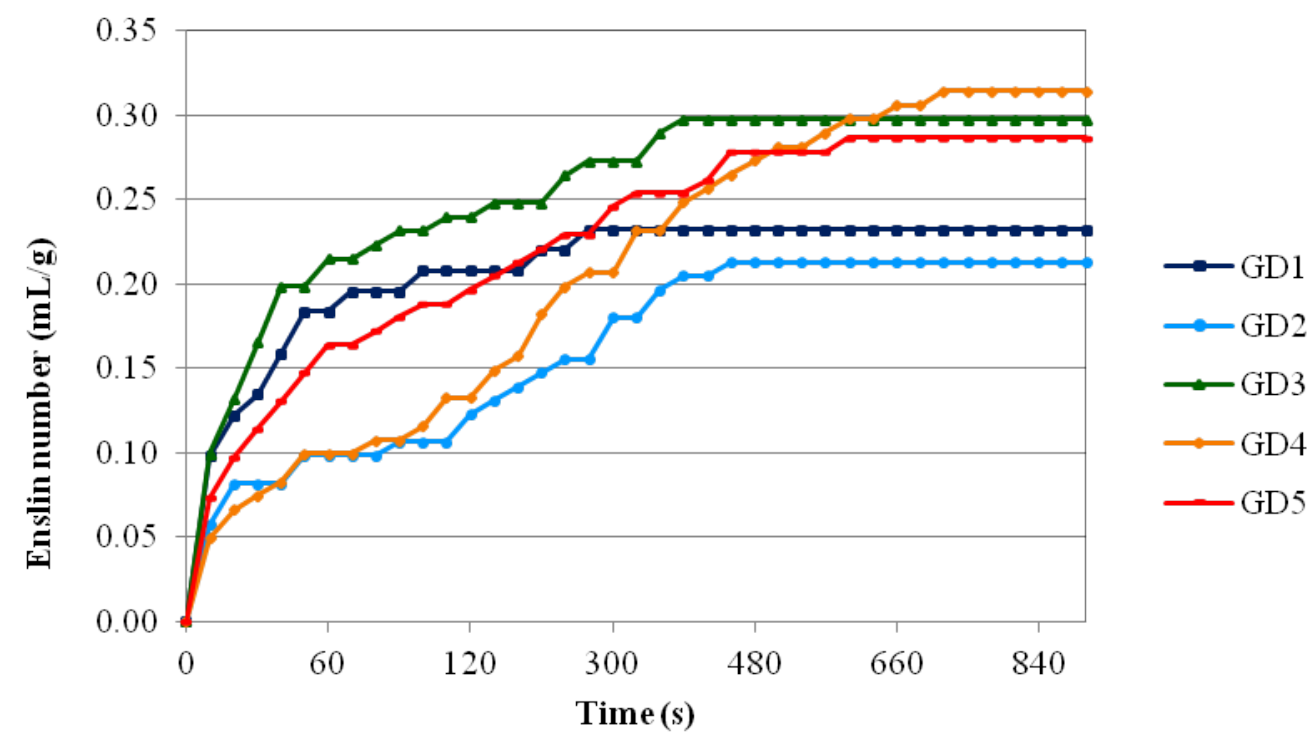

Fig. 11 Water uptake of wet granulated samples prepared with polymer dispersions

\subsubsection{Dissolution study and release modelling}

Investigation of the dissolution of a drug from a delivery system is required by the Pharmacopoeias and represents a critical step considering regulatory approval and proof of effectiveness. Prior to the approval of a generic drug, bioequivalence should be demonstrated that includes the dissolution study. Therefore, innovators strive to obtain patent protection for the dissolution profiles, too [93]. From a pharmacokinetic perspective, the liberation of the API from the delivery system is a rate-determining step in the majority of the cases that eventually influences the entering of the API into plasma or site of action.

Dissolution tests were carried out in an Erweka DT 700 dissolution apparatus (Erweka GmbH, Heusenstamm, Germany), using the paddle method (Dissolution test for solid dosage forms - Apparatus 2 (paddle method), [80]). The dissolution medium was $900 \mathrm{~mL}$ of phosphate buffer solution of $\mathrm{pH} 6.8$ (adjusted according to the $\mathrm{Ph}$. Eur.). The dissolution temperature was maintained at $37 \pm 0.5^{\circ} \mathrm{C}$ and the rotation speed was set at $50 \mathrm{rpm}$. Samples (5 mL) were automatically collected from the dissolution medium at 1, 2, 3, 4, 5, 6, 7, and $8 \mathrm{hr}$. Three replicates were tested for each tablet formulation batch. Absorbance was measured

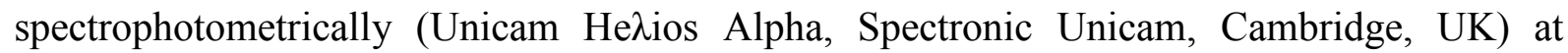
$\lambda_{\max }=331 \mathrm{~nm}$. 
The dissolution data were submitted to statistical analysis. Mathematical models were used to describe the dissolution profiles of 5-ASA from the matrices. Several mathematical equations were applied to find the one best characterizing the drug release.

Following the fitting of the drug dissolution curves with mathematical models, the Korsmeyer-Peppas model was found to be the most characteristic for the curves in the majority of the cases, where not only diffusion, but also erosion was involved in the drug release (Table 24). The Korsmeyer-Peppas model is a semi-empirical model which can be used to analyze data on drug release from polymers [94]. The model implies that the fractional release of drug is exponentially related to the release time, i.e. a power law equation:

$$
\frac{M_{t}}{M_{\infty}}=k t^{n}
$$

where $\mathrm{M}_{t} / \mathrm{M}_{\infty}$ is a fraction of drug released at time $t, k$ is the rate constant and $n$ is the release exponent.

Table 24 Formulations dissolving according to the Korsmeyer-Peppas model

\begin{tabular}{|cccc|}
\hline Sample & $\mathbf{k}$ & $\mathbf{n}$ & $\mathbf{R}^{2}$ \\
\hline DC1 & 10.4439 & 0.568 & 0.9995 \\
\hline DC2 & 11.7439 & 0.641 & 0.9978 \\
\hline DC3 & 18.6222 & 0.723 & 0.9960 \\
\hline G5ASA1 & 10.7166 & 0.520 & 0.9995 \\
\hline G5ASA2 & 11.6521 & 0.512 & 0.9960 \\
\hline G5ASA3 & 13.1529 & 0.780 & 0.9997 \\
\hline G1 & 12.4556 & 0.567 & 0.9990 \\
\hline G2 & 17.5289 & 0.642 & 0.9951 \\
\hline GD1 & 9.9416 & 0.630 & 0.9994 \\
\hline GD2 & 9.6666 & 0.607 & 0.9964 \\
\hline GD3 & 14.3930 & 0.623 & 0.9996 \\
\hline GD4 & 10.8783 & 0.597 & 0.9996 \\
\hline GD5 & 13.2166 & 0.611 & 0.9983 \\
\hline
\end{tabular}


In four cases the Hopfenberg model was the most characteristic for the dissolution profiles (Table 25). The Hopfenberg model was characteristic when heterogeneous erosion occurred on the surface of the tablet [95]. This model can be used to analyze the release of drug from surface-eroding devices. Hopfenberg developed an equation describing the drug release from several geometries (slabs, spheres, and cylinders) displaying heterogeneous erosion:

$$
\frac{M_{t}}{M_{\infty}}=1-(1-k t)^{n}
$$

where $\mathrm{M}_{t} / \mathrm{M}_{\infty}$ is the fraction of drug released at time $t, k$ is the rate constant, and $n$ is the release exponent.

Table 25 Formulations dissolving according to the Hopfenberg model

\begin{tabular}{|c|ccc|}
\hline Sample & $\mathbf{k}$ & $\mathbf{n}$ & $\mathbf{R}^{2}$ \\
\hline DC4 & 0.1207 & 2 & 0.9924 \\
\hline DC5 & 0.1337 & 2 & 0.9936 \\
\hline G5ASA4 & 0.1230 & 2 & 0.9995 \\
\hline G5ASA5 & 0.1268 & 2 & 0.9919 \\
\hline
\end{tabular}

The release exponent ( $n$ ) was $0.45<n<0.89$ (for cylindrical tablets), and the diffusion mechanism was therefore anomalous; the drug transport mechanism was non-Fickian diffusion. This indicated the coupling of the erosion and diffusion mechanisms, enabling drug release controlled by multiple processes.

Matrices that were prepared by direct compression (DC) and had higher permeability exhibited faster dissolution and higher release rate. Contrarily, systems with low permeability proved incomplete, thus, extended drug release during the studied interval (Fig. 12). 


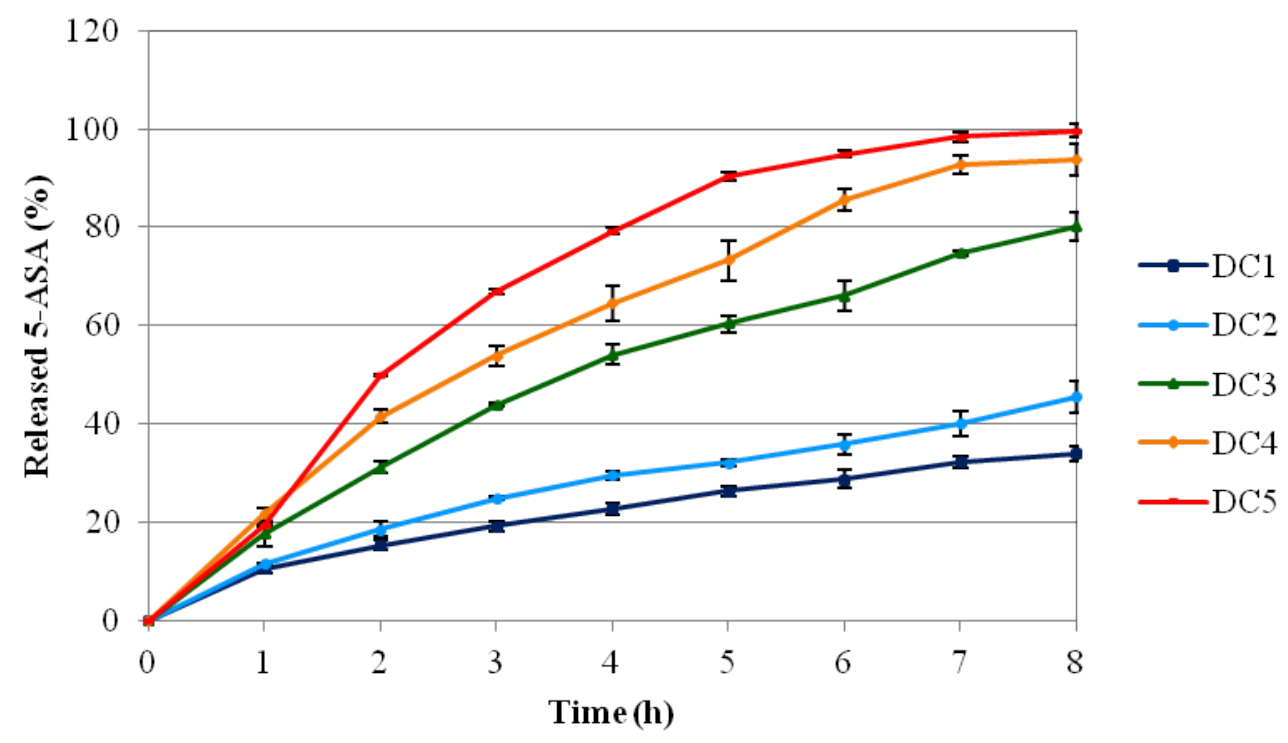

Fig. 12 Dissolution curves of tablets prepared by direct compression (DC)

The granulation of the API itself (G5ASA) did not triggered significant alteration in the release profile (Fig. 13) compared to the samples manufactured by direct compression. Both formulation methods (DC and G5ASA) verified that the release from matrices with low permeability, including the composition that involved both type of polymers in the same proportion, followed the Korsmeyer-Peppas model. Matrix systems with high permeability were characterized by the Hopfenberg model.

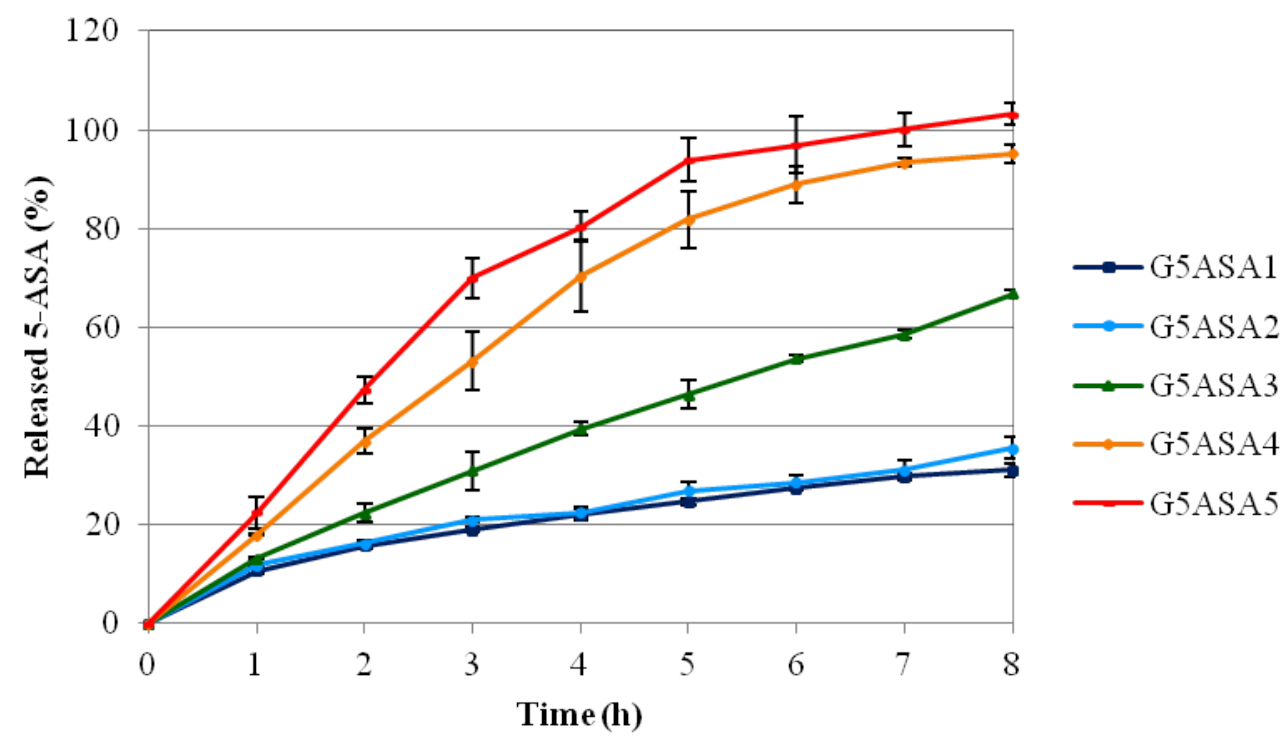

Fig. 13Dissolution curves of tablets containing polymers in the external phase (G5ASA) 
Wet granulation (G) resulted in substantial and unforeseen change. In general, each formulation exhibited accelerated drug liberation; however, the matrices with the lowest permeability (G1 and G2) sustained the release profile described by the Korsmeyer-Peppas model. Concurrently, the application of matrix forming polymers with high permeability provided a sudden, burst-like drug release making the formulations (G3, G4, G5) unsuitable for extended release. Consequently, these systems could not be fitted with any mathematical model (Fig. 14).

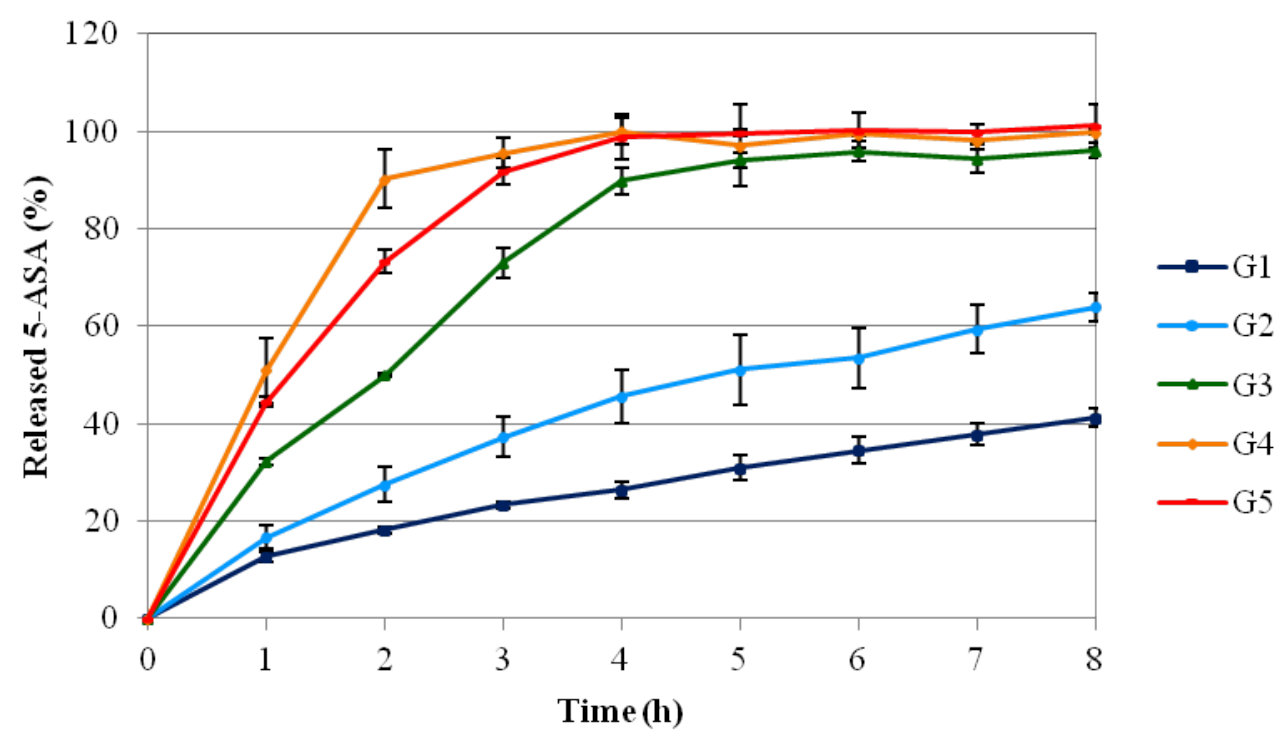

Fig. 14 Dissolution curves of wet granulated samples prepared with water $(G)$

The fourth processing method (GD) operated with aqueous polymer dispersions that acted as matrix former and binder in the agglomerates. Each formulation displayed delay in the drug release rate compared to the samples prepared by direct compression. Approximately $50 \%$ decrease was observed in the final percentage of the dissolved API (Fig. 15). The change in the release profile was also confirmed by the mathematical modelling: each composition followed the release kinetics determined by the Korsmeyer-Peppas model. Application of polymer dispersions in wet granulation provided a viable method that is appropriate for producing prolonged release matrix systems and allowed to incorporate higher drug load (Table 21). On the other hand, the influence of the polymer permeability on release rate ceased following granulation. 


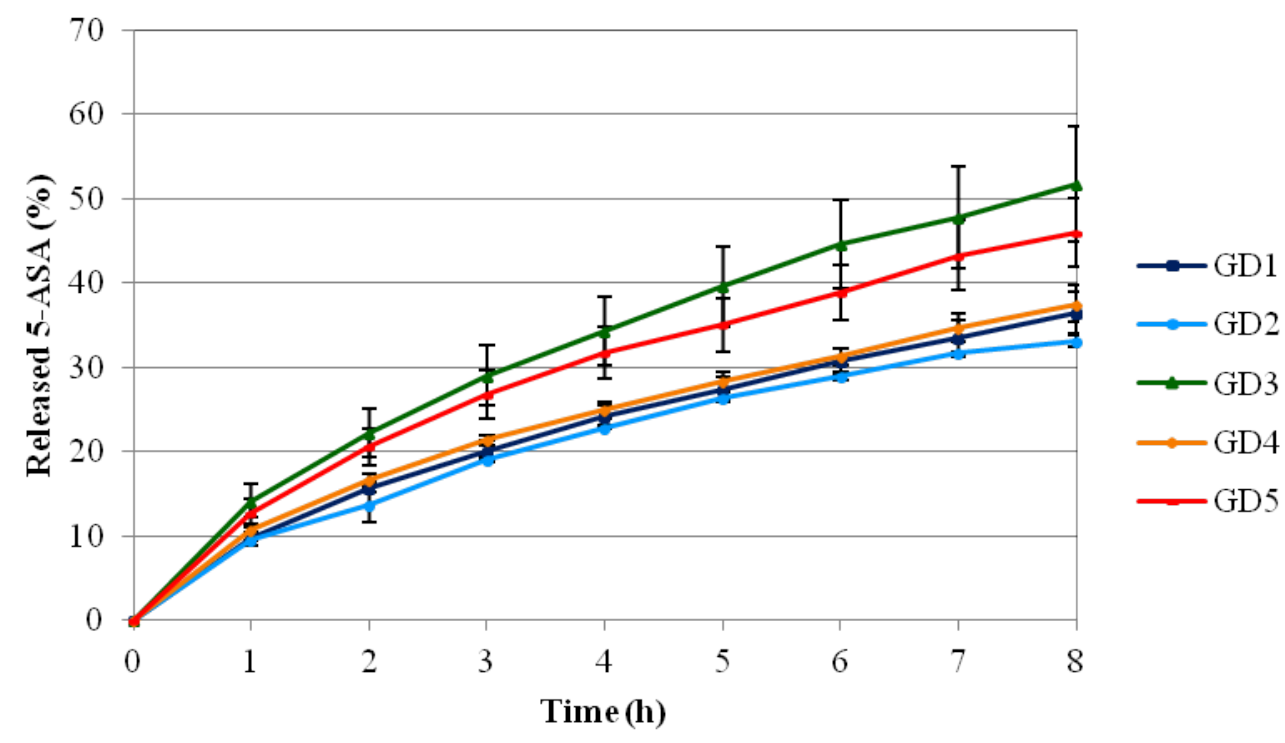

Fig. 15 Dissolution curves of wet granulated samples prepared with polymer dispersions (GD)

\subsubsection{Morphological analysis}

Microscopic structure of the granules was analyzed with the aid of a scanning electron microscope (SEM) (Hitachi 4700, Hitachi Ltd., Tokyo, Japan). A sputter coating apparatus (Polaron E5100, Polaron Equipment Ltd., Greenhill, UK) was used to induce electric conductivity on the surface of the samples. The air pressure was $1.3-13 \mathrm{mPa}$.

The SEM pictures revealed that the baseline orthorhombic crystals of 5-ASA partially remained intact, but rounded particles also developed during the wet granulation with water (Fig. 16). The polymers formed an amorphous network. On wet granulation with the polymer dispersions, it was observed that the 5-ASA reverted into sharp, needle-like crystals as a result of rapid recrystallization (Fig. 17). Uncovered crystal particles spread over the granules due to the fact that a small amount of polymer was present in the form of a thin film layer. However, there were 5-ASA crystals which were not covered by the polymer because of the relatively large amount of the API. The polymer particles of the dispersion with high specific surface area were homogeneously distributed in the bulk and this contributed to film formation. It is presumed that the aqueous dispersion formed a film in the granules, providing them with a compact inner texture and a consequently prolonged drug release. The coalescence of latex particles occurred and a relatively continuous film layer could form. This film was able to 
retain the 5-ASA and prolong the dissolution. In contrast, the process described above could not occur, or only partially in the solid polymers where there were insufficient time and moisture for the complete solvation of the polymeric chains, and the linkages could not form to retain the 5-ASA molecules and protect them, despite the higher amount of polymers. This draws attention to the fact that an appropriate ratio of the polymers in the matrix is a crucial point during formulation.
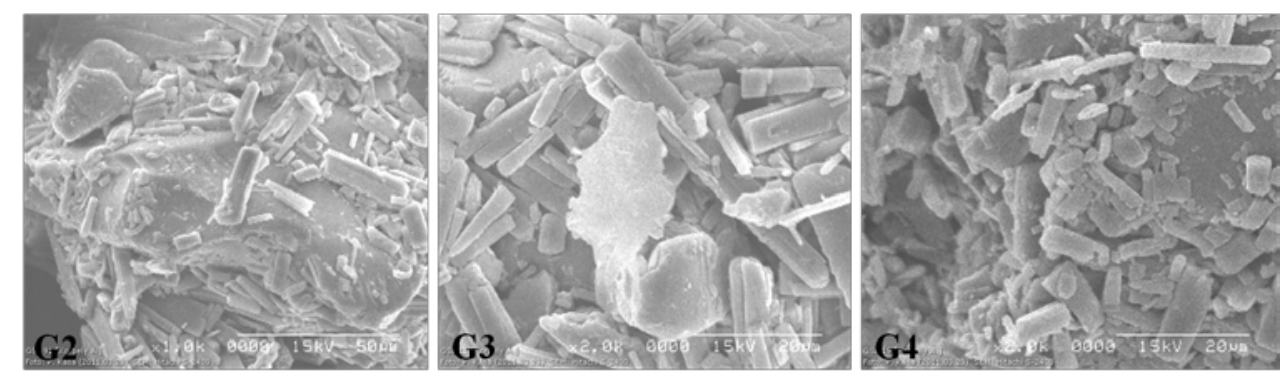

Fig. 16 Morphology of granules prepared by wet granulation with water
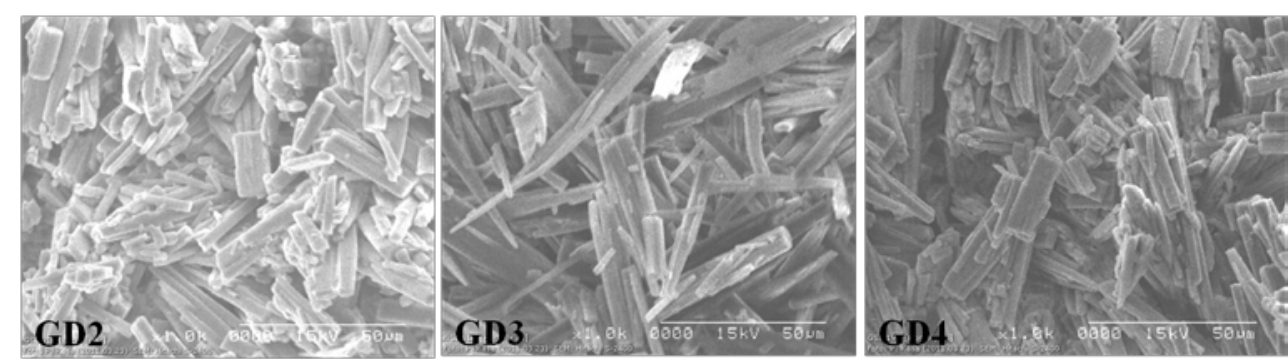

Fig. 17 Morphology of granules prepared by wet granulation with polymer dispersions

\subsection{Conclusion}

This section intended to describe the release kinetics from matrices based on timedependent polymethacrylate copolymers following different processing methods. It needs to be emphasized that the polymer itself does not guarantee a tailored drug release, the possible processing methods should also be considered during the design of a specific formulation. This study focused on how the different granulation methods affect the dissolution and its kinetics from inert matrix systems. The applied polymers are designed to ensure timecontrolled release, however the present study revealed that not only the material properties of the excipients can provide a tailored drug release, but a pharmaceutical processing method can also contribute to the final released drug rate. Consequently a wet granulation technique which involve only the granulation of the active compound - e.g. to improve its physical 
properties - and application of matrix forming polymers as an external phase during tableting may result in highly similar profile than that, that the directly compressed tablets provide. Nonetheless, a wet granulation affecting both the active ingredient and polymer excipients may increase the dissolution rate and accelerate the dissolution process. Contrary to this effect, utilization of the matrix formers in aqueous dispersions, simultaneously functioning as binders of granules, can lead to prolonged release; therefore, if a more retarded drug release is required, this kind of process can promote a long-lasting drug dissolution effect. Remarkably, the matrix systems with low permeability released the API according to the KorsmeyerPeppas model, i.e. diffusion was the determinant mechanism during dissolution. The Hopfenberg model was applicable to the highly water-permeable matrices due to the more pronounced surface erosion. 


\section{FINAL CONCLUSIONS, NOVELTY, PRACTICAL USEFULNESS}

The applicability of polymethacrylate-based copolymers was investigated in orally administered, solid matrix systems in order to deliver locally acting drugs into the gastrointestinal system. Antacid matrix tablets were manufactured with an acid-soluble, $\mathrm{pH}$ dependent matrix forming polymer that has mainly been used and investigated as film coating. The second system intended to serve the basis of time-controlled colon delivery. The main purpose of the study was to determine the dissolution/disintegration behaviour of matrix systems based on polymethacrylate copolymers, commonly called Eudragit ${ }^{\circledR}$ polymers. Furthermore, granulation methods and their effects were investigated as possible processing techniques aiming the improvement of processability of baseline powder blends.

Summarizing the novelty and usefulness can be stated:

- A stimulus-controlled matrix type tablet was formulated with an antacid effect. It may provide the benefit over the commercial formulations that the disintegration, and thus the liberation of active ingredients only occurs in the case of a low $\mathrm{pH}$ of the stomach. Elevation of the $\mathrm{pH}$ gradually decelerates the disintegration, therefore minimizing the possible side effects due to unnecessary drug release.

- Application of $\mathrm{pH}$-independent swellable polymers in temporal control of drug release was studied in the second section. The results are useful in the design and formulation of time-dependent colon delivery systems that require high drug loading and processing of the baseline materials due to poor compressibility.

Both studies dealt with different granulation techniques that are commonly used in the pharmaceutical industry, albeit they have a significant effect on the properties of the product, these consequences have been less scrutinized. The present study had the goal to provide scientists with fundamental information about the possible behavioural alterations of polymethacrylate polymers during processing. 


\section{REFERENCES}

[1] Kanjickal D.G., Lopina S.T., Critical Reviews in Therapeutic Drug Carrier Systems, 21(5):345-386, 2004

[2] Siepmann J., Siegel R.A., Rathbone M.J.: Fundamentals and Applications of Controlled Release Drug Delivery, Advances in Delivery Science and Technology. Overview of Controlled Release Mechanisms, Springer, 2012

[3] Perioli L., D’Alba G., Pagano C., European Journal of Pharmaceutics and Biopharmaceutics, 80(3):621-629, 2012

[4] Wagstaff A.J.,Goa K.L., Drugs 61-15(8):2221-2228, 2001

[5] Wen H., Park K.: Oral Controlled Release Formulation Design and Drug Delivery: Theory to Practice, John Wiley \& Sons, Inc., 2010

[6] Brannon-Peppas L., Biomaterials, 11:1-14, 1997

[7] Gad S.C.: Pharmaceutical Manufacturing Handbook: Production and Processes, John Wiley \& Sons, Inc., 2008

[8] Richter A., Anton S.E., Koch P., Dennett S.L., Clinical Therapeutics, 25(8):2307-2335, 2003

[9] Gutowska A., Bark J.S., Kwon I.C., Bae Y.H., Kim S.W., Journal of Controlled Release, 48(2):141-148, 1997

[10] Sangalli M.E, Maroni A., Zema L., Busetti C., Giordano F., Gazzaniga A., Journal of Controlled Release, 73(1):103-110, 2001

[11] Roy D., Cambre J.N., Sumerlin B.S., Progress in Polymer Science, 35(1-2):278-301, 2010

[12] Jenquin M.R., McGinity J.W., International Journal of Pharmaceutics, 101(1-2): 23-34, 1994

[13] Swarbrick J.: Encyclopedia of Pharmaceutical Technology, $3^{\text {rd }}$ Edition, Informa Healthcare. 2006

[14] Aulton M.E.: Aulton's Pharmaceutics. The Design and Manufacture of Medicines, Churchill livingstone, Elsevier, Edinburgh, 2007

[15] Abdul S., Chandewar A.V., Jaiswal S.B., Journal of Controlled Release, 147(1):2-16, 2010 
[16] Singh M.N., Hemant K.S.Y., Ram M., Shivakumar H.G., Research in Pharmaceutical Sciences, 5(2):65-77, 2010

[17] Crank J.: The Mathematics of Diffusion, Clarendon Press, Oxford, 1975

[18] Peppas N.A., Mathematical modelling of diffusion processes in drug delivery polymeric systems in: Smolen V.F., Ball L. (Eds.): Controlled Drug Bioavailability, Vol. 1, John Wiley \& Sons, New York, pp. 203-237, 1984

[19] Remington: The Science and Practice of Pharmacy, Lippincott Williams \& Wilkins, Baltimore, p 947, 2006

[20] Srivastava R., Kumar D., Pathak K., International Journal of Pharmaceutics, 427(2):153-162, 2012

[21] Sackett C.K., Narasimhan B., International Journal of Pharmaceutics, 418(1):104-114, 2011

[22] Thombre A.G., Himmelstein K.J., Biomaterials, 5(5):250-254, 1984

[23] Göpferich, A., Biomaterials, 17(2):103-114, 1996

[24] Asghar L.F.A., Chure C. B, Chandran S., AAPS PharmSciTech, 10(2):418-429, 2009

[25] Colombo P., Bettini R., Santi P., Peppas N.A., Pharmaceutical Science and Technology Today, 3:198-204, 2000

[26] Shen I.S., Jasti B.R., Li X.: Design of Controlled-Release Drug Delivery Systems in: Standard Handbook of Biomedical Engineering and Design, McGraw Hill, New York, 2003

[27] Narasimhan B., Langer R., Journal of Controlled Release, 47:13-20, 1997

[28] Barakat N.S., Elbagory I.M., Almurshed A.S., AAPS PharmSciTech, 9(4):1054-1062, 2008

[29] Dredán J., Zelkó R., Antal I., Bihari E., Rácz I., International Journal of Pharmaceutics, 160:257-260, 1998

[30] Chien Y.W., Lin S., Clinical Pharmacokinetics, 41(15):1267-1299, 2002

[31] Conte U., Maggi L., Colombo P., La Manna A., Journal of Controlled Release, 26(1):39-47, 1993

[32] Xu J., Bovet L.L., Zhao K., International Journal of Pharmaceutics, 359:63-69, 2008

[33] Akhgari A., Sadeghi F., Garekani H.A., International Journal of Pharmaceutics, 320(1-2):137-142, 2006 
[34] Ceballos A., Cirri M., Maestrelli F., Corti G., Mura P., Il Farmaco, 60(11-12):913-918, 2005

[35] Siepmann F., Le Brun V., Siepmann J., Journal of Controlled Release, 115(3):298-306, 2006

[36] Glaessl B., Siepmann F., Tucker I., Siepmann J., Rades T., European Journal of Pharmaceutics and Biopharmaceutics, 73(3):366-372, 2009

[37] McGinity J.W., Cameron G.C., Cuff G.W., Drug Development and Industrial Pharmacy, 9:57-68, 1983

[38] Takka S., Rajbhandari S., Sakr A., European Journal of Pharmaceutics and Biopharmaceutics, 52(1):75-82, 2001

[39] http://eudragit.evonik.com/product/eudragit/en/products-services/eudragitproducts/pages/default.aspx

Accessed: 3 March 2013

[40] Breitkreutz J., Bornhöft M., Wöll F., Kleinebudde P., European Journal of Pharmaceutics and Biopharmaceutics, 56(2):247-253, 2003

[41] Cerea M., Zheng W., Young C.R., McGinity J.W., International Journal of Pharmaceutics, 279(1-2):127-139, 2004

[42] Wilson C.G., Crowley P.J. (eds.): Controlled Release in Oral Drug Delivery, Advances in Delivery Science and Technology, Springer US, 2011

[43] Duarte A.N.C., Roy C., Gonzalez A.V., Duarte C.M.M., Paternault P.S., International Journal of Pharmaceutics, 332(1-2):132-139, 2007

[44] US Patent, Registration Number: 2797160, Registration Date: December 23, 2003, Owner: Rohm GmbH \& Co.

[45] Varshosaz J., Faghihian H., Rastgoo K., Drug Delivery, 13:295-302, 2006

[46] Hickey A.J., Ganderton D.: Pharmaceutical Process Engineering, Marcel Dekker, Inc., New York, 2001

[47] Palmieri G.F., Lovato D., Martelli S., Drug Development and Industrial Pharmacy, 25(5):671-677, 1999

[48] Kleinebudde, P., European Journal of Pharmaceutics and Biopharmaceutics, 58(2):317326, 2004 
[49] Gibson, M.: Pharmaceutical Preformulation and Formulation, $2^{\text {nd }}$ Edition, Informa Healthcare, 2009

[50] Parikh D.M.: Handbook of Pharmaceutical Granulation Technology, Marcel Dekker, Inc., New York, 2009

[51] Ghebre-Selassie, I.: Pharmaceutical Pelletization Technology, Marcel Dekker Inc., New York, 1989

[52] Lister J.D., Ennis B.J., Iveson S.M., Hapgood K., Powder Technology, 117:3-39, 2001

[53] Faure A., York P., Rowe R.C., European Journal of Pharmaceutics and Biopharmaceutics, 52(3):269-277, 2001

[54] Zhai H., Li S., Jones D.S., Walker G.M., Andrews G.P., Chemical Engineering Journal, 164(2-3):275-284, 2010

[55] Ochoa L., Igartua M., Hernández R.M., Gascón A.R., Solinis M.A., Pedraz J.L., European Journal of Pharmaceutics and Biopharmaceutics, 77(2):306-312, 2011

[56] Perissutti B., Rubessa F., Moneghini M., Voinovich D., International Journal of Pharmaceutics, 256(1-2): 53-63, 2003

[57] Cheng H.J., Hsiau S.S., Powder Technology, 199(3): 272-283, 2010

[58] Brabander C. D., Vervaet C., Remon J.P., Journal of Controlled Release, 89(2):235247, 2003

[59] Schubert M.L., Current Opininion in Gastroenterology, 23(6):595-601, 2007

[60] Majumdar D., Bebb J., Atherton J., Medicine, 39(3):154-161, 2011

[61] Weeks D.L., Eskandari S., Scott D.R., Sachs G., Science, 287:482-485, 2000

[62] El-Omar E.M., Gut, 55:144-146, 2006

[63] Soll A., The American Journal of Medicine, 105(5):10S-16S, 1998

[64] Wallace J.L., Best Practice \& Research Clinical Gastroenterology, 14(1):147-159, 2000

[65] Sweetman S.C.: Martindale, The Complete Drug Reference, $33^{\text {rd }}$ Edition, Pharmaceutical Press, London, 2002

[66] Woodson G.C., Bone, 22(6):695-698, 1998

[67] Pleuvry B. J., Anaesthesia \& Intensive Care Medicine, 7(2):65-69, 2006

[68] Vanpee D., Delgrange E., Gillet J.B., Donckier J., The Journal of Emergency Medicine, 19(2):169-171, 2000

[69] Friend D.R., Advanced Drug Delivery Reviews, 7(1):149-199, 1991 
[70] Stenson W.F., Hanauer S.B., Cohen R.D.: Inflammatory Bowel Disease, in: Yamada T.: Textbook of Gastroenterology, Blackwell Publishing Ltd., Oxford, UK, 2009

[71] http://www.merckmanuals.com/professional/gastrointestinal_disorders/inflammatory _bowel_disease_ibd/overview_of_inflammatory_bowel_disease.html\#v894373 Accesssed: 3 March 2013

[72] Dignass A.U. et al., Clinical Gastroenterology and Hepatology, 7(7):762-769, 2009

[73] Kamm M.A. et al, Gastroenterology, 132(1):66-75, 2007

[74] RoweR.C., Sheskey P.J.,Weller P.I.: Handbook of Pharmaceutical Excipients, $4^{\text {th }}$ Edition,Pharmaceutical Press, London, 2003

[75] Rao V.M:, Engh K., Qiu Y., International Journal of Pharmaceutics, 252:81-86, 2003

[76] Yang M., Cui F., You B., You J., Wang L., Zhang L., Kawashima Y., Journal of Controlled Release, 98:219-229, 2004

[77] Johansen A., Schæfer T., Kristensen H.G, International Journal of Pharmaceutics, 183(2):155-164, 1999

[78] Carr R.L., Chemical Engineering, 72:69-72, 1965

[79] Wu J.S., Ho H.O., Sheu M.T., European Journal of Pharmaceutical Sciences 12(4):417-425, 2001.

[80] European Pharmacopoeia, $4^{\text {th }}$ Edition, Council of Europe, Strasbourg Cedex, France, 2001

[81] Sun C., Grant D.J.W., Pharmaceutical Development and Technology, 6(2):193-200, 2001

[82] Garr J.S.M., Rubinstein M.H., International Journal of Pharmaceutics, 72:117-122, 1991

[83] Leuenberger H., Puchkov M., Krausbauer E., Betz G., Powder Technology, 189(2):141-148, 2009

[84] Cavinato M., Bresciani M., Machin M., Bellazzi G., Canu P., Santomaso A.C., International Journal of Pharmaceutics, 387:48-55, 2010

[85] http://eudragit.evonik.com/product/eudragit/en/products-services/eudragitproducts/protective-formulations/e-po/pages/default.aspx

Accessed: 3 March 2013

[86] Andrew E.R., Bradbury A., Eades R.G., Nature 182:1659, 1958 
[87] Lowe I. J., Physical Review Letters, 2:285, 1959

[88] Peppercorn MA, Goldman P., Gastroenterology , 64:240-245, 1973

[89] Nielsen OH, Bondesen S., British Journal of Clinical Pharmacology, 16:738-740, 1983

[90] Parfitt G.D.: Dispersion of powders in liquids, Wiley, New York, 1973

[91] Wu S., Journal of Polymer Science, 34:19-30, 1971

[92] Rowe R.C., International Journal of Pharmaceutics, 52:149-154, 1989

[93] Berry I.R., Martin R.P.: The Pharmaceutical Regulatory Process, $2^{\text {nd }}$ Edition, Informa Healthcare, 2008

[94] Peppas N.A., Pharmaceutica Acta Helvetiae, 60:110-111, 1985

[95] Hopfenberg H.B.: Controlled release polymeric formulations, in: Paul D.R., Haris F.W.: ACS Symposium Series, Vol. 33, American Chemical Society, Washington, DC, 1976 


\section{ACKNOWLEDGEMENTS}

Foremost I offer my sincerest gratitude to my supervisor Prof. Dr. Klára Pintye-Hódi who has supported me throughout my thesis with her patience and knowledge whilst allowing me the room to work in my own way. I attribute the standards of my Ph.D. thesis to her encouragement and effort and without her profound contribution this thesis would not have been completed or written.

I give my sincere thanks to Dr. János Bajdik, my first supervisor who supported and encouraged me to undertake scientific research in Pharmaceutical Technology and gave me the chance to develop and gain practical and theoretical experience. His stamina and profound knowledge inspired me throughout my Ph.D. studies.

I would like to take the opportunity to express my gratitude to Prof. Dr. Piroska SzabóRévész who granted me the opportunity to continue my research work in the Department of Pharmaceutical Technology. I would like to thank her for always providing me with invaluable advice and placing her deepest confidence in me.

My special thanks goes to Dr. Péter Kása Jr. who has not only captured several microscope images but provided me with continuous support and constructive suggestions during the experimental work.

I would like to express my great appreciation to Dr. Attila Domján for the extensive study in polymer interaction by solid-state NMR spectroscopy, and to my co-author, Dr. András Kelemen who performed the mathematical modelling of dissolution kinetics study.

I am obliged to the former and present colleagues at Department of Pharmaceutical Technology who provided me with ideas, recommendations or technical support. I am grateful for their cooperation during the $\mathrm{PhD}$ programme.

Finally I wish to thank my parents and friends for their support, patience and encouragement throughout my studies. 


\section{APPENDIX}

\section{PUBLICATIONS RELATED TO THE THESIS}


I 


\title{
Formulation of intelligent tablets with an antacid effect
}

\author{
János Bajdik, Anita Korbely and Klára Pintye-Hódi \\ Department of Pharmaceutical Technology, University of Szeged, Hungary
}

\begin{abstract}
Matrix systems with a local antacid effect were produced in this study. Aluminium hydroxide and magnesium trisilicate in constant concentrations were used as active agents. Eudragit ${ }^{\circledR} \mathrm{E}$ PO was applied as a matrix former and sodium bicarbonate as a disintegrant (third antacid component), in different ratios. Their effects on the properties of the tablets were studied. Such formulated systems must be insoluble if the $\mathrm{pH}$ of the stomach is less acidic, but a rapid disintegration must occur if necessary. It can be concluded that Eudragit ${ }^{\circledR} \mathrm{E} P \mathrm{P}$ in appropriate composition can ensure tablets with $\mathrm{pH}$-dependent disintegration. Its binding effect allows tablet making from the elastic active component. The liberation of antacid materials from this system is controlled. If the $\mathrm{pH}$ reached 2.5 , the erosion of the tablet was reduced. In contrast with expectations, the application of poorly compressible and effervescent sodium bicarbonate increased the time for disintegration of the tablets, because of its extended alkalizing effect around the tablet. This system with this acrylic component is appropriate to produce a controlled-release local antacid preparation.
\end{abstract}

Keywords: Antacid; direct compression; disintegration; Eudragit ${ }^{\circledR}$ EPO; polymer matrix

\section{Introduction}

The basis of most methods of treating peptic ulcers is the control of the gastric acidity. Gastric antacids act locally to reduce the acidity of the stomach contents. Antacids are generally inorganic bases. These components (mainly magnesium and aluminium salts) can bind different components e.g. phosphates, different active agents (tetracyclines, digoxin and sulfonamides). If the antacid is used in excess other potential side-effects may be severe, e.g. milk-alkali syndrome, renal calculi, bone problems, intestinal effects, neurotoxicity, etc. ${ }^{[1-5]}$

Elevation of the $\mathrm{pH}$ from 1.0-3.5 eliminates 99\% of the hydrogen ion in the stomach, and very little proteolytic activity will remain after this level is achieved. It is known that higher values can be reached with antacids. $^{[6]}$ At $\mathrm{pH}>4.5$, the pepsin activity is markedly decreased and it is completely inactivated at $\mathrm{pH}>6 \cdot^{[7]}$ Since the low $\mathrm{pH}$ of the stomach normally kills ingested microorganism, antacids increase the vulnerability to infection. ${ }^{[8]}$ Because of this situation, the application of antacid components with controlled release is a reasonable demand. Different routes to this goal are attempted, e.g. the formulation of hydrotalcite, which is aluminium magnesium carbonate hydroxide hydrate with a special structure, which can be applied in conventional tablets or in suspension. Hydrotalcite-like compounds are layered solids consisting of positively charged layers and interlayer charge-compensating anions. ${ }^{\left[{ }^{[9]}\right.}$ The hydrogen binding of this material is controlled by the special structure, but it also binds the phosphate ion and thus the undesired effects of excess hydrotalcite must be considered. The intercalation of different active agents is also well known. ${ }^{[10,11]}$

The aim of this study was the formulation of matrix systems with a local antacid effect. These monolytic systems must be intact if the $\mathrm{pH}$ of the stomach is less acidic, but a rapid disintegration must occur if necessary. The excess of the active agent is eliminated without release from the matrix. Accordingly, the potential unwanted effect of the unliberated components need not be taken into account.

Direct compressible matrices were applied in this part of our study. The main active components with well known effects were aluminium hydroxide $(\mathrm{AH})$ and magnesium trisilicate (MT). ${ }^{[12]}$ The matrix former 
was an acrylic component soluble in acidic media. It is generally used as a gastrosoluble, taste-masking polymer in organic solution, or as a drug release modulator in matrix systems, bioadhesive films, interpolyelectrolyte complexes and microcapsules, ${ }^{[13-16]}$ but this polymer has not been used alone in matrix systems previously. The amounts of the main two active agents were constant, and the proportions of effervescent sodium bicarbonate (SB) and the matrix former were varied. The objective of the application of SB was a reduction of the time of disintegration of the matrix in acidic media; and it is also a known antacid agent. The properties of the powder mixtures and the mechanical properties and disintegration of the matrix formed were evaluated.

\section{Materials and methods}

\section{Materials}

The antacid components (Ph. Eur.) were aluminium hydroxide (AH), magnesium trisilicate (MT) and sodium bicarbonate (SB) and they obtained from Hungaropharma Plc. (Budapest, Hungary). The matrixforming agent (Eudragit ${ }^{\circledR}$ E PO [EE]) was a gift from Degussa Pharma Polymers (Darmstadt, Germany). The samples containing mixtures of these components are detailed in Table 1. The S0 sample contained only the main antacid components in a ratio of 1:1. This sample was used to evaluate the effect of the matrix former.

\section{Preparation of tablets}

Different samples were compressed into tablets with a Korsch EK0 eccentric tablet machine (Emil Korsch Maschinenfabrik, Berlin, Germany). The punches were convex, $13 \mathrm{~mm}$ in diameter. The tablets weighed $420 \pm 5 \mathrm{mg}$. The compression forces applied were $5 \pm 2$, $15 \pm 2$ and $25 \pm 2 \mathrm{kN}$.

\section{Evaluation of powder mixtures}

A Powder Testing System PTG-1 (Pharma Test Apparatebau GmbH, Hainburg, Germany) was applied to determine the flow time of $100 \mathrm{~mL}$ of sample. A teflon

Table 1. Compositions of tablets.

\begin{tabular}{lcccc}
\hline Sample & AH $(\mathrm{mg})$ & MT $(\mathrm{mg})$ & SB $(\mathrm{mg})$ & EE (mg) \\
\hline S0 & 210 & 210 & - & - \\
S1 & 135 & 135 & - & 150 \\
S2 & 135 & 135 & 25 & 125 \\
S3 & 135 & 135 & 37.5 & 112.5 \\
S4 & 135 & 135 & 50 & 100 \\
S5 & 135 & 135 & 75 & 75 \\
S6 & 135 & 135 & 100 & 50 \\
\hline
\end{tabular}

tunnel was used with an orifice $10 \mathrm{~mm}$ in diameter. A stirrer was operated at $25 \mathrm{rpm}$. Three parallel experiments were performed.

A STAV 2003 Stampfvolumeter (Engelsmann A.G., Ludwigshafen, Germany) was utilized for the determination of densities (tapped $\left(\rho_{\infty}\right)$ and loose $\left(\rho_{0}\right)$ ). Carr's index was calculated from these results. ${ }^{[17]}$ Three parallel tests were carried out.

Carr's index $=\frac{\rho_{\infty}-\rho_{0}}{\rho_{\infty}} \times 100$

An Enslin apparatus with a glass filter with $5 \mathrm{~cm}$ in diameter and a pipette with $0.01 \mathrm{~mL}$ accuracy were used for evaluation of the water uptake of the mixtures. $0.25 \mathrm{~g}$ of each powder was tested; five parallel experiments were performed.

The $\mathrm{pH}$-changing potencies of the powder mixtures were tested in $100 \mathrm{~mL}$ of fluid used for the testing of tablets disintegration. The liquid with $\mathrm{pH} 1.2 \pm 0.1$ was prepared from hydrochloric acid, while the phosphate buffers with $\mathrm{pH} 2.0 \pm 0.1,2.5 \pm 0.1$ and $3.0 \pm 0.1$ were produced according to $\mathrm{Ph}$. Eur. The powder mixtures with the mass of a tablet $(420 \mathrm{mg})$ were placed into the test buffer and stirred for $20 \mathrm{~min}$ at $100 \mathrm{rpm}$. The $\mathrm{pH}$ of the test liquid was checked with a $\mathrm{pH}$ tester (WinLab pH-Meter, Windaus-Labortechnik GmbH \& Co. KG, Clausthal-Zellerfeld, Germany). Three parallel tests were carried out.

\section{Evaluation of tablets}

The times required for tablet disintegration were measured with an Erweka ZT 71 (Erweka GmbH) apparatus. Twelve tablets were evaluated at each $\mathrm{pH}$. The active agent can alter the $\mathrm{pH}$ of the medium so the test liquids $(700 \mathrm{~mL})$ were changed every $20 \mathrm{~min}$ to ensure constant $\mathrm{pH}$ (the deviation of the $\mathrm{pH}$ was less than 0.3 ). The friability tests were performed in an Erweka friabilator (Erweka $\mathrm{GmbH}$ ) according to Ph. Eur. Thickness was measured with a screw micrometer with an accuracy of $0.001 \mathrm{~mm}$ (Mitutoyo Co., Kawasaki, Japan).

\section{Results and discussion}

It can be seen from the results of the flowability studies that these properties of the mixtures were not the most appropriate for direct compression (Table 2). ${ }^{[18]}$ The flowability of the powder mixture was reduced when the micronized matrix former was applied. The flow times of the powder were better for the samples containing larger amounts of SB. This component slightly increases the bulk density of the mixture. The water uptake also increased with increasing proportion of 
Table 2. Properties of powder mixtures.

\begin{tabular}{lccccc}
\hline Sample & Flow time $(\mathrm{s})$ & Loose density $\left(\mathrm{g} / \mathrm{cm}^{3}\right)$ & Tapped density $\left(\mathrm{g} / \mathrm{cm}^{3}\right)$ & Carr's index $(\%)$ & Enslin number $(\mathrm{ml} / \mathrm{g})$ \\
\hline S0 & $74.9 \pm 11.9$ & $0.325 \pm 0.005$ & $0.414 \pm 0.006$ & $21.6 \pm 1.4$ & $2.31 \pm 0.10$ \\
S1 & $165.1 \pm 16.6$ & $0.277 \pm 0.009$ & $0.409 \pm 0.001$ & $32.3 \pm 2.0$ & $0.25 \pm 0.04$ \\
S2 & $162.9 \pm 17.0$ & $0.290 \pm 0.013$ & $0.426 \pm 0.003$ & $31.9 \pm 2.9$ & $0.37 \pm 0.05$ \\
S3 & $157.2 \pm 10.2$ & $0.303 \pm 0.004$ & $0.442 \pm 0.003$ & $31.5 \pm 0.9$ & $0.38 \pm 0.04$ \\
S4 & $157.8 \pm 8.9$ & $0.313 \pm 0.005$ & $0.450 \pm 0.003$ & $30.4 \pm 0.8$ & $0.41 \pm 0.04$ \\
S5 & $148.1 \pm 14.7$ & $0.328 \pm 0.012$ & $0.468 \pm 0.004$ & $29.9 \pm 2.4$ & $0.56 \pm 0.06$ \\
S6 & $121.3 \pm 13.0$ & $0.350 \pm 0.012$ & $0.490 \pm 0.002$ & $28.5 \pm 2.4$ & $0.65 \pm 0.09$ \\
\hline
\end{tabular}

this component. This change was considerable since a more than 2-fold increase in the amount of water was detected for $\mathrm{S} 6$ relative to S1. The presence of the matrix former polymer very markedly reduced this parameter of the samples.

The pH-changing potency of the components depends on the properties of buffers. The effect of mixtures of main antacid components was very relevant at every pHs (Table 3 ). This property was slightly higher for the powders containing higher amounts of SB. This increasing tendency could be observed mainly at higher $\mathrm{pH}$. It can be concluded from these results that as compared with SB, the antacid effect of the polymer is not significant since the lowest value was detected for S1, which contained the highest amount of polymer.

It was found during the compression that the compositions S0 and S6 were not suitable for tablet making because of capping. The thickness of the tablet formed decreased with increasing amount of SB (Table 4). This parameter can be important during the erosion of the sample. The differences may be explained by the different bulk densities. The friability of the tablets increased with increase of the SB content (Table 5). This phenomenon can be explained by the poorer compactibility of the SB and by the very good binding property of the polymer. The insufficient mechanical property of SB was supported by the capping of the tablets prepared from powder mixtures containing high proportions of the effervescent component. The decreasing effect of high compression force was also observed.

The disintegration at $\mathrm{pH} 1.2$ was rapid (Table 6). There was no effect of the compression force on the disintegration of the sample without SB. The disintegration time increased very slightly with increasing amount of SB. An exception was S5 compressed at $5 \mathrm{kN}$. In this case, the mechanical property of the tablet was the poorest so the effect of the effervescent component could be detected. The wetting of the powder was also best for this composition.

The tendencies in the disintegration at $\mathrm{pH} 2$ were similar to those at $\mathrm{pH} 1.2$ and this parameter was more independent of the composition and compression force (Table 6). Change of the $\mathrm{pH}$ of the medium did not cause an appreciable change in the disintegration of the tablet.
Table 3. $\mathrm{pH}$ of different test liquids after mixing with powder mixtures.

\begin{tabular}{lcccc}
\hline Sample & $\begin{array}{c}\text { Test liquid } \\
\text { with pH 1.2 }\end{array}$ & $\begin{array}{c}\text { Test liquid with } \\
\text { pH 2.0 }\end{array}$ & $\begin{array}{c}\text { Test liquid } \\
\text { with pH 2.5 }\end{array}$ & $\begin{array}{c}\text { Test liquid } \\
\text { with pH 3.0 }\end{array}$ \\
\hline S0 & $1.54 \pm 0.03$ & $2.37 \pm 0.02$ & $5.87 \pm 0.08$ & $6.16 \pm 0.05$ \\
S1 & $1.52 \pm 0.02$ & $2.15 \pm 0.02$ & $5.66 \pm 0.12$ & $5.70 \pm 0.03$ \\
S2 & $1.45 \pm 0.02$ & $2.27 \pm 0.03$ & $5.94 \pm 0.03$ & $6.17 \pm 0.07$ \\
S3 & $1.47 \pm 0.01$ & $2.30 \pm 0.01$ & $5.99 \pm 0.15$ & $6.30 \pm 0.04$ \\
S4 & $1.46 \pm 0.02$ & $2.31 \pm 0.01$ & $6.23 \pm 0.06$ & $6.33 \pm 0.04$ \\
S5 & $1.51 \pm 0.02$ & $2.32 \pm 0.01$ & $6.24 \pm 0.05$ & $6.48 \pm 0.02$ \\
S6 & $1.51 \pm 0.02$ & $2.36 \pm 0.03$ & $6.34 \pm 0.06$ & $6.59 \pm 0.05$ \\
\hline
\end{tabular}

Table 4. Thickness of tablets (in mm).

\begin{tabular}{llll}
\hline Sample & $5 \mathrm{kN}(\mathrm{n}=10)$ & $15 \mathrm{kN}(\mathrm{n}=10)$ & $25 \mathrm{kN}(\mathrm{n}=10)$ \\
\hline S1 & $3.812 \pm 0.037$ & $3.440 \pm 0.038$ & $3.335 \pm 0.028$ \\
S2 & $3.764 \pm 0.016$ & $3.446 \pm 0.028$ & $3.080 \pm 0.027$ \\
S3 & $3.532 \pm 0.020$ & $3.335 \pm 0.021$ & $2.918 \pm 0.032$ \\
S4 & $3.565 \pm 0.021$ & $3.361 \pm 0.017$ & $2.960 \pm 0.025$ \\
S5 & $3.451 \pm 0.029$ & $3.252 \pm 0.008$ & $2.881 \pm 0.024$ \\
\hline
\end{tabular}

Table 5. Friability of tablets (in \%).

\begin{tabular}{llll}
\hline Sample & $5 \mathrm{kN}$ & $15 \mathrm{kN}$ & $25 \mathrm{kN}$ \\
\hline S1 & 0.032 & 0.002 & 0.024 \\
S2 & 0.132 & 0.024 & 0.009 \\
S3 & 0.204 & 0.147 & 0.107 \\
S4 & 0.293 & 0.205 & 0.128 \\
S5 & 0.336 & 0.235 & 0.093 \\
\hline
\end{tabular}

The disintegration time at $\mathrm{pH} 2.5$ was significantly longer (Table 7). The decreasing effect of higher compression force on the disintegration time was clear. The application of SB as an alkalizing agent increased the time. It exhibited a very good correlation with the $\mathrm{pH}-$ changing potency of the powders. Only two exceptions can be detected; the values of S5 for lower compression forces exhibited a decrease relative to $\mathrm{S} 4$.

The disintegration time at $\mathrm{pH} 3$ was the longest (Table 7). It was more than $4 \mathrm{~h}$ for S5 compressed at $25 \mathrm{kN}$. The tendencies of the alterations were very similar to those detected at $\mathrm{pH} 2.5$, but in this case the only exception was the S5 sample compressed at $5 \mathrm{kN}$.

The S5 sample, compressed at low force, was an exception at different pHs. For evaluation of this 
Table 6. Disintegration time at different $\mathrm{pHs}$ (in min).

\begin{tabular}{|c|c|c|c|c|c|c|}
\hline \multirow[b]{2}{*}{ Sample } & \multicolumn{3}{|c|}{ pH 1.2} & \multicolumn{3}{|c|}{ pH 2.0} \\
\hline & $5 \mathrm{kN}$ & $15 \mathrm{kN}$ & $25 \mathrm{kN}$ & $5 \mathrm{kN}$ & $15 \mathrm{kN}$ & $25 \mathrm{kN}$ \\
\hline S1 & $11.01 \pm 1.30$ & $11.63 \pm 2.15$ & $11.51 \pm 1.32$ & $13.08 \pm 1.46$ & $13.91 \pm 1.04$ & $14.50 \pm 0.88$ \\
\hline S2 & $12.89 \pm 0.92$ & $13.56 \pm 1.27$ & $14.43 \pm 1.67$ & $14.63 \pm 1.36$ & $14.80 \pm 1.41$ & $16.03 \pm 2.48$ \\
\hline S3 & $11.34 \pm 1.02$ & $12.66 \pm 0.78$ & $16.15 \pm 2.57$ & $14.34 \pm 1.17$ & $15.68 \pm 0.77$ & $16.08 \pm 1.90$ \\
\hline S4 & $12.22 \pm 1.06$ & $12.56 \pm 0.66$ & $16.95 \pm 2.09$ & $16.75 \pm 1.25$ & $16.88 \pm 1.76$ & $16.88 \pm 2.41$ \\
\hline S5 & $9.87 \pm 0.38$ & $11.22 \pm 1.25$ & $16.97 \pm 1.82$ & $15.64 \pm 1.01$ & $16.35 \pm 0.92$ & $16.81 \pm 2.44$ \\
\hline
\end{tabular}

Table 7. Disintegration time at different $\mathrm{pHs}$ (in min).

\begin{tabular}{|c|c|c|c|c|c|c|}
\hline \multirow[b]{2}{*}{ Sample } & \multicolumn{3}{|c|}{$\mathrm{pH} 2.5$} & \multicolumn{3}{|c|}{ pH 3.0} \\
\hline & $5 \mathrm{kN}$ & $15 \mathrm{kN}$ & $25 \mathrm{kN}$ & $5 \mathrm{kN}$ & $15 \mathrm{kN}$ & $25 \mathrm{kN}$ \\
\hline S1 & $66.40 \pm 6.53$ & $65.20 \pm 11.28$ & $71.43 \pm 9.06$ & $110.70 \pm 5.14$ & $112.27 \pm 13.68$ & $127.31 \pm 7.27$ \\
\hline S2 & $103.19 \pm 4.26$ & $114.86 \pm 8.24$ & $113.50 \pm 8.25$ & $127.73 \pm 12.27$ & $143.93 \pm 17.39$ & $165.41 \pm 18.86$ \\
\hline S3 & $104.16 \pm 4.95$ & $121.57 \pm 3.35$ & $127.10 \pm 14.51$ & $147.15 \pm 10.91$ & $160.49 \pm 13.05$ & $165.41 \pm 15.87$ \\
\hline S4 & $115.92 \pm 7.17$ & $145.52 \pm 8.64$ & $148.46 \pm 10.69$ & $184.36 \pm 8.59$ & $183.43 \pm 4.51$ & $188.56 \pm 16.78$ \\
\hline S5 & $89.92 \pm 5.29$ & $128.05 \pm 5.12$ & $164.51 \pm 17.82$ & $151.82 \pm 6.46$ & $218.65 \pm 10.37$ & $242.41 \pm 22.78$ \\
\hline
\end{tabular}

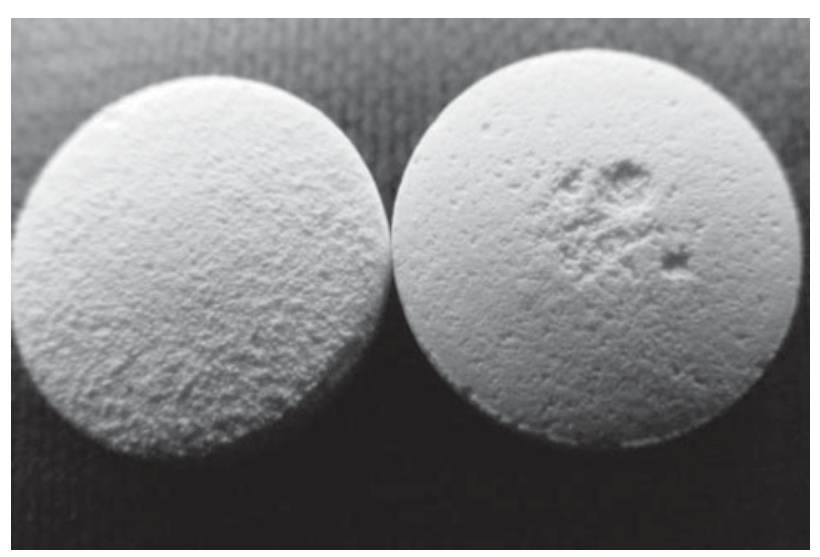

Figure 1. Surface of the matrix after 20-min disintegration (left: S4, right: S5).

product, independent tests were performed with $\mathrm{S} 4$ and S5 tablets prepared at $5 \mathrm{kN}$. The tablets were removed from the test liquid (pH 3) after $20 \mathrm{~min}$. The more uneven eroded surface for S5 can be seen in Figure 1. A large amount of SB caused weak points in the tablets, where the disintegration can be quicker. This may be explained by the higher friability and the better wettability. The S5 tablets were the thinnest samples, so this phenomenon can combine with the weaker texture and cause quicker disintegration.

The disintegrated proportion of the tablet mass after 20 min was higher for S5 $(13.68 \pm 0.82 \%$ for S4 and $15.69 \pm 0.42 \%$ for S5). These values predict a shorter disintegration time (146 min for S4 and $127 \mathrm{~min}$ for S5) than that measured. It may be stated that the process was initially quicker, and later became slower. The explanation may be the removal of the less strongly bound particles and also the formation of a thin alkaline fluid layer about the core, which restricts the solubility of the polymer matrix in the later period.

\section{Conclusion}

It can be concluded that in a solid polymer matrix of Eudragit ${ }^{\circledR}$ E PO can ensure tablets with $\mathrm{pH}$-dependent disintegration. The flowability of powder mixtures is reduced with this polymer, but the binding effect of this component is suitable for the formation of tablets from an antacid component with a high tendency to capping. The liberation of antacid materials from this system can be controlled. If the $\mathrm{pH}$ of the stomach is $>2$, the disintegration of the tablet is appropriately decreased. The possibility of a harmful change in the $\mathrm{pH}$ of the gastric juice or the binding of other physiologically relevant materials induced by the antacid preparation can be eliminated with this type of preparation.

Application of SB as an additional component increased the disintegration time of the tablets (except at low $\mathrm{pH}$ and low compression force), because of its extended alkalizing effect around the tablet. Thus, its effervescent effect can not reduce the erosion time in this composition.

Finally, it may be concluded that this system with the applied acrylic component is suitable for the production of intelligent controlled-release local antacid preparations.

\section{Acknowledgements}

This work was supported by Hungarian Scientific Research Fund (OTKA) grant F-049310.

Declaration of interest: The authors report no conflicts of interest. The authors alone are responsible for the content and writing of the paper. 


\section{References}

1. Woodson GC. An interesting case of osteomalacia due to antacid use associated with stainable bone aluminum in a patient with normal renal function. Bone (1998); 22:695-698.

2. Parfitt K. Martindale. 32nd ed. London: Pharmaceutical Press (1999).

3. Vanpee D, Delgrange E, Gillet JB, Donckier J. Ingestion of antacid tablets (Rennie ${ }^{\circledR}$ ) and acute confusion. J Emerg Med (2000); 19:169-171.

4. Córdoba-Díaz D, Córdoba-Díaz M, Awad S, Córdoba-Borrego M. Effect of pharmacotechnical design on the in vitro interaction of ketoconazole tablets with non-systemic antacids. Int J Pharm (2001); 226:61-68.

5. Pleuvry BJ. Pharmacological remedies for gastric disorders. Anaesth Intens Care 7:65-69.

6. Hardman JG, Limbird LE. Goodman \& Gilman's: The pharmaceutical basis of therapeutics. 10th ed. New York: The McGrawHill Companies Inc (2001).

7. Kalant H, Roschlau WHE, Sellers EM. Principles of medical pharmacology. 4th ed. Toronto: Oxford University Press (1985).

8. Hauben M, Horn S, Reich L, Younus M. Association between gastric acid suppressants and Clostridium difficile colitis and community-acquired pneumonia: analysis using pharmacovigilance tools. Int J Infect Dis (2007); 11:417-422.

9. Ambrogi V, Perioli L, Marmottini F, Rossi C.Use of calcined Mg-Al-hydrotalcite to enhance the stability of celecoxib in the amorphous form. Eur J Pharm Biopharm (2007); 66:253-259.
10. Nakayama $\mathrm{H}$, Wada $\mathrm{N}$, Tsuhako $\mathrm{M}$. Intercalation of amino acids and peptides into $\mathrm{Mg}$-Al layered double hydroxide by reconstruction method. Int J Pharm (2004); 269:469-478.

11. Ambrogi V., Fardella G., Grandolini G., Perioli L. Intercalation compounds of hydrotalcite-like anionic clays with antiinflammatory agents - I. Intercalation and in vitro release of ibuprofen. Int J Pharm (2001); 220:23-32.

12. van Riet-Nales DA, van Aalst P, de Kaste D, Barends DM. An improved in vitro method for the evaluation of antacids with in vivo relevance. Eur J Pharm Biopharm (2002); 53:217-225.

13. Repka MA, McGinity JW. Bioadhesive properties of hydroxypropylcellulose topical films produced by hot-melt extrusion. J Control Release (2001); 70:341-351.

14. Rao VM, Engh K, Qiu Y. Design of pH-independent controlled release matrix tablets for acidic drugs. Int J Pharm (2003); 252:81-86.

15. Yang M, Cui F, You B, You J, Wang L, Zhang L, Kawashima Y. A novel $\mathrm{pH}$-dependent gradient-release delivery system for nitrendipine: I.Manufacturing, evaluation in vitro and bioavailability in healthy dogs. J Control Release (2004); 98:219-229.

16. Moustafine RI, Kemenova VA, van den Mooter G. Characteristics of interpolyelectrolyte complexes of Eudragit E 100 with sodium alginate. Int J Pharm (2005); 294:113-120.

17. Carr RL. Classifying flow properties of solids. Chem Eng (1965); 72:69-72.

18. Wells JI. Pharmaceutical preformulation the physicochemical properties of drug substances. Chichester: Ellis Horwood Ltd (1988). 
II 


\title{
Evaluation of phenomena occurring during the preparation of matrix granules by the hot melt technique
}

\author{
János Bajdik • Anita Korbely • Klára Pintye-Hódi
}

Received: 24 August 2009/Accepted: 3 November 2010/Published online: 12 December 2010

(C) Akadémiai Kiadó, Budapest, Hungary 2010

\begin{abstract}
The aim of this study was to evaluate the applicability of hot melt granulation for the formulation of a $\mathrm{pH}$-sensitive intelligent tablet containing heat- and moisture-sensitive components. An appropriate combination of magnesium trisilicate, aluminium hydroxide, sodium bicarbonate, and basic butylated methacrylate copolymer (Eudragit E PO) exhibited a good disintegration profile, but poor processibility. Hot melt granulation was applied with the aid of polyethylene glycol 2000 to increase the tablettability. The effects of the composition and the process on the properties of the granules and tablets formed were assessed with thermoanalytical and conventional testing methods. The heating of mixtures containing basic butylated methacrylate copolymer (Eudragit E PO) below its glass transition caused a relevant change in the wettability of the granules. This was induced by an alteration in the microstructure of the agglomerates. Tablets prepared from the granules containing an appropriate ratio of polymers exhibited an appropriate mechanical and disintegration profile. The thermal behaviour of the mixture of polymers cannot be predicted from the properties of the starting materials. Their interaction, demonstrated by DSC, can cause significant structure-forming problems in the matrices. The parameters of the granules and tablets varied with the quantity of the polymer applied. With an appropriate combination of polymers, hot melt granulation can be a suitable method for the preparation of intermediates for the formulation of controlled-release antacid tablets. Thermal analysis can promote an understanding of the process and determination of its operational parameters.
\end{abstract}

J. Bajdik · A. Korbely · K. Pintye-Hódi $(\bowtie)$

Department of Pharmaceutical Technology, University of

Szeged, Eötvös u. 6, Szeged H-6720, Hungary

e-mail: klara.hodi@pharm.u-szeged.hu
Keywords Differential scanning calorimetry . Disintegration - Hot melt granulation - Interaction . Matrix tablets

\section{Introduction}

The acidity of the gastric juice becomes excessive in various gastrointestinal diseases. In these cases, administered gastric antacids act locally to reduce the acidity of the stomach contents. Their components (mainly magnesium and aluminium salts) can bind different components, e.g. phosphates or active agents such as tetracyclines, digoxin and sulphonamides. If the antacid is used in excess, its potential side-effects may be severe, e.g. milk-alkali syndrome, renal calculi, bone problems, intestinal effects, neurotoxicity [1-5].

Elevation of the pH from 1.0 to 3.5 eliminates $99 \%$ of the hydrogen ions in the stomach, and very little proteolytic activity will persist after this level is achieved. It is known that higher values can be reached with antacids [6]. At $\mathrm{pH}>4.5$, the pepsin activity is markedly decreased, and it is completely inactivated at $\mathrm{pH}>6$ [7]. Since the low $\mathrm{pH}$ of the stomach normally kills ingested microorganisms, antacids increase the vulnerability to infection [8]. In view of this situation, the application of antacid components with controlled release is a reasonable demand.

The aim of our current project was the formulation of matrix systems with a local antacid effect. These monolytic systems must be intact if the contents of the stomach are less acidic, but rapid disintegration must occur if necessary. The excess of the active agent is eliminated without release from the matrix of the dosage form. Accordingly, the potential unwanted effects of the unliberated components need not be taken into account. It is known that there is periodic 
interdigestive activity in the gastrointestinal tract, which is important for the regular mechanical and enzymatic cleansing of the gastrointestinal lumen and may serve to remove indigestible and/or foreign material, and to prevent bacterial overgrowth or the pathological activation of enzymes [9]. The interdigestive migrating motor complex is a cyclical contraction sequence with an average duration of approximately $7 \mathrm{~min}$ that sweeps through the stomach and small intestine about every 90 min during fasting in healthy people [10]. If the tablets remain intact until this time, the possibility of unwanted effects can be decreased.

The optimum composition of the main active components (aluminium hydroxide and magnesium trisilicate), the acrylic matrix former basic butylated methacrylate copolymer (Eudragit E PO) and effervescent sodium bicarbonate was determined earlier. The best tablets exhibited disintegration time $>4 \mathrm{~h}$ in the stomach at $\mathrm{pH} 3$, but of $<15 \mathrm{~min}$ at $\mathrm{pH} 1.2$ [11]. Preparation of this intelligent tablet by means of direct compression was difficult, since the processibility (flowability and compressibility) of the powder was insufficient. In this case, therefore, intermediates must be prepared [12]. This was also a very difficult step, since the applied components are not appropriate for wet granulation. Sodium bicarbonate is sensitive to water [13], whilst the other components are only insoluble in water and the water uptake of the micronized matrix former is very poor. It is not possible to achieve even wettability of the powder mixture without decomposition of the ingredients. An alternative granulation method is the hot melt technique [14, 15]. In this case, heat-sensitive materials cannot be used, a problem that can arise for sodium bicarbonate, but only at higher temperature [13]. Accordingly, the use of a binder with a low melting point, and hence a low temperature of granulation, can solve this problem. The glass transition temperature of the matrix former is known to be nearly $55^{\circ} \mathrm{C}$ [16]. Polyethylene glycol 2000 exhibits a similar melting point [13], and can therefore be a potential binder. Its effects on the properties of the granules and tablets formed were evaluated with conventional testing methods used in pharmaceutical technology (flowability, compressibility, wettability, particle size analysis, friability and disintegration of tablets) and differential scanning calorimetry (DSC). The aims of these tests were to promote an understanding of the granulation process and to assess its applicability for these components.

\section{Materials and methods}

\section{Materials}

The antacid components (Ph. Eur.) were aluminium hydroxide $(\mathrm{AH})$, magnesium trisilicate (MT) and sodium bicarbonate (SB), all obtained from Hungaropharma Plc. (Budapest, Hungary). The matrix-forming agent [basic butylated methacrylate copolymer, Eudragit ${ }^{\circledR}$ E PO (EE)] was a gift from Degussa Pharma Polymers (Darmstadt, Germany). Polyethylene glycol 2000 (PEG 2000) (Fluka Chemie GmbH, Buchs, Switzerland) was applied as a binder during the melt granulation.

Hot melt granulation

To obtain a homogeneous mixture, the powder was blended at $50 \mathrm{rpm}$ for $10 \mathrm{~min}$ with a Turbula mixer (W.A. Bachofen, Basel, Switzerland). Granules were prepared from these blends in a high-shear granulator (ProCepT 4M8 granulator, ProCepT nv, Zelzate, Belgium). The temperature applied during the process was determined by the results of the thermoanalytical measurements. A jacketed glass vessel was used and a thermostat (Julabo F12, Julabo Labortechnik GmbH, Seelbach) was applied to ensure the permanent temperature. A pre-warming was applied to attain the equilibrium temperature of the powder. This was $5-7{ }^{\circ} \mathrm{C}$ lower than the set value. The operational parameters were as follows:

Impeller speed: $1000 \mathrm{rpm}$

Chopper speed: $4000 \mathrm{rpm}$

Process time at the equilibrium temperature: $10 \mathrm{~min}$

Mass of powder mixture: $150 \mathrm{~g}$

Applied temperature: $70{ }^{\circ} \mathrm{C}$

Granules were dried on trays under ambient conditions $\left(25 \pm 2^{\circ} \mathrm{C}\right)$ for $24 \mathrm{~h}$.

\section{Preparation of tablets}

The compositions of the granules are detailed in Table 1. Granules were compressed into tablets with a Korsch EK0 eccentric tablet machine (Emil Korsch Maschinenfabrik, Berlin, Germany). The punches were convex and measured $13 \mathrm{~mm}$ in diameter. The compression force applied was $15 \pm 2 \mathrm{kN}$. The number of tablets manufactured was $500 \pm 20$ pieces.

Evaluation of powder mixtures

A Powder Testing System PTG-1 (Pharma Test Apparatebau $\mathrm{GmbH}$, Hainburg, Germany) was applied to determine the flow time of $100 \mathrm{~mL}$ of sample. A Teflon tunnel was used with an orifice $10 \mathrm{~mm}$ in diameter. A stirrer was operated at $25 \mathrm{rpm}$, if necessary. Three parallel experiments were performed.

A STAV 2003 Stampfvolumeter (Engelsmann A.G., Ludwigshafen, Germany) was utilized for the determination of densities [tapped $\left(\rho_{\infty}\right)$ and loose $\left(\rho_{0}\right)$ ] and consequently the compressibility. Carr's index was calculated from these results [17]. Three parallel tests were carried out. 
Table 1 Compositions of samples

\begin{tabular}{lrrrrrr}
\hline & S0 $/ \mathrm{mg}$ & $\mathrm{S} 1 / \mathrm{mg}$ & $\mathrm{S} 2 / \mathrm{mg}$ & $\mathrm{S} 3 / \mathrm{mg}$ & $\mathrm{S} 4 / \mathrm{mg}$ & $\mathrm{S} 5 / \mathrm{mg}$ \\
\hline AH & 135 & 135 & 135 & 135 & 135 & 135 \\
MT & 135 & 135 & 135 & 135 & 135 & 135 \\
SB & 50 & 50 & 50 & 50 & 50 & 50 \\
EE & 100 & 100 & 100 & 100 & 100 & - \\
PEG 2000 & - & - & 50 & 100 & 150 & 100 \\
Total & 420 & 420 & 470 & 520 & 570 & 420 \\
\hline
\end{tabular}

${ }^{a}$ Prepared by direct compression

Carr's index $=\frac{\rho_{\infty}-\rho_{0}}{\rho_{\infty}} \times 100$.

The sizes of the granules were assessed after drying. An analytical sieve (Retsch GmbH, Haan, Germany) was used for these experiments. The D50 values of the samples were determined with sieving system software (Retsch EasySieve 2.0).

An Enslin apparatus with a glass filter $5 \mathrm{~cm}$ in diameter and a pipette with $0.01 \mathrm{~mL}$ accuracy were used in the evaluation of the water uptake of the mixtures. $0.25 \mathrm{~g}$ of each powder was tested; three parallel experiments were performed. Heat treatment of the starting component was also performed in a moisture analyser (HR73 Halogen Moisture Analyser, Mettler-Toledo $\mathrm{GmbH}$, Greifensee, Switzerland). The temperature and time applied were the same as during granulation $\left(70{ }^{\circ} \mathrm{C}\right.$ for $\left.10 \mathrm{~min}\right)$. The water uptake of these powders was also determined.

\section{Evaluation of tablets}

The times required for tablet disintegration were measured with an Erweka ZT 71 (Erweka $\mathrm{GmbH}$ ) apparatus; 12 tablets were evaluated at each $\mathrm{pH}$. The active agent can alter the $\mathrm{pH}$ of the medium. The $\mathrm{pH}$ of the test liquid was checked with a pH-tester (WinLab pH-Meter, WindausLabortechnik GmbH \& Co. KG, Clausthal-Zellerfeld, Germany). The test liquids ( $700 \mathrm{~mL}$ ) were changed every 20 min to ensure constant $\mathrm{pH}$ (the deviation of the $\mathrm{pH}$ was $<0.3$ ). The test was carried out in four solutions with different $\mathrm{pH}$. The $\mathrm{pH}$ was adjusted with phosphate buffer according to $\mathrm{Ph}$. Eur.

The directly compressed tablets disintegrated in the liquid $\mathrm{pH} 3.0$ in more than $4 \mathrm{~h}$. Accordingly, the study stopped at this $\mathrm{pH}$.

The compositions of the disintegration media are the following:

\section{Solution of $\mathrm{pH} 1.2$}

hydrochloric acid

sodium hydroxide

water
Phosphate buffer solution of $\mathrm{pH} 2.0$

disodium hydrogen phosphate

potassium dihydrogen phosphate

water

phosphoric acid

Buffer solution of $\mathrm{pH} 2.5 \mathrm{R} 1$

dilute phosphoric acid

dilute sodium hydroxide solution

water

Phosphate buffer solution of pH 3.0 R1

$$
\begin{aligned}
& \text { potassium dihydrogen phosphate } \\
& \text { phosphoric acid } \\
& \text { water. }
\end{aligned}
$$

The friability tests were performed in an Erweka friabilator (Erweka $\mathrm{GmbH})$ according to Ph. Eur. The breaking strength has been determined in the Heberlein (Flisa, Le Locle) apparatus.

\section{DSC studies}

The thermoanalytical examinations were carried out with a Mettler-Toledo DSC 821e (Mettler-Toledo GmbH, Switzerland) instrument. Dynamic methods were used, with a heating rate of $10{ }^{\circ} \mathrm{C} \mathrm{min}^{-1}$. The interval was $25-200{ }^{\circ} \mathrm{C}$ for the testing of the interactions of the polymers, and 0-200 ${ }^{\circ} \mathrm{C}$ for the study of the behaviour of sodium bicarbonate. Argon was used as a purge gas. Ten milligram samples were added to the aluminium pans $(40 \mu \mathrm{L})$. The curves were evaluated with STAR $^{\mathrm{e}}$ Software. The investigated samples were the following:

- Polymer mixtures in different ratios:

- basic butylated methacrylate copolymer (Eudragit E PO): PEG $2000=2: 1$

- basic butylated methacrylate copolymer (Eudragit $\mathrm{E}$ PO): PEG $2000=2: 2$

- basic butylated methacrylate copolymer (Eudragit $\mathrm{E}$ PO): PEG $2000=2: 3$

- PEG 2000.

\section{Results and discussion}

DSC studies

In the first step before the granulation, the maximum temperature that can be used during the process was determined. DSC revealed that the heat-induced decomposition of SB started above $80^{\circ} \mathrm{C}$ (Fig. 1) [18]. The 
Fig. 1 DSC curve of SB

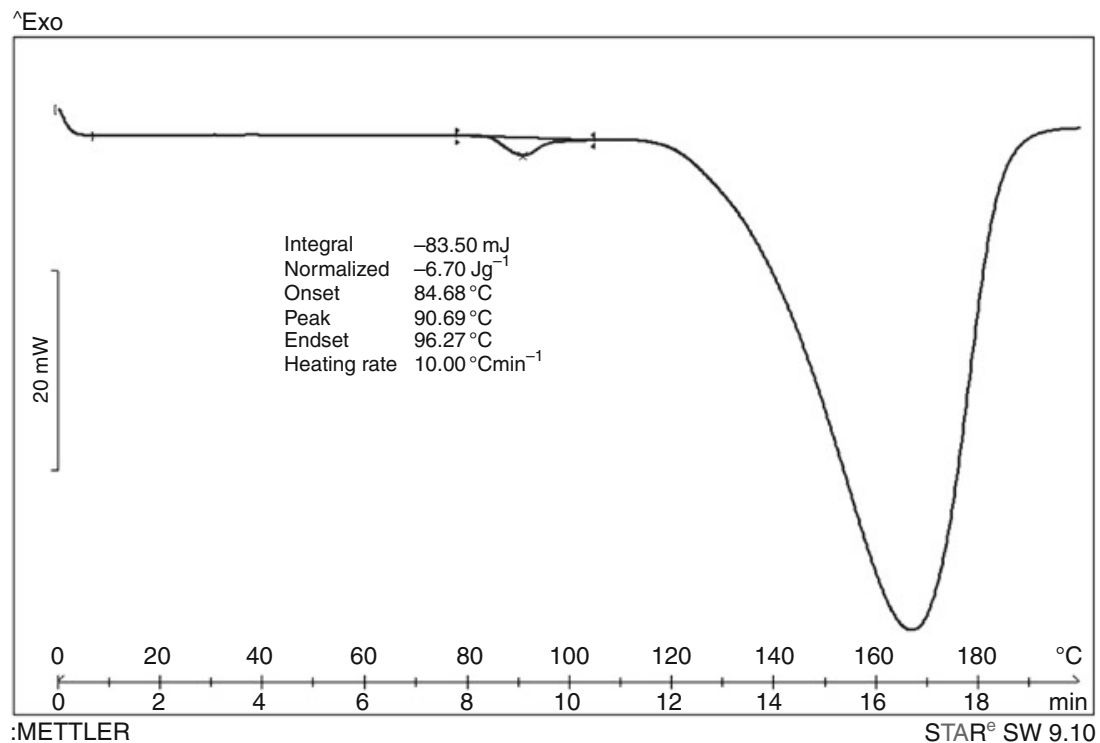

Table 2 Parameters of granules

\begin{tabular}{lclclc}
\hline Samples & Flowing time/s & Bulk density $/ \mathrm{g} \mathrm{cm}^{-3}$ & Carr's index $/ \%$ & Enslin number $/ \mathrm{mL} \mathrm{g}^{-1}$ & $\mathrm{D} 50 / \mathrm{mm}$ \\
\hline S0 & $157.8 \pm 8.9^{\mathrm{a}}$ & $0.313 \pm 0.005$ & $30.4 \pm 0.8$ & $0.41 \pm 0.04$ \\
S1 & $153.6 \pm 15.4^{\mathrm{a}}$ & $0.387 \pm 0.007$ & $26.4 \pm 0.8$ & $1.62 \pm 0.05$ \\
S2 & $80.3 \pm 6.4^{\mathrm{a}}$ & $0.448 \pm 0.008$ & $26.7 \pm 1.7$ & $1.19 \pm 0.03$ & - \\
S3 & $8.5 \pm 2.3$ & $0.742 \pm 0.001$ & $9.3 \pm 0.6$ & $0.74 \pm 0.02$ & 0.154 \\
S4 & $4.1 \pm 0.2$ & $0.719 \pm 0.001$ & $3.5 \pm 0.3$ & $0.66 \pm 0.03$ & 0.242 \\
S5 & $60.4 \pm 3.6^{\mathrm{a}}$ & $0.537 \pm 0.007$ & $19.2 \pm 0.8$ & $1.03 \pm 0.02$ & 0.376 \\
\hline
\end{tabular}

${ }^{\text {a }}$ With stirring at $25 \mathrm{rpm}$

temperature for the granulation must therefore be below this temperature. The temperature of the powder mixture exhibited a lower value than that of the wall of the heated container of the granulator, and the melting points and glass transitions of the macromolecular components must also be considered. The temperature applied must therefore be in the interval $65-80^{\circ} \mathrm{C}$. The temperature chosen for the granulation was $70^{\circ} \mathrm{C}$.

Flowing and wetting properties of the granules

The parameters of the granules were compared with the properties of the powder mixture (Table 2). Free flowing of the powder without stirring was detected only for S3 and S4. Increase of the ratio of PEG 2000 and EE decreased not only this parameter, but also the Carr's index, and increased the particle size and the bulk density, and hence the performance of the granulation. The particle size was not determined for $\mathrm{S} 0$, since in this case only the separation of the starting components can be attained. The heating of the powder mixture without PEG 2000 caused less relevant alterations in the flowability and compressibility of the
Table 3 Wettability of the components

\begin{tabular}{lllll}
\hline Components & $\begin{array}{l}\text { Enslin } \\
\text { number/ } \\
\mathrm{mL} \mathrm{g}^{-1}\end{array}$ & $\begin{array}{l}\text { Weight loss } \\
\text { induced by } \\
\text { heating/\% }\end{array}$ & $\begin{array}{l}\text { Enslin } \\
\text { number after } \\
\text { heating/ } \\
\mathrm{mL} \mathrm{g}^{-1}\end{array}$ & $\begin{array}{l}\text { Relative } \\
\text { change of } \\
\text { Enslin } \\
\text { number/\% }\end{array}$ \\
\hline AH & $4.73 \pm 0.16$ & 8.10 & $5.27 \pm 0.02$ & 11.1 \\
MT & $1.37 \pm 0.02$ & 6.49 & $1.59 \pm 0.02$ & 16.1 \\
SB & $0.45 \pm 0.03$ & 0.23 & $0.49 \pm 0.05$ & 8.9 \\
EE & $0.03 \pm 0.01$ & 0.63 & $0.16 \pm 0.04$ & 533.3 \\
\hline
\end{tabular}

starting composition, but the wettability was changed significantly $(p<0.05)$. This parameter was 4 times higher for the heat-treated sample. A modification was revealed without the same change in compressibility. Independent heat treatment of the individual components was therefore performed under the conditions of the granulation. The alterations induced in the wettability were compared (Table 3). The weight loss induced by this treatment was highest for AH. During the water uptake test, this amount of water must be considered, but the relative change was also calculated. There was no obvious relationship between 
the loss on drying and the relative change in water uptake. The highest change in water uptake was detected for the poorly wetting EE. This component lost its microparticulate individuality, and formed a hard layer. This was powderized before this test. Such a phenomenon can cause slight sticking of the particles, but its relevance was low, and it caused only a slight modification in the compressibility. Alterations in wettability cannot be explained merely by the changes in wettability of the separate components. In the powder mixture, the wettability of the materials with poor water uptake properties predominated. The enrichment of certain components on the surface of other components is well known [19], and their properties therefore become more important. During the heating of this blend, the microstructure of the powder mixture and its agglomerate also changed. The softening of this polymer caused a rearrangement of this component in the powder mixture and accordingly the properties of the active agents became dominant.

The use of PEG 2000 alone without EE led to poorer flowability and compressibility than for S4, but to better properties than for the sample prepared without PEG 2000. The difference in the wetting was interesting, since for S3 and S4 this parameter was lower than for the two endpoint compositions (S1 and S5). This can be explained by interactions (between the active agent and polymers and/or between the polymers) occurring during the formulation.

\section{Properties of tablets}

Tablets were prepared from the granules and their properties were compared with those of the comprimates obtained by direct compression [11] (Tables 4 and 5). The composition without PEG 2000 exhibited poorer friability and retardation (extended release of the active ingredients) than those of the starting composition. The $\mathrm{pH}$-sensitive disintegration profile was decreased. The tablets prepared from granules produced without the matrix former displayed weak mechanical properties, and broke during the test. The quickest disintegration was observed for S2, where the $\mathrm{pH}$-sensitive effect was negligible. The best disintegration
Table 5 Dimensions of tablets

\begin{tabular}{lll}
\hline Samples & Thickness/mm & Diameter/mm \\
\hline S0 & $3.36 \pm 0.02$ & $13.06 \pm 0.01$ \\
S1 & $3.46 \pm 0.05$ & $13.10 \pm 0.01$ \\
S2 & $3.61 \pm 0.02$ & $13.11 \pm 0.02$ \\
S3 & $3.64 \pm 0.02$ & $13.13 \pm 0.02$ \\
S4 & $3.77 \pm 0.02$ & $13.06 \pm 0.02$ \\
S5 & $2.97 \pm 0.02$ & $13.14 \pm 0.01$ \\
\hline
\end{tabular}

profile was that of S4. The properties of the granules were also best for this composition. It can be concluded that there was no obvious connection between the wettability of the sample and the disintegration. The slowest disintegration was detected for the sample that exhibited the poorest wettability, but this tendency was not valid for all the cases. The changes in the inner structure of the matrix were such that their prediction was impossible from the parameters of the starting components. This may involve interactions between the components induced by the heating.

Investigation of the possible interactions between the polymers

The DSC curve of EE demonstrated a shift of the baseline at nearly $55{ }^{\circ} \mathrm{C}$, but no other event after this (Fig. 2). This phenomenon may be responsible for the changes in the parameters of the S1 granules and consequently of these tablets. The previous wettability test indicated a significant alteration in the distribution of soft EE in the agglomerate. PEG 2000 exhibited a melting peak at a similar temperature. The possibility of the interaction of the polymers during the granulation was evaluated by the thermal analysis of powder blends containing these components in the appropriate ratios. The mixture of the polymers exhibited not only shifts in the peaks to higher temperatures, but changes in their shape. An important alteration was found at the 2:1 ratio of EE and PEG 2000, the polymer ratio of the S2 composition, which exhibited the poorest disintegration profile. The process induced by the interaction

Table 4 Parameters of tablets

\begin{tabular}{llcrrrr}
\hline Samples & Friability/\% & Breaking strength $/ N$ & \multicolumn{2}{l}{ Disintegration at $\mathrm{pH}$} \\
\cline { 4 - 6 } & & & \multicolumn{1}{l}{$1.2 / \mathrm{min}$} & \multicolumn{1}{l}{$2.0 / \mathrm{min}$} & \multicolumn{2}{c}{$2.5 / \mathrm{min}$} \\
\hline S0 & 0.21 & $174.3 \pm 9.6$ & $12.56 \pm 0.66$ & $16.88 \pm 1.76$ & $145.52 \pm 8.64$ & $183.43 \pm 4.51$ \\
S1 & 2.55 & $59.1 \pm 14.6$ & $7.48 \pm 0.58$ & $9.84 \pm 0.82$ & $27.83 \pm 6.75$ & $38.87 \pm 4.58$ \\
S2 & 1.81 & $36 \pm 6.5$ & $4.82 \pm 0.55$ & $4.56 \pm 0.47$ & $6.37 \pm 1.83$ & $10.89 \pm 2.18$ \\
S3 & 0.29 & $54.6 \pm 3.3$ & $13.74 \pm 0.62$ & $15.00 \pm 0.34$ & $50.58 \pm 4.51$ & $80.82 \pm 7.96$ \\
S4 & 0.21 & $101.5 \pm 14.2$ & $16.96 \pm 0.67$ & $17.40 \pm 0.96$ & $64.14 \pm 3.59$ & $107.42 \pm 6.58$ \\
S5 & Broken & $32.1 \pm 4.3$ & $4.18 \pm 0.28$ & $4.81 \pm 0.17$ & $11.86 \pm 3.15$ & $37.38 \pm 1.34$ \\
\hline
\end{tabular}


Fig. 2 DSC curves of polymers and their mixtures

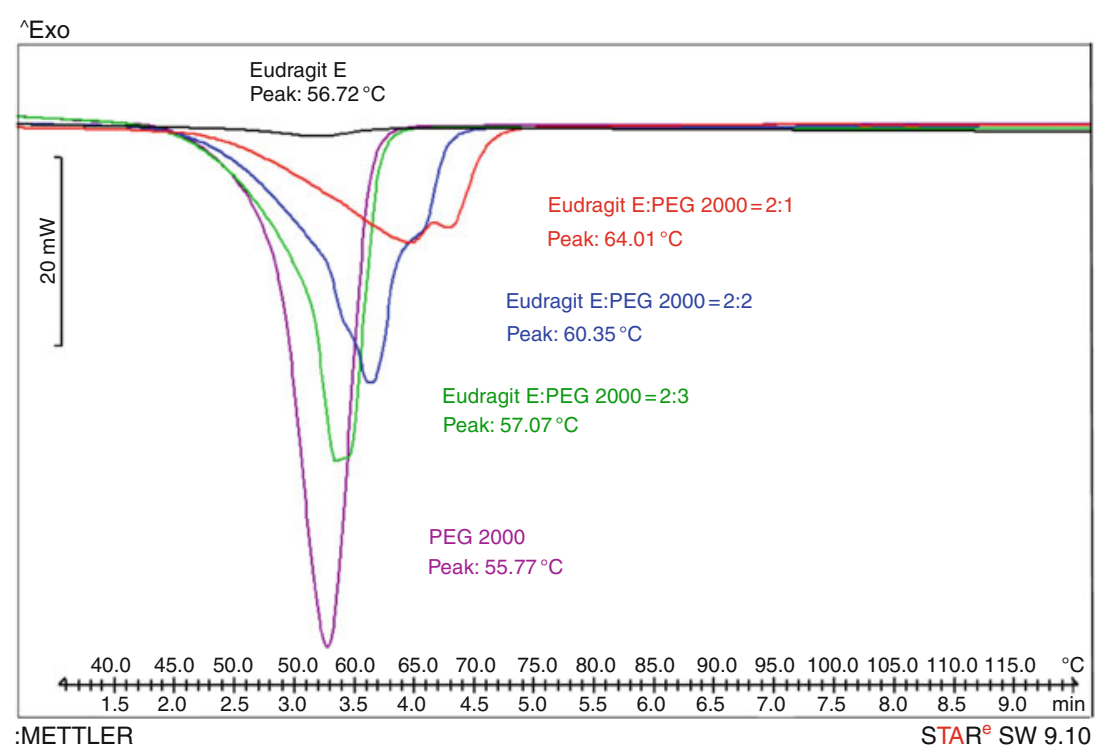

cannot be completed at the temperature of granulation. For the definite occurrence of this phenomenon, a temperature of $>80{ }^{\circ} \mathrm{C}$ should be applied during the formulation, where the risk of decomposition of the active agent is relevant. The cause of the poor properties of the tablets can therefore be explained by the incomplete formation of the structurebuilding component. The decision to ignore this composition in our matrix system was supported by the DSC experiments. The $\mathrm{S} 4$ polymer ratio exhibited a uniform peak which was quantitatively formed at the temperature of granulation. This ratio ensured the properties of the tablets and granules. In this case, not only the favourable effect of the binder, but also the synergistic effect of the rate-limiting polymer was detected.

\section{Conclusions}

It can be concluded that hot melt granulation can be applied for the preparation of matrix granules to enhance the production of controlled-release antacid tablets. The temperature of the hot melt granulation and the problems that arise during this process can be evaluated by means of thermal analysis. The heating of mixtures containing EE below its glass transition caused a relevant change in the wettability of the mixtures. This is induced by an alteration in the microstructure of the agglomerates. Tablets prepared from the granules containing EE and PEG 2000 in a ratio of 2:3 exhibited an appropriate mechanical and disintegration profile. The relationship of the two polymers can be tested via DSC. The behaviour of the mixture of polymers cannot be predicted from the properties of the pure starting materials; this method confirmed their interaction, which can cause important structure-forming problems in the matrices. There were good correlations between the parameters of the granules/tablets and the determined interactions. If this thermally induced alteration in the polymer blend is not completely finished at the temperature of the granulation, the properties of the matrices are insufficient.

This information can increase our understanding of the phenomena that occur during hot melt granulation. A welldesigned process allows application of this technique for the formulation of a $\mathrm{pH}$-sensitive intelligent solid dosage form containing heat- and moisture-sensitive components.

\section{References}

1. Woodson GC. An interesting case of osteomalacia due to antacid use associated with stainable bone aluminum in a patient with normal renal function. Bone. 1998;22:695-8.

2. Parfitt K. Martindale. 32nd ed. London: Pharmaceutical Press; 1999.

3. Vanpee D, Delgrange E, Gillet JB, Donckier J. Ingestion of antacid tablets (Rennie $\left.{ }^{\circledR}\right)$ and acute confusion. J Emerg Med. 2000;19:169-71.

4. Córdoba-Díaz D, Córdoba-Díaz M, Awad S, Córdoba-Borrego M. Effect of pharmacotechnical design on the in vitro interaction of ketoconazole tablets with non-systemic antacids. Int J Pharm. 2001;226:61-8.

5. Pleuvry BJ. Pharmacological remedies for gastric disorders. Anaesth Intens Care. 2006;7:65-9.

6. Hardman JG, Limbird LE. Goodman\&Gilman's The pharmaceutical basis of therapeutics. 10th ed. New York: The McGrawHill Companies Inc.; 2001.

7. Kalant H, Roschlau WHE, Sellers EM. Principles of medical pharmacology. 4th ed. Toronto: Oxford University Press; 1985.

8. Hauben M, Horn S, Reich L, Younus M. Association between gastric acid suppressants and Clostridium difficile colitis and community-acquired pneumonia: analysis using pharmacovigilance tools. Int J Infect Dis. 2007;11:417-22. 
9. Layer P, Goebell H. Interdigestive motility and secretion of the gastrointestinal tract. Z Gastroenterol. 1987;25:769-76.

10. Camilleri M. Integrated upper gastrointestinal response to food intake. Gastroenterology. 2006;131:640-58.

11. Bajdik J, Korbely A, Pintye-Hódi K. Formulation of intelligent tablets with an antacid effect. Pharm Dev Tech. 2009;14(5): 471-5.

12. Wells JI. Pharmaceutical preformulation the physicochemical properties of drug substances. Chicester: Ellis Horwood Ltd.; 1988.

13. Rowe RC, Sheskey PJ, Weller PI. Handbook of pharmaceutical excipients. 4th ed. London: Pharmaceutical Press; 2003.

14. Borini GB, Andrade TC, Freitas LAP. Hot melt granulation of coarse pharmaceutical powders in a spouted bed. Powder Technol. 2009;189:520-7.
15. Breitkreutz J, Bornhöft M, Wöll F, Kleinebudde P. Pediatric drug formulations of sodium benzoate: I. Coated granules with a hydrophilic binder. Eur J Pharm Biopharm. 2003;56:247-53.

16. Bauer KH, Lehmann K, Osterwald HP, Rothang G. Coated pharmaceutical dosage forms. Stuttgart: Medpharm GmbH Scientific Publishers; 1988.

17. Carr RL. Classifying flow properties of solids. Chem Eng. 1965; 72:69-72.

18. Pasquali I, Bettini R, Giordano F. Thermal behaviour of diclofenac, diclofenac sodium and sodium bicarbonate compositions. J Therm Anal Cal. 2007;90:903-7.

19. Buckton G. Interfacial phenomena in drug delivery and targeting. Chur: Harwood Academic Publishers; 1995. 
III 


\title{
Effects of Processing on the Release Profiles of Matrix Systems Containing 5-Aminosalicylic Acid
}

\author{
Anita Korbely, ${ }^{1}$ András Kelemen, ${ }^{1}$ Péter Kása $\mathrm{Jr}^{1}{ }^{1}$ and Klára Pintye-Hódi ${ }^{1,2}$
}

Received 22 May 2012; accepted 14 September 2012

\begin{abstract}
The aim of this study was to investigate the influence of different processing methods on the profiles of 5-aminosalicylic acid dissolution from controlled-release matrix systems based on Eudragit ${ }^{\circledR}$ RL and Eudragit ${ }^{\circledR}$ RS water-insoluble polymers. The pure polymers and their mixtures were studied as matrix formers using different processing methods, i.e., direct compression, wet granulation of the active ingredient with the addition of polymer(s) to the external phase, wet granulation with water, and wet granulation with aqueous dispersions. In comparison with the directly compressed tablets, tablets made by wet granulation with water demonstrated a $6-19 \%$ increase in final drug dissolution, whereas when polymers were applied in the external phase during compression, a $0-13 \%$ decrease was observed in the amount of drug released. Wet granulation with aqueous polymer dispersions delayed the release of the drug; this was especially marked (a 54-56\% decrease in drug release) in compositions, which contained a high amount of Eudragit RL 30D. The release profiles were mostly described by the Korsmeyer-Peppas model or the Hopfenberg model.
\end{abstract}

KEY WORDS: controlled release; matrix tablet; polymethacrylates; release kinetics.

\section{INTRODUCTION}

Controlled-release formulations are coming increasingly into the focus of attention, as they are designed to decrease the number of administrations through the incorporation of high doses of the active compounds, thereby enhancing patient compliance, which is crucial in the therapy of chronic diseases (1). Reservoir and matrix (also called monolithic) systems are commonly used in modified-release formulations because of their simplicity and cost-effective manufacturing. A number of manufacturing routes have been devised for the preparation of controlled-release systems, including polymer-based matrices, reservoir-type systems, bilayered tablets, and gastroretentive systems (2-8). Matrix systems involve active ingredients and excipients embedded into a matrix, where the active pharmaceutical ingredient (API) can be dispersed or dissolved. Conventional methods, such as direct compression, wet granulation, or hot melt extrusion, are employed to prepare these systems (9).

Release modeling behavior is indispensable for prediction of the dissolution behavior of drugs from delivery systems. The in vitro dissolution testing of solid dosage forms is frequently applied to reveal drug release mechanisms, the resulting data

\footnotetext{
${ }^{1}$ Department of Pharmaceutical Technology, University of Szeged, Eötvös u. 6, 6720 Szeged, Hungary.

${ }^{2}$ To whom correspondence should be addressed. (e-mail: klara.hodi@ pharm.u-szeged.hu)
}

ABBREVIATIONS: E RS, Eudragit ${ }^{\circledR}$ RS; E RL, Eudragit ${ }^{\circledR}$ RL; 5 ASA, 5-Aminosalicylic acid; E RL 30D, Eudragit ${ }^{\circ}$ RL 30D aqueous dispersion; E RS 30D, Eudragit ${ }^{\circledR}$ RS 30D aqueous dispersion; DC, Direct compression; $S_{12}$, Spreading coefficient. improving of value for the assessment and interpretation of possible risks such as dose dumping, interactions, and effects of food on bioavailability. Two basic types of equipment are generally accepted: apparatus 2 (paddle apparatus) and apparatus 4 (flow-through cells) $(10,11)$. Apparatus 2 (paddle apparatus) is widely applied in view of its simplicity, robustness, and standardizability, and considerable experience has accumulated from its use. Guidelines recommend its utilization for the testing of immediate- and modified-release dosage forms (12).

Conventionally, plastic polymers, including acrylates and ethylcellulose, are used to form insoluble matrices due to their inertness and high drug-embedding ability. Chemically, Eudragit ${ }^{\circ}$ RS (E RS) and Eudragit ${ }^{\circ}$ RL (E RL) are copolymers of ethyl acrylate, methyl methacrylate, and a low content of a quaternary ammonium salt of a methacrylic acid ester. Such salts make the polymers permeable. E RS has a lower permeability than that of E RL as it contains fewer trimethylammonioethyl methacrylate groups (13). The polymers swell $\mathrm{pH}$ independently and release the incorporated drugs via diffusion and erosion. The rate-limiting step is the liquid penetration into the matrix, and the dissolution therefore correlates strictly with this. Eudragit ${ }^{\circledR}$ dispersions are utilized as film-forming agents (14), but the matrix-forming capacities have not been adequately described.

5-Aminosalicylic acid (5-ASA) was used as API in the present study; it is commonly utilized for the first-line treatment of mild-to-moderate inflammatory bowel diseases such as Crohn's disease (15). Orally administered 5-ASA is absorbed rapidly and almost completely from the small intestine (16-18). Nonetheless, time-controlled delivery systems are advantageous in the treatment of inflammatory bowel diseases, and as orally administered dosage forms are greatly preferred to rectal 
administration (19). Controlled release is generally achieved through coating, and most commercial drugs are available as coated tablets; ethylcellulose is occasionally applied for this purpose.

The present study focused on the profiles of dissolution from inert matrix systems. Monolithic matrix tablets were prepared by direct compression and wet granulation and were investigated as regards their dissolution profiles; the morphology and structure of the granules prepared were characterized in order to evaluate the differences in the amount of API released. In the case of wet granulation with a binder, the rate of release was low. Prior to the preparation of the matrices, we performed a study to determine the surface properties of the matrix formers and 5-ASA. This revealed that 5 -ASA is more hydrophilic than the polymers. The effects of processing on matrix formulations are rarely studied. An overall understanding of the basic relations and of the effects of the processing methods is indispensable in the development of matrix systems, as the interactions that can occur during processing can influence the drug release and stability.

The various processing methods may result in products with different physical properties, including morphology, and whose dissolution can suffer a retardation effect or a sudden, unexpected burst. There may be differences in capillary force, the driving force in coalescence in film formation, especially if wet granulation is applied.

Direct compression is the most convenient method by which to prepare solid dosage forms, due to its cost and time effectiveness, although some excipients and APIs are unsuitable for compression in this way, because of their poor flowability. In our study, the compressed sample was applied for comparison and not as the final dosage form. Since 5ASA possesses poor flow properties, appropriate processing techniques are required. The simplest and most common method is granulation, particularly wet granulation. This has the advantages that the particles are approximately spheroids and a number of options are available for production (although its utilization with moisture-sensitive APIs is limited) (20).

The polymers were applied alone or in combination and in the form of a powder or an aqueous dispersion in the formulations. In the combinations, different ratios of $\mathrm{E}$ RS and E RL (1:1, 1:9, and 9:1) were examined.

\section{MATERIALS AND METHODS}

\section{Materials}

5-Aminosalicylic acid was purchased from Alfa Aesar, while Eudragit@ RL PO (E RL PO), Eudragit® RS PO (E RS PO), and the aqueous dispersions E RL 30D and E RS 30D were kindly donated by Evonik Rhöm GmbH, Darmstadt, Germany. Distilled water was applied as solvent for wet granulation. Distilled water and diiodomethane (Sigma-Aldrich, Steinheim, Germany) served as the probe liquids to assess the polar and disperse components of the surface energy.

\section{Preparation of Matrix Tablets}

The tablets were prepared by means of four different processing methods: direct compression, compression of the wet-granulated API with polymer(s) in the external phase, compression of the wet-granulated API and polymers, and wet granulation of the API with aqueous dispersion(s) of the polymer(s). Each processing method included five different tablet formulations. The tablets were compressed with a hydraulic press (Specac Inc., Graseby, UK); samples were pressurized at $10 \mathrm{kN}$ with a dwell time of $10 \mathrm{~s}$, the punch was $13 \mathrm{~mm}$ in diameter, and the tablets were flat-shaped. The tablets usually contained $50 \% 5$-ASA and $50 \%$ polymer, but in the samples prepared with polymer dispersions, the amount of the API was increased up to $88 \%$. The processing methods were as follows (Table I):

1. Direct compression: a mixture of 5-ASA and solid polymer (s) in mass a ratio of 1:1 was blended in a rotating shaker mixer (Turbula mixer, W.A. Bachofen, Basel, Switzerland) at $50 \mathrm{rpm}$ for $10 \mathrm{~min}$ before direct compression. The comprimates weighed $400 \mathrm{mg}$ and contained $200 \mathrm{mg}$ API. These samples were denoted by the code DC.

2. Wet granulation of the API: 5-ASA was granulated with distilled water in a high-shear granulator (ProCepT nv, Zelzate, Belgium; kneading parameters: chopper speed, 3,000 rpm; impeller speed, 1,000 rpm; rate of liquid dosing, $5 \mathrm{~mL} / \mathrm{min}$ ). The wet mass was forced through a $1.2-\mathrm{mm}$ mesh sieve to achieve a more homogeneous particle size. The granulation was performed in a stainless steel vessel: Preliminary results have shown that the work of adhesion was less in a steel vessel than in a glass one. Drying was carried out under ambient conditions $\left(25^{\circ} \mathrm{C}, 60 \%\right.$ relative humidity) for $24 \mathrm{~h}$. The polymer(s) was (were) added to the external phase before compression: A mixture of granulated 5-ASA and solid polymer(s) in a mass ratio of 1:1 was blended in a rotating shaker mixer (Turbula mixer, W.A. Bachofen, Basel, Switzerland) at $50 \mathrm{rpm}$ for $10 \mathrm{~min}$ before compression (G5ASA).

Table I. Composition of Tablets

\begin{tabular}{lcccc}
\hline Tablet code & 5ASA $(\mathrm{mg})$ & E RS $(\mathrm{mg})$ & E RL $(\mathrm{mg})$ & Total $(\mathrm{mg})$ \\
\hline DC1 & 200 & 200 & 0 & 400 \\
DC2 & 200 & 0 & 200 & 400 \\
DC3 & 200 & 100 & 100 & 400 \\
DC4 & 200 & 20 & 180 & 400 \\
DC5 & 200 & 180 & 20 & 400 \\
G5ASA1 & 200 & 200 & 0 & 400 \\
G5ASA2 & 200 & 0 & 200 & 400 \\
G5ASA3 & 200 & 100 & 100 & 400 \\
G5ASA4 & 200 & 20 & 180 & 400 \\
G5ASA5 & 200 & 180 & 20 & 400 \\
G1 & 200 & 200 & 0 & 400 \\
G2 & 200 & 0 & 200 & 400 \\
G3 & 200 & 100 & 100 & 400 \\
G4 & 200 & 20 & 180 & 400 \\
G5 & 200 & 180 & 20 & 400 \\
GD1 & 350 & 50 & 0 & 400 \\
GD2 & 350 & 0 & 50 & 400 \\
GD3 & 350 & 25 & 25 & 400 \\
GD4 & 350 & 5 & 45 & 400 \\
GD5 & 350 & 45 & 5 & 400 \\
\hline
\end{tabular}

The abbreviations refer to the preparation methods: $D C$ direct compression, G5ASA 5-aminosalicylic acid granulated with water, $G$ mixture of 5-aminosalicylic acid and polymer(s) granulated with water, $G D$ 5-aminosalicylic acid granulated with polymer dispersion(s) 
Table II. Contact Angles and Surface Free Energies of Raw Materials and Their Mixtures

\begin{tabular}{lccccc}
\hline Composition & $\begin{array}{l}\text { Contact angle } \\
\text { water } \Theta_{\mathrm{w}}\left({ }^{\circ}\right) \pm S D\end{array}$ & $\begin{array}{l}\text { Contact angle } \\
\text { diiodomethane } \Theta_{\mathrm{d}}\left({ }^{\circ}\right) \pm S D\end{array}$ & $\begin{array}{l}\text { Suface free energy } \\
\gamma_{\mathrm{s}}(\mathrm{mN} / \mathrm{m})\end{array}$ & $\begin{array}{l}\text { Disperse component } \\
\gamma_{s}^{d}(\mathrm{mN} / \mathrm{m})\end{array}$ & $\begin{array}{l}\text { Polar component } \\
\gamma_{s}^{p}\end{array}$ \\
\hline 5ASA & $32.5 \pm 1.86$ & $20.2 \pm 1.10$ & 73.0 & 43.1 & $\begin{array}{l}\text { Polarity } \\
P(\%)\end{array}$ \\
E RL PO & $71.0 \pm 1.37$ & $19.9 \pm 1.40$ & 55.0 & 43.7 & 29.9 \\
E RS PO & $70.2 \pm 1.29$ & $22.8 \pm 0.82$ & 54.6 & 42.8 & 11.3 \\
DC1 & $38.1 \pm 3.68$ & $16.4 \pm 2.74$ & 71.1 & 44.1 & 11.8 \\
DC2 & $41.2 \pm 3.25$ & $14.2 \pm 2.30$ & 70.0 & 44.5 & 27.1 \\
DC3 & $39.9 \pm 3.76$ & $16.7 \pm 2.15$ & 70.3 & 44.0 & 21.6 \\
DC4 & $40.4 \pm 3.79$ & $15.1 \pm 1.68$ & 70.3 & 44.3 & 33.8 \\
DC5 & $39.7 \pm 2.36$ & $14.4 \pm 2.72$ & 70.7 & 44.5 & 36.5 \\
\hline
\end{tabular}

5-ASA 5-aminosalicylic acid, E RS Eudragit ${ }^{\circledR}$ RS, E RL Eudragit ${ }^{\circledR}$ RL, E RL 30D Eudragit ${ }^{\circ}$ RL 30D aqueous dispersion, E RS 30D Eudragit ${ }^{\circledR}$ RS 30D aqueous dispersion, $D C$ direct compression

3. Wet granulation of the API and polymers: a mixture of 5-ASA and solid polymer(s) in a mass ratio of 1:1 was blended in a rotating shaker mixer (Turbula mixer, W.A. Bachofen, Basel, Switzerland) at $50 \mathrm{rpm}$ for $10 \mathrm{~min}$ before granulation. The mixture was granulated with distilled water in a high-shear granulator (ProCepT nv, Zelzate, Belgium; kneading parameters: chopper speed, $3,000 \mathrm{rpm}$; impeller speed, $1,000 \mathrm{rpm}$; rate of liquid dosing, $5 \mathrm{~mL} / \mathrm{min}$ ). The wet mass was forced through a $1.2-\mathrm{mm}$ mesh sieve to achieve a more homogeneous particle size. The granulation was performed in a stainless steel vessel. Drying was carried out under ambient conditions $\left(25^{\circ} \mathrm{C}, 60 \%\right.$ relative humidity) for $24 \mathrm{~h}$. These samples were denoted as $\mathrm{G}$.

4. 5-ASA was granulated with the polymer dispersion(s) in a high-shear granulator until an appropriate wet mass was achieved. The process parameters were as follows: chopper speed, 3,000 rpm; impeller speed, $1,000 \mathrm{rpm}$; rate of liquid dosing, $6 \mathrm{~mL} / \mathrm{min}$. The wet mass was forced through a $1.2-\mathrm{mm}$ mesh sieve to achieve a definite range of particle size. These samples were denoted as GD.

\section{Contact Angle Measurements}

The wetting properties of the initial materials and their mixtures were determined with the OCA 20 Optical Contact Angle Measuring System (Dataphysics Instruments $\mathrm{GmbH}$, Filderstadt, Germany). Ten parallel measurements were made. Contact angles were measured with the use of distilled water and diiodomethane as polar and apolar test liquids, respectively, which were dispensed by means of an automatic syringe. The tablets were compressed with a hydraulic press

Table III. Spreading Coefficient

\begin{tabular}{cc}
\hline Composition & Spreading coefficient $\left(S_{12}\right)$ \\
\hline 5ASA(1)+E RS PO(2) & -26.25 \\
5ASA(1)+E RL PO(2) & -26.40 \\
\hline
\end{tabular}

5-ASA 5-aminosalicylic acid, E RS PO Eudragit ${ }^{\circledR}$ RS powder, $E R L$ $P O$ Eudragit ${ }^{\circledR}$ RL powder equipped with a highly polished stainless steel punch and die (Specac Inc., Graseby, UK) $13 \mathrm{~mm}$ in diameter, under a force of $50 \mathrm{kN}$. The $\mathrm{Wu}$ equation was used to calculate the surface free energy. The spreading coefficient $\left(S_{12}\right)$ was determined according to the following equation (21):

$$
S_{12}=4\left[\frac{\gamma_{1}^{d} \gamma_{2}^{d}}{\gamma_{1}^{d}+\gamma_{2}^{d}}+\frac{\gamma_{1}^{p} \gamma_{2}^{p}}{\gamma_{1}^{p}+\gamma_{2}^{p}}-\frac{\gamma_{1}}{2}\right]
$$

where $\gamma^{\mathrm{d}}$ refers to the disperse component of surface free energy, and $\gamma^{\mathrm{p}}$ refers to the polar component.

\section{Water Uptake}

Water uptake was determined with an Enslin apparatus, consisting of a glass filter and pipette, with an accuracy of $0.01 \mathrm{~mL}$. The tablets were measured with analytical accuracy prior to being placed onto the filter, and the water uptake was recorded in milliliters at predefined time points. Three parallel measurements were performed.

\section{Dissolution Tests and Release Modeling}

Dissolution tests were carried out in an Erweka DT 700 dissolution apparatus (Erweka GmbH, Heusenstamm, Germany), using a paddle method. The dissolution medium was $900 \mathrm{~mL}$ of phosphate buffer solution of pH6.8 (adjusted according to the $\mathrm{Ph}$. Eur.). The dissolution temperature was maintained at $37 \pm 0.5^{\circ} \mathrm{C}$, and the rotation speed was set at

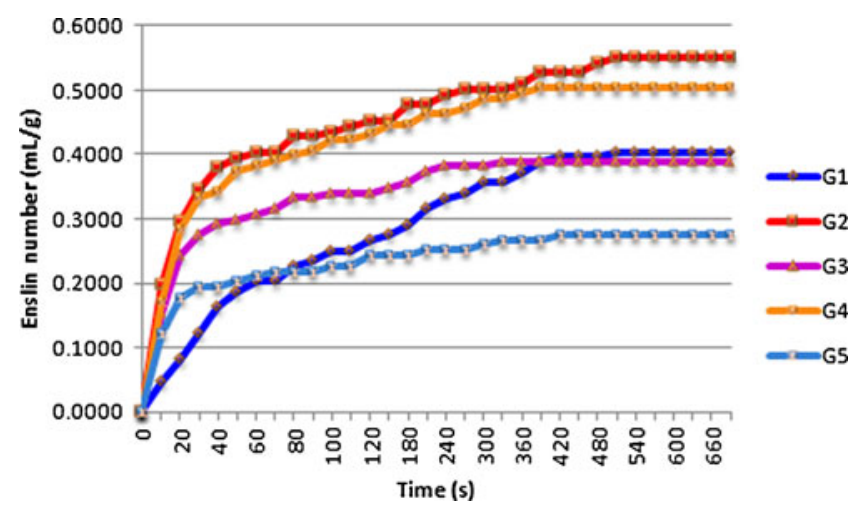

Fig. 1. Water uptake of wet-granulated samples prepared with water 


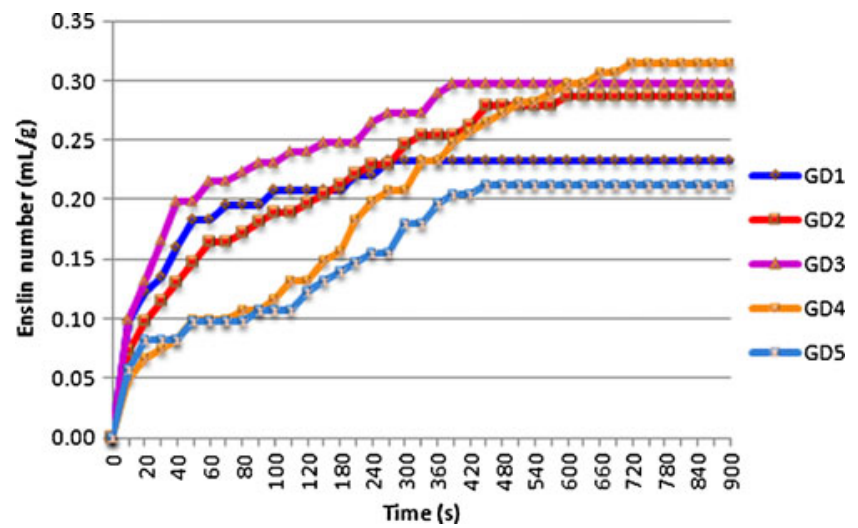

Fig. 2. Water uptake of wet-granulated samples prepared with polymer dispersions

$50 \mathrm{rpm}$. Samples $(5 \mathrm{~mL})$ were automatically collected from the dissolution medium at $1,2,3,4,5,6,7$, and $8 \mathrm{~h}$. Three replicates were tested for each tablet formulation batch. Absorbance was measured spectrophotometrically (Unicam He$\lambda$ ios Alpha, Spectronic Unicam, Cambridge, UK) at $\lambda_{\max }=$ $331 \mathrm{~nm}$.

The resulting dissolution data were subjected to statistical analysis. Mathematical models were used to describe the dissolution profiles of 5-ASA from the matrices. Several mathematical equations were applied to find the one best characterizing the drug release.

\section{Microscopic Structure of the Granules}

Photographs of wet-granulated samples were taken with the aid of a scanning electron microscope (SEM) (Hitachi 4700, Hitachi Ltd., Tokyo, Japan). A sputter coating apparatus (Polaron E5100, Polaron Equipment Ltd., Greenhill, UK) was used to induce electric conductivity on the surface of the samples. The air pressure was $1.3-13 \mathrm{mPa}$.

Table IV. Formulations Dissolving According to the KorsmeyerPeppas Model

\begin{tabular}{lccc}
\hline Sample & $k$ & $n$ & $R^{2}$ \\
\hline DC1 & 10.4439 & 0.568 & 0.9995 \\
DC3 & 18.6222 & 0.723 & 0.9960 \\
DC5 & 11.7439 & 0.641 & 0.9978 \\
G5ASA1 & 10.7166 & 0.520 & 0.9995 \\
G5ASA3 & 13.1529 & 0.780 & 0.9997 \\
G5ASA5 & 11.6521 & 0.512 & 0.9960 \\
G1 & 12.4556 & 0.567 & 0.9990 \\
G5 & 17.5289 & 0.642 & 0.9951 \\
GD1 & 9.9416 & 0.630 & 0.9994 \\
GD2 & 13.2166 & 0.611 & 0.9983 \\
GD3 & 14.3930 & 0.623 & 0.9996 \\
GD4 & 10.8783 & 0.597 & 0.9996 \\
GD5 & 9.6666 & 0.607 & 0.9964 \\
\hline
\end{tabular}

$k$ rate constant, $n$ release exponent, $D C$ direct compression, G5ASA 5 -aminosalicylic acid granulated with water, $G$ mixture of 5-aminosalicylic acid and polymer(s) granulated with water, GD 5-aminosalicylic acid granulated with polymer dispersion(s)
Table V. Formulations Dissolving According to the Hopfenberg Model

\begin{tabular}{lccc}
\hline Sample & $k$ & $n$ & $R^{2}$ \\
\hline DC2 & 0.1337 & 2 & 0.9936 \\
DC4 & 0.1207 & 2 & 0.9924 \\
G5ASA2 & 0.1268 & 2 & 0.9919 \\
G5ASA4 & 0.1230 & 2 & 0.9995 \\
\hline
\end{tabular}

$k$ rate constant, $n$ release exponent, $D C$ direct compression, $G 5 A S A$ 5-aminosalicylic acid granulated with water

\section{RESULTS AND DISCUSSION}

\section{Contact Angle Measurements}

The measurement of contact angles revealed that 5-ASA is polar and, with the presence of the same amount of highly water-insoluble polymers, did not cause a dramatic decrease in the polarity (Table II). The calculated spreading coefficient indicated that the polymer spreads on the surface of 5-ASA (Table III). Nonetheless, the fine polymer particles did not evenly cover the API crystals with their large surface and could therefore presumably not greatly reduce the polarity of the API. Knowledge of the surface free energy permits a deeper insight into how a material behaves during wetting. This property is crucial because the extent of wetting of a solid surface influences the dissolution: If there is no wetting, the solid system will not dissolve (22).

\section{Water Uptake}

The determination of water uptake kinetics is highly recommended prior to formulation as this influences the dissolution. Water was taken up more rapidly by the samples prepared by the wet granulation of the mixture of API and polymers than by the samples prepared by the granulation of the API with aqueous polymer dispersions. The curves revealed that the wetting rate was more uniform in the case of the wet-granulated samples (Fig. 1), while the more compact structure of the granules produced from the dispersions resulted in a slower water uptake due to the prevailing hydrophobic features (Fig. 2). For the wet-granulated samples prepared from the aqueous dispersions, the water uptake capacity correlated with the dissolution rate.

\section{Dissolution Study and Release Modeling}

The Korsmeyer-Peppas model was found to be the most suitable for the fitting of the drug dissolution curves in the majority of the cases, where not only diffusion but also erosion was involved in the drug release (Table IV). In four cases,

Table VI. Characterization of Exponent of Korsmeyer-Peppas Equation

\begin{tabular}{ll}
\hline Release exponent $(n)$ & Drug transport mechanism \\
\hline 0.5 & Fickian diffusion \\
$0.5<n<1$ & Non-Fickian transport \\
1 & Case II transport \\
$n>1$ & Super case II transport \\
\hline
\end{tabular}




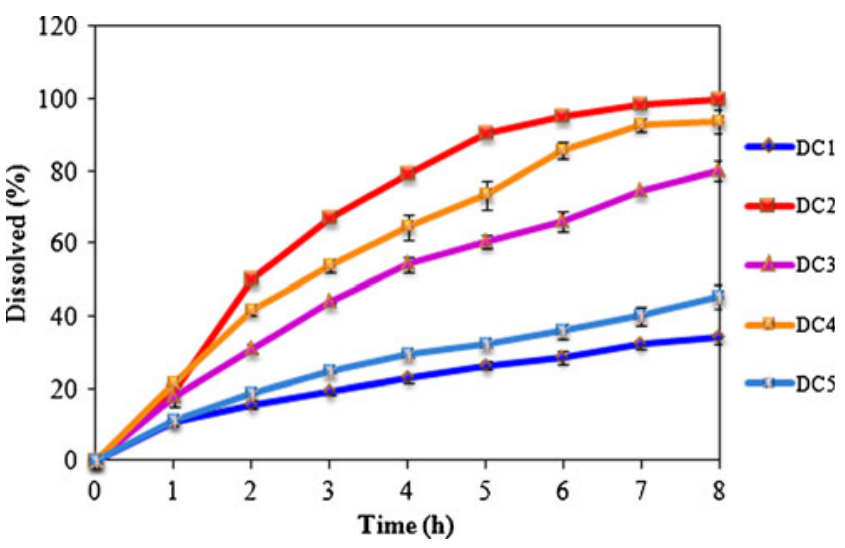

Fig. 3. Dissolution curves of tablets prepared by direct compression

however, when heterogeneous erosion occurred on the surface of the tablet, the Hopfenberg model was the most suitable (Table V).

The release exponent $(n)$ was $0.45<n<0.89$ (for cylindrical tablets), and the diffusion mechanism was therefore anomalous; the drug transport mechanism was non-Fickian diffusion. This indicated the coupling of erosion and diffusion mechanisms, leading to drug release controlled by multiple processes.

\section{Korsmeyer-Peppas Model}

This model, a semiempirical model that can be used to analyze data on drug release from polymers (23), implies that the fractional release of drug is exponentially related to the release time, i.e., a power law equation:

$$
\frac{M_{t}}{M_{\infty}}=k t^{n}
$$

where $M_{t} / M_{\infty}$ is a fraction of drug released at time $t, k$ is the rate constant, and $n$ is the release exponent.

\section{Fickian Diffusion (or Diffusion-Controlled Drug Release)}

The equation of Fick's second law:

$$
\frac{\partial C}{\partial t}=D \frac{\partial^{2} C}{\partial x^{2}}
$$

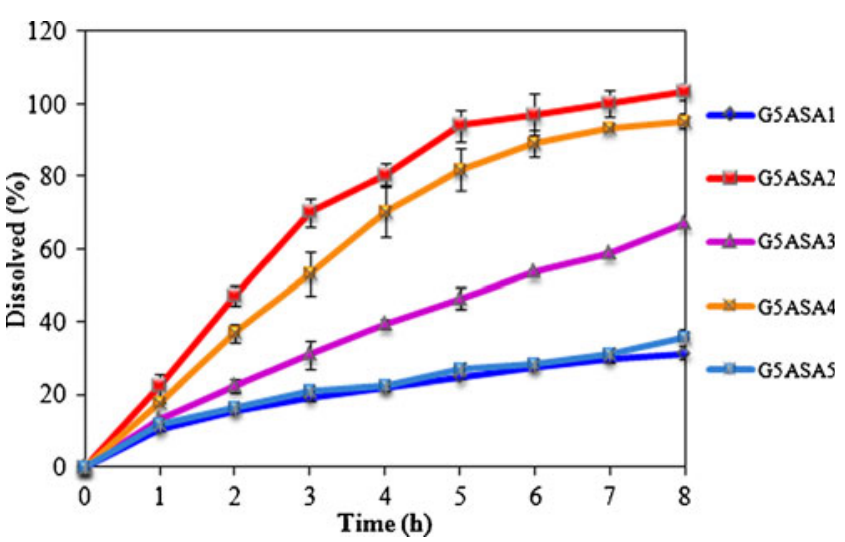

Fig. 4. Dissolution curves of tablets containing polymers in the external phase

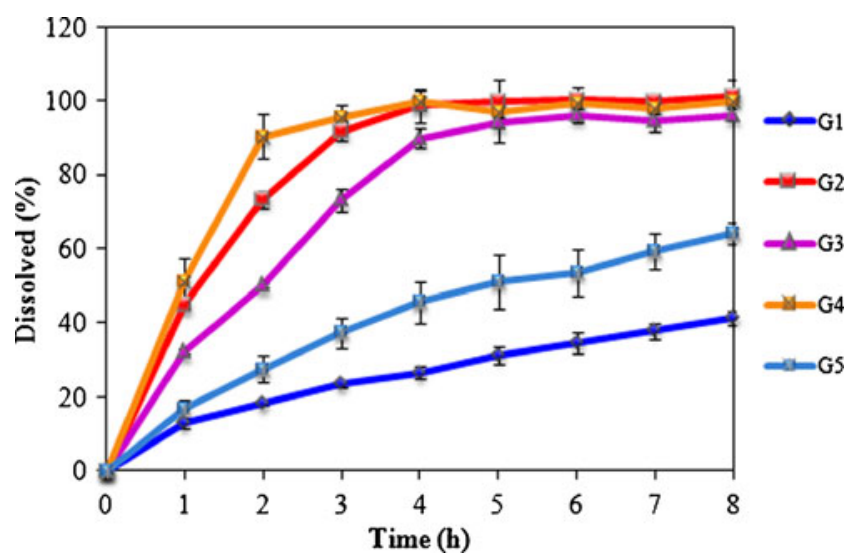

Fig. 5. Dissolution curves of wet-granulated samples prepared with water

can be used to express the diffusion of a drug from a polymer in the form of a plane sheet of thickness. $D$ is the diffusion coefficient of the drug, and $C$ is the concentration of the drug.

Crank's solution (24) of this equation for the initial and boundary conditions $\left(t=0 ;-L x<L ; C=C_{0}\right.$ and $t>0$; $\left.x= \pm 2 L ; C=C_{1}\right)$ is:

$$
\frac{M_{t}}{M_{\infty}}=2\left(\frac{D t}{L^{2}}\right)^{\frac{1}{2}}\left\{\pi^{-\frac{1}{2}}+\sum_{n=1}^{\infty}(-1)^{n} \operatorname{ierfc}\left(\frac{n L}{\sqrt{D t}}\right)\right\}
$$

where $M_{t}$ is the total amount of substance diffused from the sheet at time $t, M_{\infty}$ is the corresponding quantity after an infinite time, and ierfc is the integrated error function. For positive $t$ values, ierfc approximates to 0 , and we obtain

$$
\frac{M_{t}}{M_{\infty}}=k t^{n}
$$

where $k=2 \frac{D}{\sqrt{\pi} L^{2}}$.

\section{Non-Fickian Diffusion}

For diffusion that deviates from the Fickian equation, such as drug release from swellable polymer systems, the same equation can be used, where $k$ is now an experimentally determined parameter characteristic of the structure and

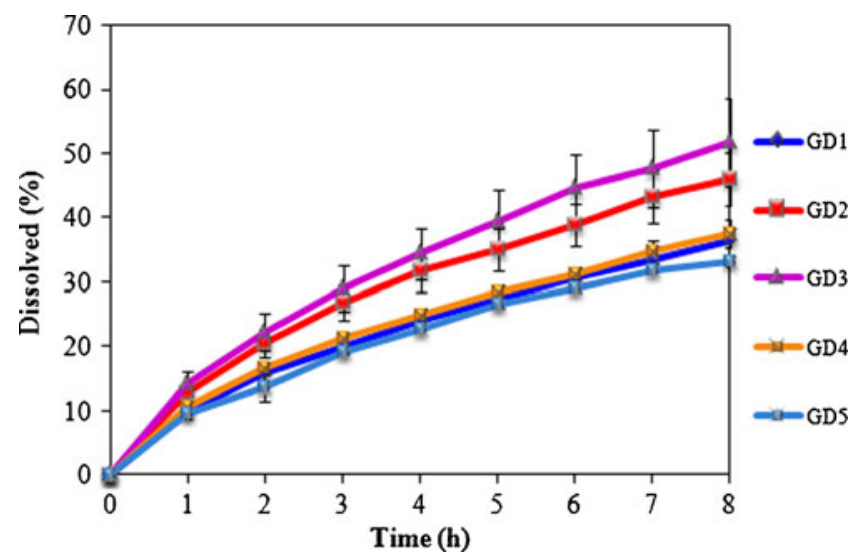

Fig. 6. Dissolution curves of wet-granulated samples prepared with polymer dispersions 

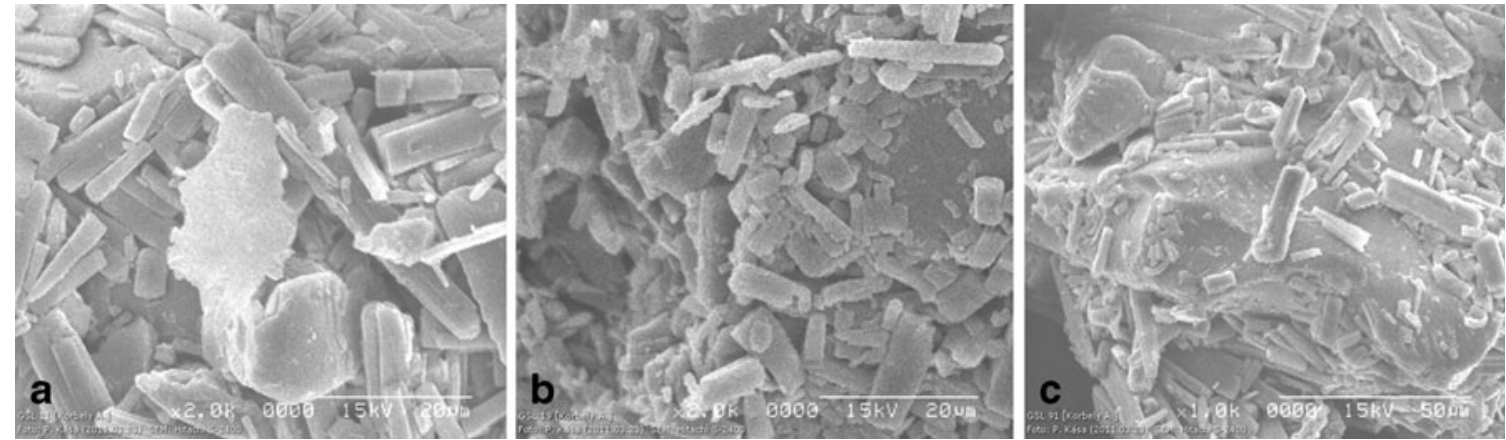

Fig. 7. Morphology of granules prepared by wet granulation with water (a G3, b G4, c G5)

geometry of the dosage form. Peppas used an $n$ value to characterize different release mechanisms (Table VI) (25).

The equation was later modified to accommodate the lag time $(T)$ :

$$
\frac{M_{t}}{M_{\infty}}=k(t-T)^{n}
$$

\section{Hopfenberg Model}

This model can be used to analyze the release of drug from surface-eroding devices. Hopfenberg developed an equation describing the drug release from several geometries (slabs, spheres, and cylinders) displaying heterogeneous erosion (26):

$$
\frac{M_{t}}{M_{\infty}}=1-(1-k t)^{n}
$$

where $M_{t} / M_{\infty}$ is the fraction of drug released at time $t, k$ is the rate constant, and $n$ is the release exponent. $k$ is equal to $k_{0} /$ $C_{0} A_{0}$, where $k_{0}$ is the erosion rate constant, $C_{0}$ is the initial concentration of drug in the matrix, and $A_{0}$ is the initial radius of a sphere or a cylinder or the half-thickness of a slab. The value of $n$ is 1, 2, and 3 for a slab, a cylinder, and a sphere, respectively.

During the design of the present study, the directly compressed formulations were intended to serve as comparators. Depending on the permeability of the applied polymer, the degree of release achieved was nearly complete (highly permeable compositions) or incomplete (formulations with low permeability) (Fig. 3). Formulations with lower permeability (DC1 and DC5) and the formulation containing polymers in a ratio of 1:1 followed the Korsmeyer-Peppas model, where both diffusion and erosion occur. The Hopfenberg model was applicable for the tablets prepared with a high amount of E RL PO (a highly permeable polymer).

The tablets containing wet-granulated API and polymers in the external phase exhibited a similar dissolution profile to that of the directly compressed samples: the highly permeable matrices were described by the Hopfenberg model, and the remaining formulations by the Korsmeyer-Peppas model. The latter formulations were associated with lower levels of dissolution (a 3-13\% reduction in the total amount of API released) (Fig. 4).

Wet granulation resulted in significant and somewhat unexpected changes, each wet-granulated formulation generally releasing more API than the amount released by the directly compressed samples. The samples containing a higher amount of E RS PO (G1 and G5) could be described by the Korsmeyer-Peppas model, while the highly permeable matrices provided a fast, burst-like dissolution that could not be described by any mathematical model (Fig. 5). These formulations are therefore not suitable for the achievement of extended drug release.

Prolonged drug release was observed for the aqueous dispersions, which served as binder and matrix former: All of these formulations displayed an approximately 50\% decrease in the total amount of drug released as compared with the directly compressed samples, and each of the dissolution curves could be fitted with the Korsmeyer-Peppas model (Fig. 6). These findings indicated that the use of aqueous polymer dispersions allows extended and steady drug release.

\section{Morphology of Granules}

The SEM pictures revealed that some of the initial orthorhombic crystals of 5-ASA remained intact, but rounded particles also developed during the wet granulation with water
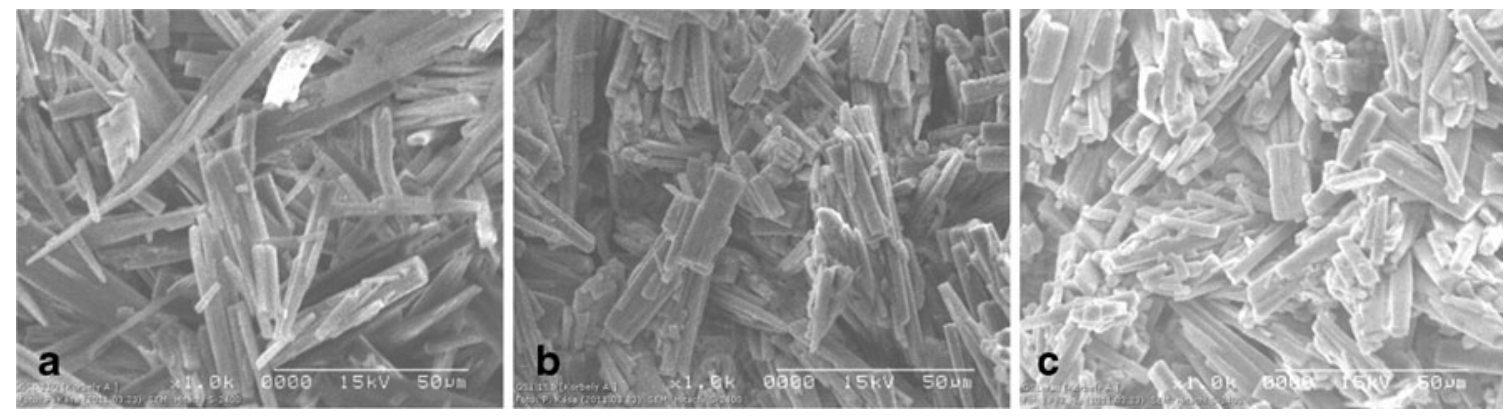

Fig. 8. Morphology of granules prepared by wet granulation with polymer dispersions (a GD3, b GD4, c GD5) 
(Fig. 7). The polymers formed an amorphous network. On wet granulation with the polymer dispersions, it was observed that the 5-ASA was converted into sharp, needle-like crystals as a result of rapid recrystallization (Fig. 8). Some 5-ASA crystals were not covered by the thin polymer film layer because of the relatively large amount of 5-ASA. The polymer particles dispersed with high specific surface area were homogeneously distributed in the bulk, and this contributed to film formation. It is presumed that the aqueous dispersion formed a film in the granules, providing them with a compact inner texture and consequently prolonged drug release. Coalescence of latex particles could occur in the dispersions and a relatively continuous film layer could form. This film was able to retain the 5-ASA and prolong dissolution. In contrast, such a process could not occur (or only partially) in the solid polymers where there was insufficient moisture for the complete solvation of the polymeric chains, and the linkages could not form to retain the 5-ASA molecules and protect them, despite the higher amount of polymers. This draws attention to the fact that an appropriate ratio of the polymers in the matrix is a critical point during formulation.

\section{CONCLUSIONS}

This study focused on how different granulation methods affect dissolution and its kinetics from inert matrix systems. The polymers applied were designed to ensure time-controlled release. The study revealed that the properties of the excipients can provide tailored drug release, but the pharmaceutical processing method can also contribute to the rate of drug release. Consequently, a wet granulation technique, which involves only granulation of the active compound (e.g., to improve its physical properties) and the application of matrix-forming polymers as an external phase during tableting, may result in a highly similar profile to that observed with directly compressed tablets. Nonetheless, wet granulation affecting both the active substance and polymer excipients may accelerate the dissolution process. In contrast, the use of matrix formers in aqueous dispersions, which simultaneously function as binding materials in the granulation, can lead to prolonged release. Thus, if more retarded drug release is required, this kind of process can promote a long-lasting drug dissolution effect. It is noteworthy that the matrix systems with low permeability released the API according to the Korsmeyer-Peppas model, i.e., diffusion was the determining mechanism during dissolution, while the Hopfenberg model was applicable to the higher water-permeable matrices as a result of the surface erosion.

\section{ACKNOWLEDGMENTS}

The Project named "TÁMOP-4.2.1/B-09/1/KONV-20100005-Creating the Center of Excellence at the University of Szeged" is supported by the European Union and co-financed by the European Social Fund.

Disclosure Statement Authors reported no conflict of interest.

\section{REFERENCES}

1. Verma RK, Krishna DM, Garg S. Formulation aspects in the development of osmotically controlled oral drug delivery systems. J Control Release. 2002;79:7-27.

2. Chang RK, Hsiao C. EUDRAGIT® RL and RS pseudolatices: properties and performance in pharmaceutical coating as a controlled release membrane for theophylline pellets. Drug Dev Ind Pharm. 1989;15(2):187-96.

3. Gillian CA, Wan PAL. Factors affecting drug release from a pellet system coated with an aqueous colloidal dispersion. Int J Pharm. 1991;73:51-68.

4. Lee L. Diffusion-controlled matrix systems. In: Kydonicus A, editor. Treatise on controlled drug delivery. New York: Marcel Dekker; 1992. p. 115-98.

5. Narasimhan B, Langer R. Zero-order release of micro and macromolecules from polymeric devices: the role of the burst effect. J Control Release. 1997;47:13-20.

6. Conte U, Maggi M. A flexible technology for the linear, pulsatile and delayed release of drugs, allowing for easy accommodation of difficult in vitro targets. J Control Release. 2000;64:263-8.

7. Peppas NA, Sahlin JJ. A simple equation for the description of the solute release: III. Coupling of diffusion and relaxation. Int J Pharm. 1989;57:169-72.

8. Talukder R, Fassihi R. Gastroretentive delivery systems: a mini review. Drug Dev Ind Pharm. 2004;30(10):1019-28.

9. Azarmi S, Ghaffari F, Löbenberg R, Nokhodchi A. Mechanistic evaluation of the effect of thermal-treating on Eudragit RS matrices. Il Farmaco. 2005;60:11-2.

10. European Pharmacopoeia 2.9.3 Dissolution test for solid dosage forms 01/2012:20903

11. USP NF 35, Physical tests $<711>$ dissolution

12. FIP Guidelines for Dissolution Testing of Solid Oral Products. 1997. http://www.fip.org/www/uploads/database_file.php? id=260\&table_id=. Accessed 30 Apr 2012.

13. Rowe RC, Sheskey PJ, Owen SC. Handbook of pharmaceutical excipients. 5th ed. Washington: Pharmaceutical Press and American Pharmacists Association; 2006.

14. Kállai N, Luhn O, Dredán J, Kovács K, Lengyel M, Antal I. Evaluation of drug release from coated pellets based on isomalt, sugar, and microcrystalline cellulose inert cores. AAPS PharmSciTech. 2010;11(1):383-91.

15. The Merck Manual Online http://www.merckmanuals.com/ professional/gastrointestinal_disorders/inflammatory_bowel_di sease_ibd/crohns_disease.html. Accessed 28 Apr 2012.

16. Peppercorn MA, Goldman P. Distribution studies of salicylazosulfapyridine and its metabolites. Gastroenterology. 1973;64:240-5.

17. Nielsen $\mathrm{OH}$, Bondesen S. Kinetics of 5-aminosalicylic acid after jejunal instillation in man. Br J Clin Pharmacol. 1983;16:738-40.

18. Schröder H, Campbell DES. Absorption, metabolism and excretion of salicylazosulfapyridine in man. Clin Pharmacol Ther. 1972;13:539-51.

19. Friend DR. Colon-specific drug delivery. Adv Drug Deliv Rev. 1991;7(1):149-99.

20. Aulton ME. Aulton's pharmaceutics. The design and manufacture of medicines. Edinburgh: Churchill Livingstone, Elsevier; 2007.

21. Rowe RC. Binder-substrate interactions in granulation: a theoretical approach based on surface free energy and polarity. Int J Pharm. 1989:52:149-54.

22. Parfitt GD. Dispersion of powders in liquids. New York: Wiley; 1973.

23. Peppas NA. Analysis of Fickian and non-Fickian drug release from polymers. Pharm Acta Helv. 1985;60:110-1.

24. Crank J. The mathematics of diffusion. Oxford: Clarendon; 1975.

25. Costa P, Lobo JMS. Modeling and comparison of dissolution profiles. Eur J Pharm Sci. 2001;13(2):123-33.

26. Hopfenberg HB. Controlled release polymeric formulations. In: Paul DR, Haris FW, editors. ACS Symposium Series, vol. 33. Washington: American Chemical Society; 1976. p. 26-31. 